\title{
La légende de saint Jacques de Nisibe
}

A côté des saints qui n'ont pas d'histoire, il $y$ a ceux qui en ont plusieurs. Saint Jacques de Nisibe est de ce nombre. Ayant vécu à la limite extrême du monde romain, sur la frontière mouvante et disputée de la province transeuphra tésıenne et de la Perse, il a laissé un souvenir vénéré parmi plusieurs peuples, entre lesquels les dissensions religieuses après les conflits politiques devaient un jour elever une barrière, puis creuser un abîme. Chez les Grecs, chez les Arméniens de la Persarménie, chez les Syriens du Tur-'Abdin, il s'est formé autour de sa mémoire différents groupes de légendes qui se sont développés sans se rejoindre. Le texte que nous nous proposons de faire connaitre est un essai de syncrétisme entre ces traditions divergentes, essai tardif et demeuré sans écho en dehors de l'hagiographie arménienne. A défaut d'autre valeur, il offre l'intérêt de rassembler dans une vue d'en. semble tous les récits dont la vie de saint Jacques a fourni le thème ou le prétexte. Avant de chercher à démêler ces sources légendaires, il convient de rappeler ce que l'on sait d'à peu près certain touchant l'illustre évèque de Nisibe.

\section{Les textes historiques.}

I. Saint Jacques de Nisibe est nommé dans toutes les listes des Pères de Nicće '. Cette mention, qui est l'équivalent d'une signature, est probablement le souverir le plus direct qui soit resté de lui.

1 H. Gelzer, H. Hiloenfeld et O. Cuntz, Patrum Nicac4torum 40 mina latine graece coptice syriace arabice armeniace (Leipzig, Iso8). pp. 20, 21, 64, 84 (85), ro2, 15o. Nous laissons la question de savuir si Jacques de Nisibe aurait également assisté au concile d'Antioche et signé au procès-verbal de cette assemblée (cf. G. Cuprrus, Act. SS., Iul. t. IV, $\S \S 8-25$, pp. $32-34)$. 
2. Saint líphrem l'a célébré à plusieurs reprises dans les hymnes réunis sous le titre collectif de Carmina Nisibena." A travers les imagres diffuses et incohérentes de son style, on voit qu' Éphrem ne connait pas de prédécesseur à saint Jacques sur le siège de Nisibe. Il en donne deux à Vologèse successeur de Babu; trois à Abraham successeur de Vologèse [17; I06-108], mais son énumération commence toujours à saint Jacques. Jacques, Babu et Vologèse sont les trois pontifes de la cité, les seuls dont elle sache le nom [carm. I3-I6, pass.]. L'église de Nisibe est Iacobi filia: כ [ [4, I0o]. Jacques en a défriché et fécondé le sol $\left[\mathrm{I}_{4}, \mathrm{I}_{4}-\mathrm{I}_{5}\right]$. Il fut le premier pontife de Nisibe, comme Constantin fut le premier empereur chrétien $[20,2 \mathrm{I}]$; il a engendré son troupeau : il l'a porté dans son sein [I4, Ir7]; il l'a allaité durant les premières années [14, 123]. Après un épiscopat paisible $[\mathbf{1} 3,80-8 \mathrm{I}]$, Jacques vit l'épreuve se déchaîner sur sa ville. Il prit une part active à la défense de Nisibe assiégée une première fois [ $\left.\tau_{3}, 98-99\right]$ par les Perses. Après sa mort, il fut inhumé à l'intérieur des murs, et son tombeau continue de protéger la cité $\left[\mathrm{I}_{3}, \mathrm{II}_{\mathbf{2}}-27\right]$.

3. Chronique de saint Jérôme, à l'année 338 : Facobus Nisibenus agnoscitur, ad cuius preces saepe urbs discrimine liberata est ${ }^{2}$. Cette mention a été transcrite littéralement dans le Martyrologe de Lyon ${ }^{3}$.

4. La Chronique d'Édesse, rédigée vers l'an 540", confirme l'indication chronologique de saint Jérôme: Anno $D C L I X^{\mathrm{s}}$ defunctus est domnus lacobus Nisibis episcopus ' ${ }^{6}$. La même date a passé dans les "canons, de Jacques d'Écesse ?,

1 Sancti Ephraemi Syri carmina Nisibena, ed. G. Brckell (i.eipzig, 1866).

a Eusebius Werke, t. VII. Die Chronik des Hieronymus. Hieronymi Chronicon, ed. R. Helm, t. I. Text. (= Die Griechischen Schriftsteller der ersten drei fahrhunderte, t. XXIV; Leipzig, IgI3), p. 234.

'C'est la source cherchée par Dom Quentin (Les martyrologes historiques, Paris, I908, p. 205).

- F. HAAse, Die Abfassungszeit der Edessertischen Chronik, dans Oriens Christianus, N. S., t. VII-VIII (1918), p. 88-96.

5 A. D. $337-338$.

b Ed. I. GuIDI, Chronica minora, dans Corpus scribtorum christianorum orientalium. Scriptores syri. Textus, ser. 3, t. IV (Paris, :903), p. 4.

: Ed. E. W. Brooks, Chronica minora, t. c., p. 29o. L'année 338 peut en effet être considérée comme la seconde année de Constance, à 
dans le pseudo-Denys de Tell-Mahré et dans Bar-Hebraeus '

5. Gennade, De viris illustribus, cap. I ; Iacobus, cognomento Sapiens, Nisibenae nobilis. Persarum modo civitatis episcopus <fuit>, unus ex numero sub Maximino persecutore confessorum et eorum qui in Nicaena synodo Arianam perversitatem "omousion" oppositione damnarunt. Hunc virum beatus Hierony'mus in libro Xpoviкūv velut magnarum virtutum hominem nominans in catalogo scribarum cur non posuerit facile excusabitur si consideremus... - Suit le passage célèbre où les cuvres d'Aphraates sont attribuées à Jacques de Nisibe; après quoi le biographe reprend : - Moritur hic vir Constantii temporibus et, iuxta praeceptum patris eius Contantini, intra muros Nisiben sepelitur ob custodiam videlicet civitatis: quod secundum fidem Constantini evenit. Nam post multos annos ingressus Iulianus Nisiben et, vel gloriae sepulti invidens vel fidei Constantini, cuius ob id domum persequebatur, iussit efferri de civitate sancti corporis reliquias; et post paucos menses consulendae licet reipublicae Iovianus imperator, qui Iuliano successerat, tradidit barbaris civitatem, quae usque hodie Persarum dicioni, cum finibus suis subiecta servit?

6. Grégoire de Tours, dans l'Historia Francorum, 1. I, ch. 37 , paraphrase la chronique de.saint Jérôme : Sub Constantis autem imperio, Iacobus Nisebenus fuit, ad cuius praeces inclikatae aures divinae clementiae multa pericula a civitate eius repulerunt ${ }^{3}$.

7. La compilation syriaque, connue depuis Land sous le nom bizarre de Liber Chalipharum et que M. E. W. Brooks fait remonter aux environs de l'année 743 ', place sous le règne de Constantin II et de ses frères la notice suivante, sans indication de date ${ }^{s}$ : Sapor rex Persarum in Mesopotamiam venit ut Nisibi potiretur: quam obsedit per sex et sexaginta dies.

laquelle Jacques d'Édesse rapporte la mort de saint Jacques et l'élection de Vologèse.

1 Voir ci-après; cf. L. HaLlier, Untersuchungen über die Edessénischen Chronik. Text des Codex Vat. Syr. No CXIII, dans Texte und Untersuchungen, t. IX (I893), p. 95-96.

$\approx$ Ed. E. C. RrchaRDSON, Texte und Untersuchungen, t.XIV, I (r896), p. 6I-62.

5 Ed. W. ARndt, M. G. Scr. rer. Merov. t. I (Hannoverae, I885), p. $5 \mathrm{x}$.

4 E. W. Brooks, Chronica minora, t. IV. Versio, p. 6I.

"Ed. Brooks, Chronica minora, Textus, t. c., p. szo. La même notice est reproduite, au détail près, par Jacques d'Édesse (Brooxs, ibid. p: 28g). 
Iacobus autem Nisibis episcopus, precibus suis exercitum ab ea reppulit. (Persae) domum digressi fanem pestemque pro mercede invenerunt.

La première partie de cet extrait concorde avec la Chronique de saint Jérôme à l'année 338: Sapor rex Persarum Mesopotamia vastata duobus ferme mensibus Nisibin obsedit". Le Chronicon Paschale, à l'année 337 , sans nommer saint Jacques,

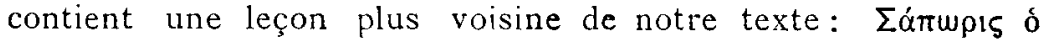

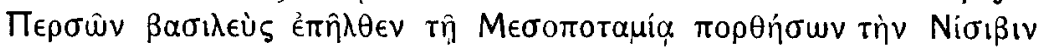

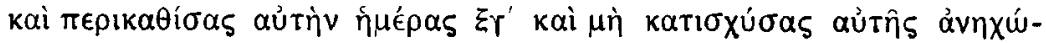
$\rho \eta \sigma \epsilon v^{2}$. Enfin la source grecque que l'on devine derrière ces emprunts apparaît au complet dans la chronographie de Théo. phane, sous l'année $5^{829^{\mathrm{J}}}$ Rappelons que Théophane, postérieur d'un bon demi-siècle au Liber Chalipharum, ne peut cependant guère avoir utilisé un texte syriaque.

8. En contradiction avec la notıce susdite, le même Liber Chalipharum en ajoute deux autres: la première au milieu d'un sommaire chronologique qui forme en quelque sorte l'introduction générale de l'ouvrage : Omnium autem annorum summa quinque milia octingenti et quadraginta anni sunt, usque ad primum annum quo Persae adversus Nisiben ascenderunt; quo itidem anno domnus lacobus, vir magnus et iustus, Nisibis episcopus, occubuit, trigesimo obsidionis's die. Ante annum ex hoc mundo migraverat Contantinus rex invictus regnumque filiis legaverat ${ }^{\circ}$.

La seconde vient dans le corps de l'ouvrage, sous l'année 049 des Grecs ${ }^{7}$. Après avoir relaté la mort de Constantin et l'accession de ses fils à l'empire, le chroniqueur poursuit : Eodem anno Persae adversus Nisiben ascenderunt; atque per triginta dies obsidio valida fuerat cum domnus Iacobus Nisibis episcopus occubuit ${ }^{8}$.

1 Helm, t, c., p. 235.

$\because$ P. G., t. XVII, p. 7 I7.

- Theophanis Chronograplia, ed. C. De Boor (Lipsiae, I883), p. 34-35.

4 M. E. W. Brooks a fort clairement montré que les informations communes à Théophane d'une part, à Denys de Tell-Mahré et à Michel le Syrien d'autre part, doivent provenir d'un auteur melkite de Palestine, qui écrivait en grec, peu après 780 (The sources of Theophanes and the Syriac chroniclers, dans Byzantinische Zeitschrift, t. XV, Ig06, p. 578-87). Voir aussi C. H. Becker, Eine neue christliche Quelbe zur Geschichte des Islams, dans Der Islum, t. IIL (IgI2), p. 295-96.

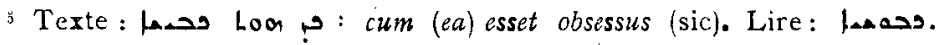

6. Brooks, t. c., p. 96

'A. D. $637-638$.

8 BROOKS, t. c., p. I32. 
A la source de ces deux notices concordantes, il faut supposer quelque document aujourd'hui perdu: document syriaque plutôt que grec, car toute la tradition byzantine l'ignore ou le contredit; dociment ancien. car il doit être antérieur à la légende qui, d'assez bonne heure, attribua à saint Jacques la délivrance miraculeuse de Nisibe ${ }^{1 .}$ A la rigueur, on peut en découvrir une indication équi :alente sous le ly risme légèrement amphigourique des Carmina Nisibena. D'après saint Éphrem, Jacques vécut en paix jusqu'aux derniers temps de sa vie: il n'assista donc qu'au premier siège, et il ne dut même pas en voir la fin, puisqu'il n'est fait aucune allusion à son rôle personnel dans la victoire. Il est au contraire parlé, avec intention, de la puissance tutélaire de son tombeau. Et pourquoi faire remarquer, en termes emphatiques, que ce tombeau, le sien seul, et non celui de ses sucesseurs. se trouve à l'inté. rieur des murs, si ce n'est pas là une exception, qui fut peutêtre imposée par le blocus? Avec un écrivain habitué à s'exprimer en langage clair. cette exégèse serait tirée par les cheveux. Mais les allusions poétiques des Carmina Nisibrsa permettent si même elles n'exigent une interprétation plus compliquée.

9. Élie bar-Šinàiā, métropolitain de Nisibe, insère dans sa Chronographie, à l'année 6r2 ${ }^{*}$, la notice ci-après, qu'ii dit empruntée à la Chronique des métropolitains de Nisibe ": Hoc anno primus Nisibis episcopus constitutus est Babovaeus: qui cum metropolitae dignitatem non haberet, eius nomen in diptycho post nomen sancli Iacobi positum est.

1 C'est sans doute la même source qui reparaît, appauvrie et troublée, dans

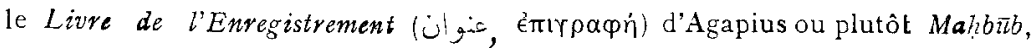
ćvêque de Manbi sexcentesimo quadragesimo altero [année 642 d'Alexandre $=$ A. D. 62I-632],.. quo anno Sapor rex. Persarum, audita morte Constantiri magni, ascendit et Nisibin excursu tempturit, quam triginta dies obsedit. Cum autem in eam per. rumpere non posset in regnum suum revertit. Tum christianos qui in dicione sua erant graviter vexare coepit neque, donec morturs est, cum iis sic agere desiit. Ilto etiam anno vita functus est Iacobus Nisibis epescopus, et in eius locum successit Babovaeus, post quem exstitit Vulogeses (ed. A. VAsilikv, Patrologia orientalis, t. VII [IgII], p. 564-65). Cf. inf. p. Ig6, note 4 .

${ }^{2}$ A. D. 300-30r.

${ }^{3}$ Ed. Th. J. LAmY, Élie de Nisibe, sa Chronologie, dans Bulletins de l'Académie royale de Belgique, $3^{e}$ sér., t. XV (1888), F 575. 
En trois autres endroits, Ėile bar-Šināiā cite à propos de saint Jacques non plus la Chronique mais l'Histoire des nétropolitains de Nisibe:

A l'année $620^{-1}$ : Hoc anno vita functus est Babovaeus Nisibis episcopus, atque electus est domnus lacobus, qui in monte cum domno Augin habitabat, et in ecclesia Nisibis constitutus est episcopus".

A l'année $624^{3}$ : Hoc anno domnus lacobus templum magnum exstruere coepit cuius opus integrum annis septem exaedificavit ${ }^{4}$.

Enfin à l'année $649^{3}$ : Hoc anno, vila functus est dommus lacobus Nisibis metropolita, in cuius locum domnus Vologeses sucessit, qui in monte Edessae solitariam vitam agebat".

La Chronique des métropolitains de Nisibe n'est connue que par les citacions d'Elie, dont la dernière paraît se rapporterì̀ l'année 30 I de l'hégire (9I3-9I4 de J.C.) ${ }^{7}$. De son témoignage, il faut retenir seulement que le nom de saint Jacques précédait celui de Babu dans les diptyques. Sur ce point de fait, une erreur était à peine possible de la part d'un annaliste local et surtout de la part d'Élie, pour qui la liste officielle et liturgique des métropolitains était un document familier. Le reste est une glose érudite, qui ne peut, à aucun égard, être mise en balance avec l'autorité de saint Éphrem.

Rien ne prouve avec certitude que l'Histoire des métropolitains de Nisibe soit distincte de l'ouvrage précédent. Elle est représentée dans la compilation d'Élie bar-Šinãiā par des extraits dont le dernier se rapporte à l'année 672 (360-36r de J.-C.) ${ }^{8}$. Il est complètement inadmissible qu'un ouvrage portant ce titre se soit arrêté aux environs de l'an 36r. En tout cas, ce qu'il relate touchant saint Jacques de Nisibe a trop l'air de

1. A. D. 308-309.

LAMY, t. c.. p. 376

A. D. 3I2-3I3.

- Lamy, t. c., p. 376. La Passion entièrement labuleuse de sainte Fébronie de Nisibe rapporte qu'un évếue anonyme éleva à la martyre une église, dont la construction dura sir ans (BEDJAN, Acta martyrum et sanctorum, t. V, Paris I895, p. 6 ro ; cf. Act. SS., Iun. t. V, P. 33). Ce lait, dont la réalité est dans une certaine mesure indépendante du caractère apocryphe de la Passion, aurait eu lieu durant la période correspondant à l'épiscopat de saint Jacques (voir PaPeiroch, l. c., p. $3^{8}$ ).

i A. D. 337-338.

"LAMY, t. c., p. $37^{6}$,

CE. L.J. Delaporte, La Chronographie d'Élie bar-Sinaya métropolitain de Nisibe $=$ Bibliothèque de l'école des Hautes Études, fasc. 182, Paris, 1910), p. IX.

$\times$ Delaporte, ibid 
refléter la fabuleuse histoire de Mār Augin pour ne pas inspirer quelque méfiance ${ }^{1}$.

Dans cette revue des témoignages qui sont ou qui paraissent indépendants de nos textes hagiographiques, nous n'avons pas à mentionner le chapitre consacré à Jacques de Nisibe par Fauste de Byzance dans son Histoire d'Arménze. Malgré son ancienneté respectable et la bonne réputation de son auteur, ce récit n'est au fond qu'une amplification épique, inspirée peut-être par des souvenirs locaux. Sa place est parmi les produits de la tradition littéraire dont il est, pour nous, le premier témoin. Nous le ferons connaitre en son lieu.

Réserve faite des données historiques qui seraient encore reconnaissables chez Fauste, les extraits qui viennent d'être cités représentent les seuls points fixes autour desquels on pourrait tenter de reconstituer la biographie de Jacques de Nisibe. Il faut aussi les avoir présents à l'esprit pour retracer, non l'histoire du saint, mais celle de sa légende et réduire cette légende à sa très contestable valeur.

\section{§ II. La légende grecque.}

Le clocument qui, dans l'église grecque et dans l'église latine, a le plus contribué à entourer d'épisodes apocryphes ou démarqués la mémoire de l'évêque de Nisibe est le chapitre

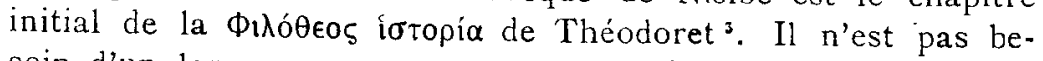
soin d'un long examen pour se convaincre que ce récit ést brossé d'imagination ou d'après des sources légendaires, en dehors de toutes les attestations positives qui viennent d'être rappelées. Aux rạres endroits où il se rapproche de l'histoire, c'est pour la noyer sous des développements fantastiques. Nous allons essayer d'en démêler la composition et d'en indiquer les sources; mais pour n'avoir pas à détailler tout au long le contenu de la pièce, on nous permettra de renvoyer le lecteur aux paragraphes correspondants de la Vie armé nienne $(=\mathbf{A})$ dont nous donnons ci-après la traduction. Le chapitre de Théodoret $s^{\prime} y$ retrouve à peu près tout entier, morceaux par morceaux. Voici donc le contenu de ce texte dont la fortune a quelque chose d'incompréhensible.

\footnotetext{
1 Voyez la Vie arménienne, \$§ ıo, 19, 20.

2 Livre III, ch. Io.

$\therefore B H G . \mathbf{I} 439-\mathrm{I} 440$.
} 
I. Prologue où Théodoret se compare à Moyse écrivant l'histoire d'Abel, d'Hénoch, de Noé et de Melchisédech [cf. A $\$ I]$.

2. Patrie de saint Jacques; son genre de vie et les prodiges de son ascétisme [cf. A, \$2]. Aucune date n'est marquée. Pour toute indication chronologique, une phrase vague et déclamatoire sur l'idolâtrie régnante.

Dès les premiers mots du récit, on est frappé par une ressemblance littérale avec le début de la Vie syriaque de saint Éphrem ${ }^{1 .}$

\section{HistorJa RELIGIOSA}

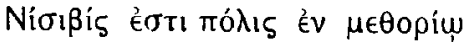

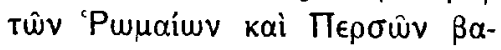
$\sigma i \lambda \in i \alpha$ s.

La Vie d'Éphrem doit avoir été rédigée peu d'années après

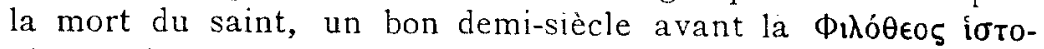
pía. Mais elle a été si librement remaniée et interpolée dans la suite, que la date de chaque passage en particulier peut être remise en question. Il est donc bien entendu que, provisoirement, le parallólisme des deux textes ne décide rien ni dans un sens ni dans l'autre.

2. Voyage de saint Jacques en Perse. Auprès d'une source, des lavandieres lui manquent de respect [cf. A, $\left.\$ x_{5}\right]$. Cet incident débute exactement comme un épisode de la Vie d'Éphrem :

\section{Historia RELIGIOSA}

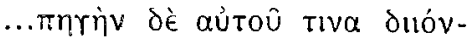

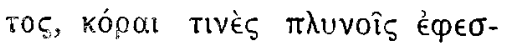

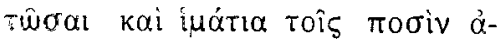

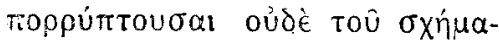

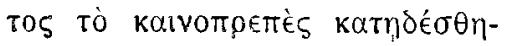

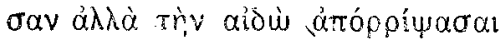

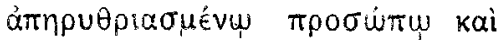

\section{Vita Ephraem}

Ad fuvium pervenit qui urbem circumluit, Daisan nomine. Et circumspiciens mulieres conspexit supellectilem abluentes. Ipse vero in ripa fluminis consistens illas intuebatur. Porro mulier quaedam ex allis arrectis in eum oculis

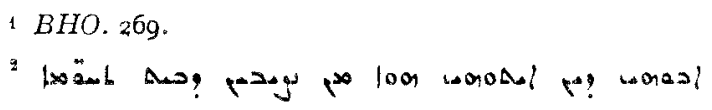




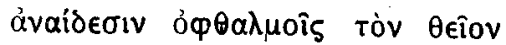

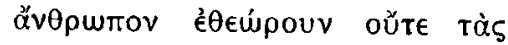

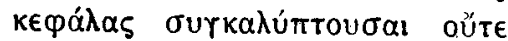
eum perdiu considerare coepit. Quod ille indigne forens ait...

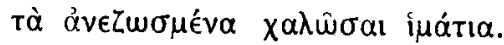

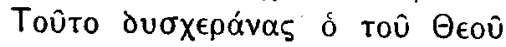

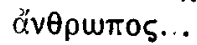

Dans la Vie d'Éphrem, tout se borne à un reproche du saint et à une repartie assez judicieuse de la lavandière. Chez Théodoret, Jacques de Nisibe, pour punir les étourdies qui l'ont insulté, fait d'un coup deux miracles, dont il répare l'un par un nouveau prodige. Malgré cette différence dans le dénouement, les deux épisodes sont certainement apparentés. Nous notons la ressemblance, sans en rien conclure pour le moment.

4. Miracle de saint Jacques pour amener à résipiscence un uge prévaricateur [cf. A, \$ I6].

5. Election de saint Jacques à l'épiscopat. Ce passage est remplacé dans $\mathrm{A}$, par un long épisode emprunté à la légende de Mār Augin [cf. A, $\$ \$ 3-4]$. Vertus pastorales de Jacques [cf. A, \$ I , init.].

6. Châtiment d'un imposteur qui feignait d'être mort et que ses complices avaient apporté aux pieds de saint Jacques [cf. $\mathrm{A}, \$ \mathrm{r}]$. Antonelli avait déjà reconna ${ }^{1}$ que cet épisode répétait un miracle attribué à saint Grégoire le Thaumaturge par Grégoire de Nysse ${ }^{2}$ et à saint Expiphane par Sozomène ${ }^{3}$. Ce dernier, qui connaît aussi l'exemple de saint Grégoire, fait à ce propos une réflexion qui marque déià un commencement

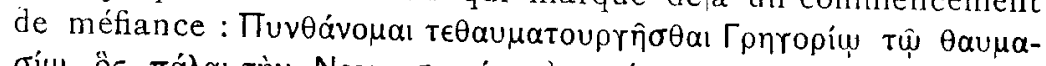

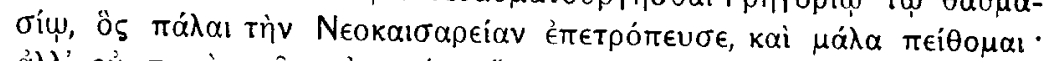

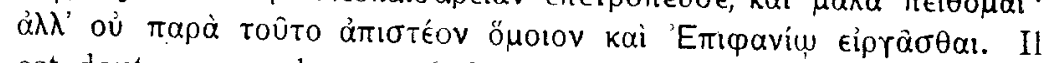
est douteux que beaucoup de lecteurs'se rassurent aussi faci-

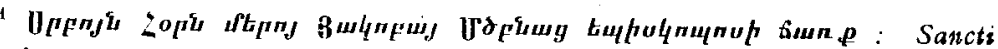
patris nostri Iacobi episcopi Nisibeni sermones (Romac, $175^{6}$ ), p. xxilı, note. Nous ne ferons à personne l'injurc de lui rappeler que ces sermons pseudépigraphes sont une traduction arménienne des catéchèses d'Aphraates. Voir ci-dessus, p. 287 .

$=$ BHG. 7 I5; P. G., t. XLVI, p. 94I-47.

"Historia ecclesiastica, 1. VII, c. 27, ed. R. Hussey (Oxonii, t860), p. 771-72. 
lement sur la ressemblance entre le récit de Théodoret et celui de Grégoire de Nysse, - que cette ressemblance soit le fait de Théodoret lui-même ou de l'auteur auquel il se serait confié.

7. Jacques de Nisibe au concile de Nicée [cf. A, $\$$ I8]. A cet épisode se rattache une historiette fabuleuse sur la mort d'Arius. Les partisans de l'hérésiarque, voyant leur maître frappé d'anathème, intercèdent auprès de l'évêque Alexandre d'Alexandrie pour obtenir la grâce du coupable. L'évêque s'y refuse, et, sur les conseils de Jacques de Nisibe, il est décidé qu'on observera un jeûne de sept jours, pour obtenir que Dieu lasse connaître sa volonté. A l'expiration de ce terme, Arius, qu'on attendait en vain à l'église pour l'office du dimanche,

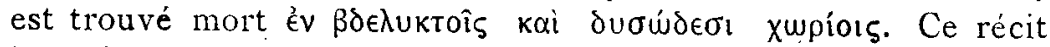
incohérent offre un exemple complet de toutes les libertés que la fiction peut prendre avec l'histoire. Les circonstances vraies de la mort d'Arius, relatées par Socrate ${ }^{1}$ et Sozomène d'après saint Athanase ', y sont amalgamées, a! prix d'un anachronisme flugrant, avec une historiette apocryphe, dont la première idée remonte peut-être à la Passion de saint Pierre d'Alexandrie '. Cuperus a jugé toute cette anecdote si extravagante qu'il l'a traitée comme une interpolation, pour la raison asse $z$ faible qu'elle est en contradiction manifeste avec l'Histoire ecclésiastique du même Théodoret, et pour le motif plus sérieux qu'elle devait être'absente du manuscrit d'après lequel

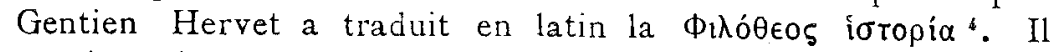
aurait pu invoquer également, s'il l'avait connue, la Vie syriaque de Jacques de Nisibe, traduite de Théodoret ${ }^{5}$, où l'épisode en question ne se lit pas. On remarquera toutefois que la Vie arménienne le rapporte ( $\$$ I8), d'après une source probablement syriaque.

Réserve faite de ce passage suspect, la narration de Théodoret offre ici un nouveau parallélisme avec la Vie de saint Éphrem.

1 Historia ecclesiastica, 1. I, c. 3, ed. R. Hussey (Oxonii, 1853), pe r69-7x.

2 Hist. 1. II, 29, 4 ; 39, 3-7 (Husser, t. c., p. 209-213).

$\overline{3}$ J. Viteau, Passions des sabits Ecaterins et Piervo.d'Alexandrie, Barbara ct Anysia (Paris, 1897), p. $7 \mathbf{1}$; cf. Act. SS., Nov. t. III, p. 339.

'Act. SS., Iul. t. IV, pp. 32, 43.

:BHO. 405-406. Bedjan, Acta martyrum et sanctorum, t. IV (Paris, I894), p. $263-73$. 


\section{Historia RELIGIOSA}

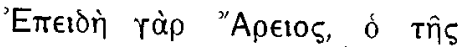
katà toû Movorevoûs kaì toû

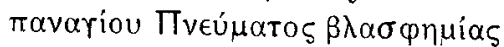

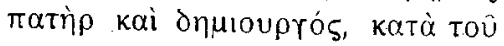

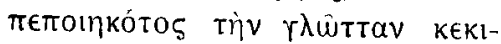

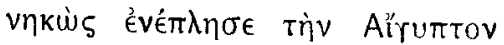

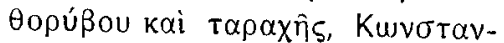
rivos dè ó $\mu$ ériotos $\beta a \sigma i \lambda \in \dot{U} \varsigma_{\text {, }}$

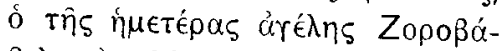

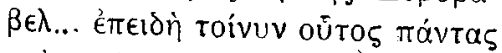

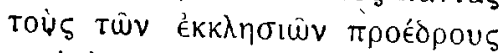

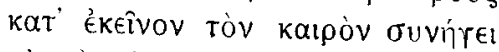

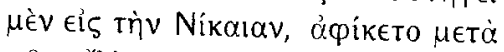

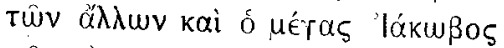

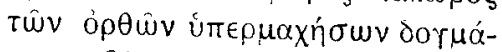

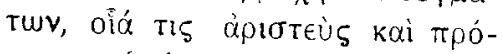

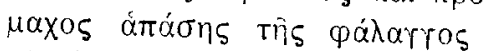

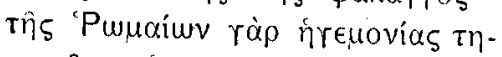

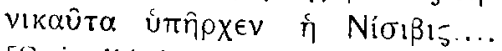
[Suit l'épisode de la mort d'A-

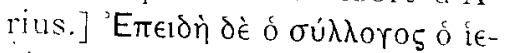
pòs dı

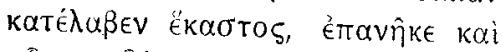

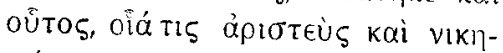

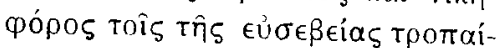

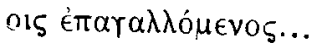

\section{VITA EPHRAaM}

Brevi post tempore, cum Arius ille qui-Filio et Spiritui naledixit et adversus creatorem summ suam linguan concitant, Aesyptum tumultu compleret, Constantinus rex victor episcopos qui tum erant in Nicaeam urbem congre. gavit. Venerabilis auten zir Dei invitatus ut cum collegis suis conveniret. secum assumpsit beatum domnum Ephraem et ad sanctan synodum eum adduxit. Viam igitur ingressi, abierunt ipse et wenerabilis air Dei, ut (ille) propter veran fidem pusnaret, tamquan dux exercitus christianorum totius imperin romani. Postquam autem (1rius) iste cum suis asseclis plexus anathomate et eiectus poenas aedit, ommibus ad suan quisque regionem revertentibus. revertit etian sanctus dommus lacobus, quasi dux victor parta vicuria lactans..

8. Délivrance miraculeuse de Nisibe assiégée par les Perses [cf. A, \$23]. Ici, un résume serait insuffisant. Le problème critique que ce passage donne à résoudre. ne peut être posé en termes clairs que sur le détail du texte et des rédactions parallèles.

Préalablement à la question littéraire, qui est proprement lobjet te notre recherche; l'épisode du siège de Nisibe soulevait autrefois une difticulté historique', qui aujourd'hui doit être considérée comme résolue. Les événements dónt s'est

- Voir les travaux de Garnicr, Valois. I'illomont et autres, rappeles dans le commentaire de cuperus, et ec commentairc lui-méme, $\$ \$ 4-44$, t.c. P. $37 \cdot 40$. 
emparée la rhétorique de Théodoret sont connus : Io par un passage du Chronicon Paschale, qui reproduit ou du moins cite comme référence une relation de l'évêque de Nisibe, Vologèse ${ }^{1} ; 2^{\circ}$ par les discours I et II de l'empereur Julien ${ }^{2}$, où sont décrites avec une emphase pédantesque les opérations du siège et de la défense ; $3^{\circ}$ par les allusions et les tirades $1 y-$ riques répandues dans les Carmina Nisibena de saint Éphrem et dont tous les détails concrets s'emboitent, avec une exactitude surprenante, dans la narration de Julien et de la Chronique Pascale ${ }^{3}$. Il n'y a rien à tirer des écrivains postérieurs comme Philostorge, Théophane, Mšihāā-zekhā d'Adiabène ${ }^{4}$, Michel le Syrien, Barhebraeus et autres, tous tributaires des sources historiques, indiquées plus haut, ou des sources légendaires dont il nous reste à parler.

Des témoignages originaux, il ressort à l'évidence que Théodoret, entre plusieurs licences vénielles chez un hagiographe, est tombé dans une confusion extrême des temps, des choses et des personnes. Les événements qu'il met en scène au gré de son imagination ou d'après une relation fantaisiste, se sont passés en 350, pendant le dernier des trois sièges auxquels assista saint Éphrem ${ }^{5}$, douze ans après la mort de saint Jacques. Le rôle prêté à ce dernier est donc une fiction, sans. autre fondement qu'un souvenir déjà indistinct des services rendus par le saint évêque au cours du premier siège, en 338 .

D'autres méprises et d'autres erreurs se sont greffées sur ce quiproquo initial; elles n'entrent ici en ligne de compte que comme indices du développement de la légende.

Théodoret a récrit l'épisode du siège de Nisibe dans son

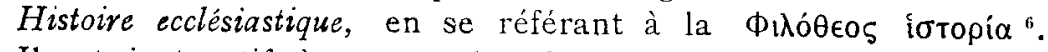
Il est instructif de mettre les deux textes en regard l'un de l'autre.

1 P. G., t, XCII, p. 724-28.

2 Ed. F. C. Hertlein (Leipzig, 1875), pp. 33.39, 79-80.

"Les références ont été colligées avec grand soin dans les prolégomènes de Bickell, \$IV, p. Ir-I8.

4A. Mingana, Sontrces syriaques, t. I, I. Mšitzāi-zekhā (Leipzig. [rgo7]), p. 47-49. Comme trait original, Mšihā-zekhā ajoute que la persécution décidée par Sapor fut une vengeance de la défaite qu'il avait subie à Nisibe par les prières de saint Jacques. Rapprucher le texte d'Agapios, ci-dessus, p. 289 , it. I.

${ }^{x}$ Les deux premiers curent lieu en 338 et en 346 (cf. Bickell, loc. cit., p. $\mathbf{I} \mathbf{I}-\mathbf{I} \boldsymbol{2})$.

fiI, 3o; éd. L. Parmantier, Theodyet Kirchengeschichte dans Dic griechischen christlichen Scluriftsteller (Leipzig, IgII), p. r67-69. 


\section{Historia RELIGIOSA}

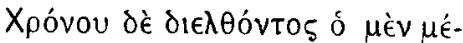

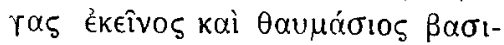

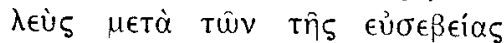

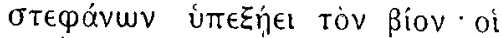

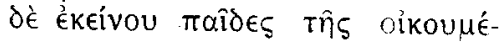

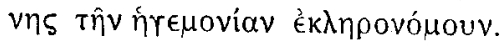

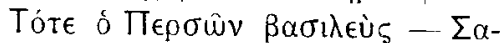

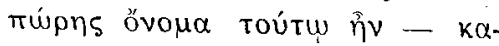

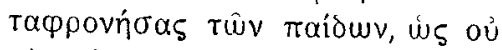

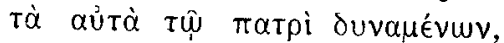

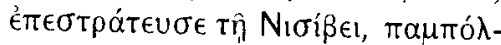

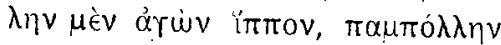

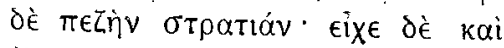

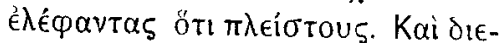

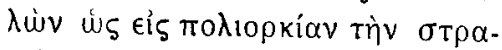

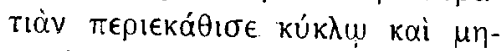

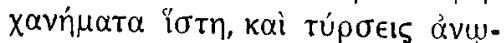

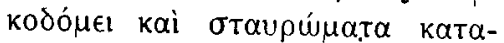

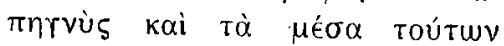

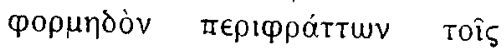

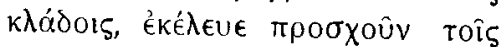

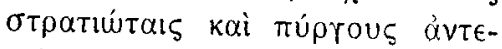

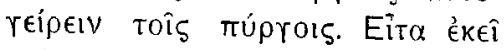

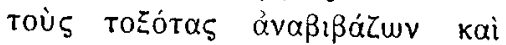

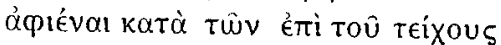

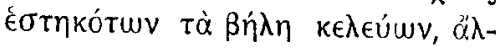

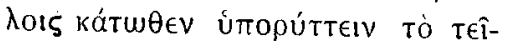

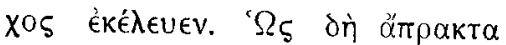

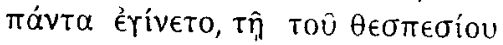

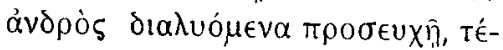

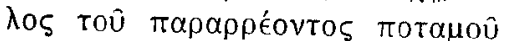

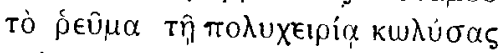

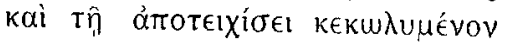

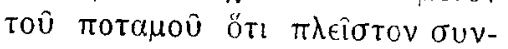

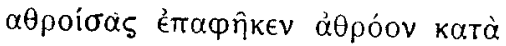

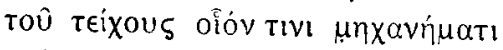

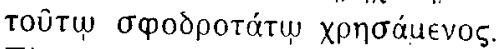
Tò dè oủk ท̆verke tìv toû üd $\alpha$ -

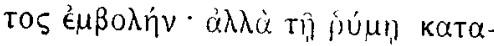

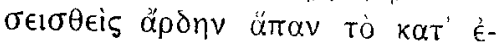

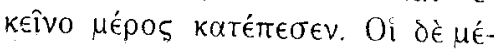

\section{HISTORIA ECCLESIASTICA}

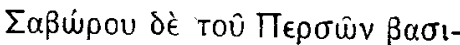

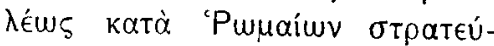

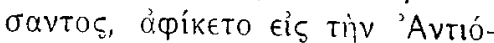

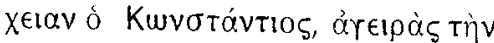

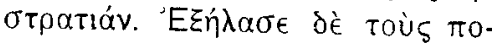

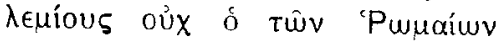

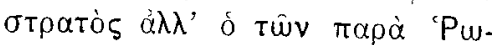

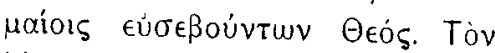
dè tîs vikñs tó́trov érù dınrńбoual.

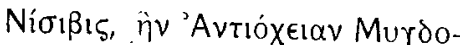

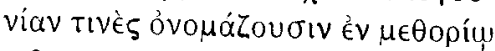

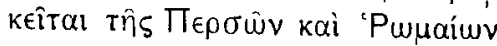

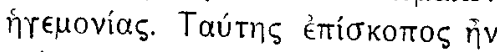

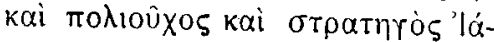

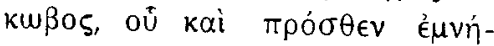

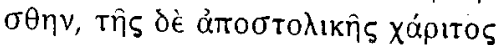

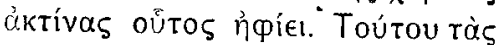
àzıaráotous kai moluvuvítous

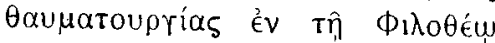
'Ioropía ourrpáuas, iepittov oí-

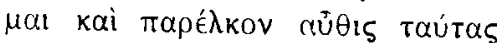

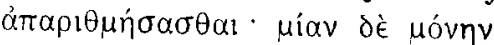

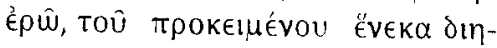
rímaros. Tìv útiò toútov кußep-

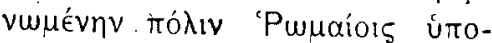

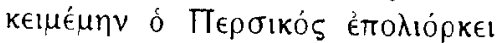

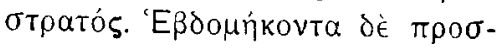

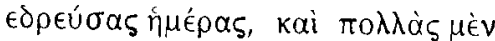

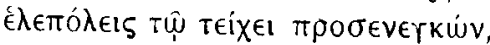

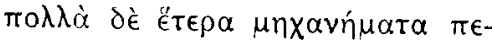

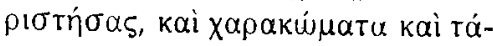

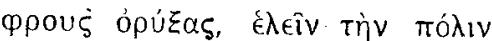

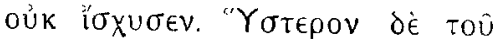

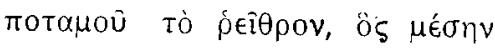

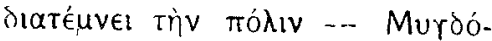

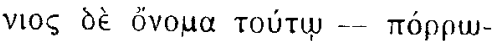

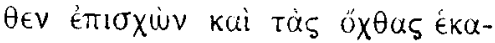

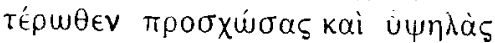

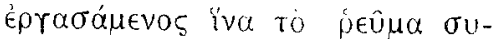

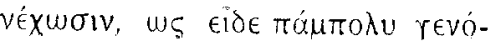




\section{HISTORIA RELIGIOSA}

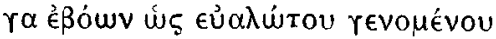

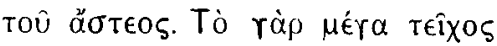

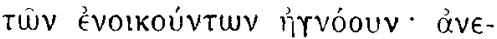

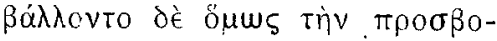

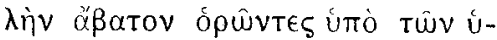

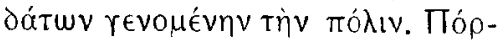

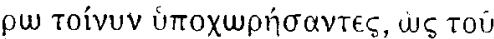

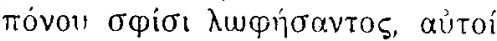

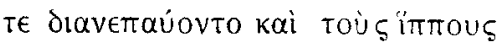

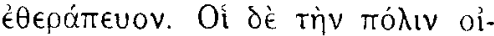

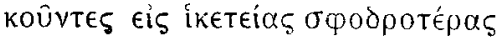

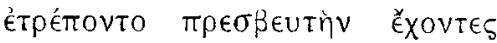

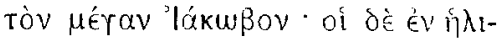

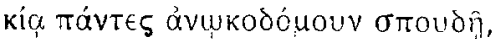
oüte kákhous oúte ápuovias íml-

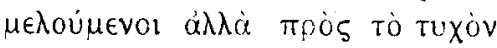

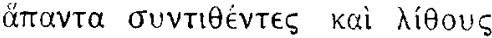

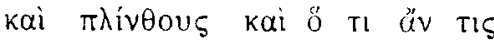

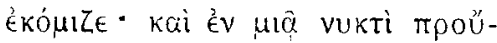

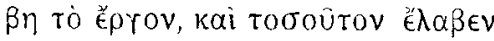

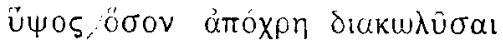

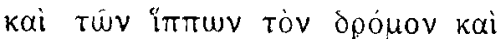
$\tau$ Tuิv ảv

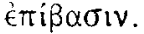

\section{HISTORIA ECCLESIASTICA}

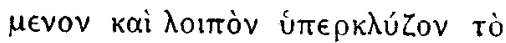

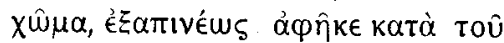

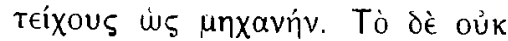

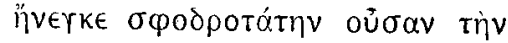
$\pi \rho \circ \sigma \beta о \lambda \eta \dot{v} v, \alpha \lambda \lambda \lambda^{\prime} \in \lambda k i \theta \eta \eta$

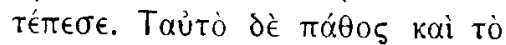

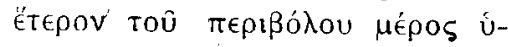

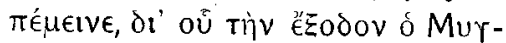

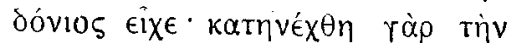

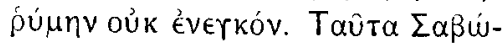

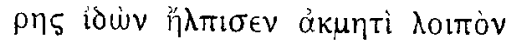

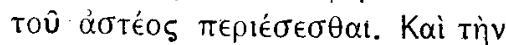

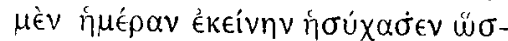

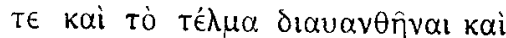

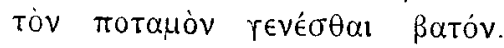

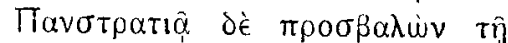

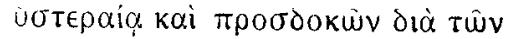

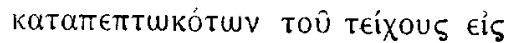

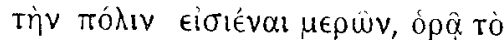

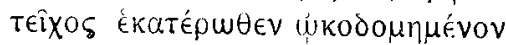

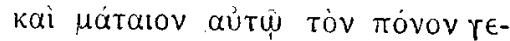
revinévov. 'O rà $\theta$ ễos ékêิvos

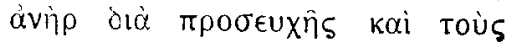

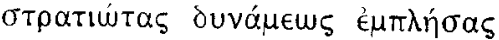

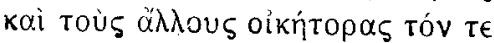

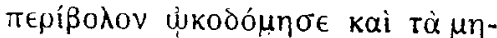

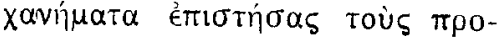

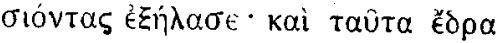

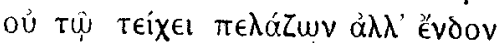

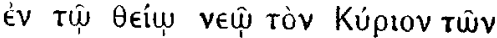

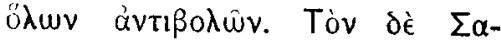

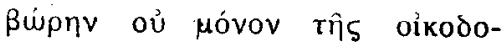

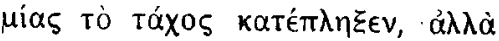

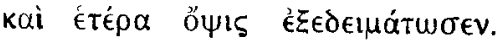

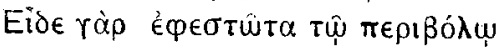

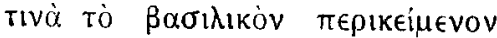

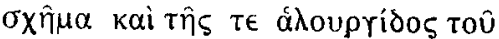

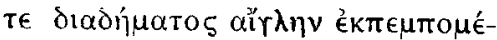

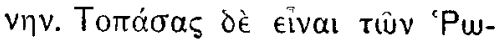

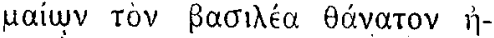

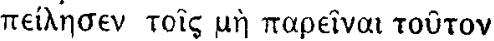


Historia RELIGIOSA

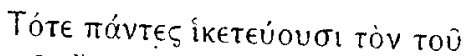

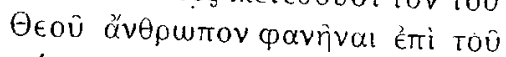

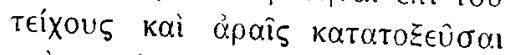

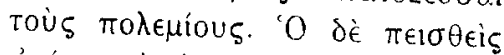

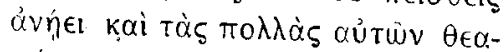

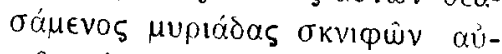

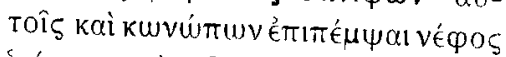

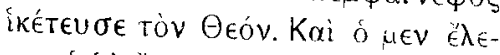

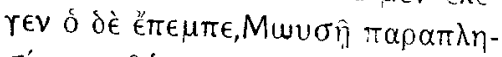

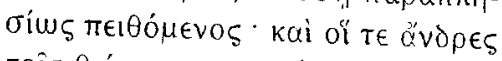

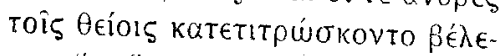

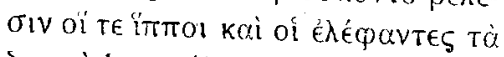

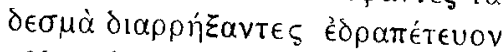

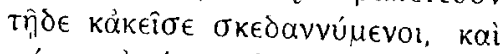

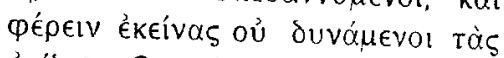

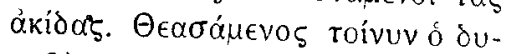

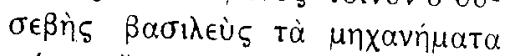

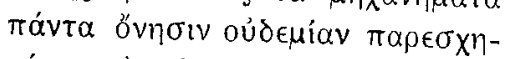

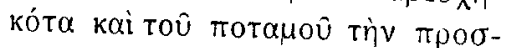

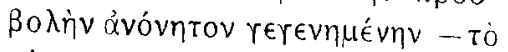

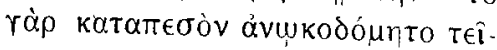

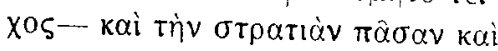

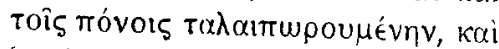

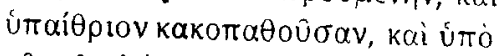

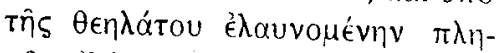

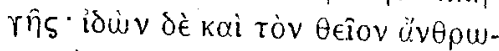

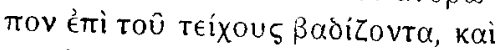

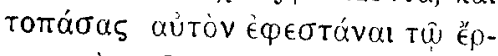

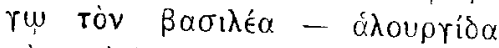

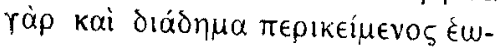

\section{HISTORIA ECCLESIASTICA}

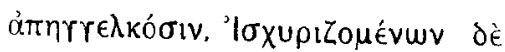

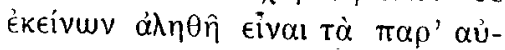
tûv eipnuéva kaì tòv Kuvotáv-

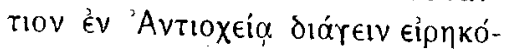

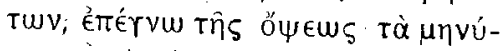

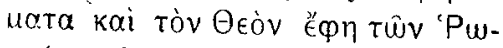

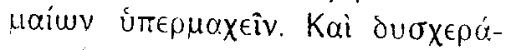

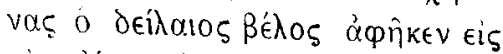

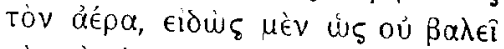

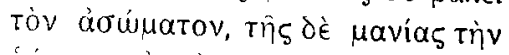
fúunv oủk èverkúv.

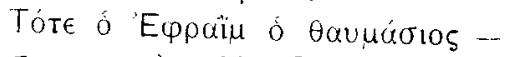
ourrpaqeùs dé oũtos äp:otos $\pi u \rho \dot{\alpha} \cdot \Sigma u ́ \rho O I S$ Éréveto - Tov $\theta$ Êे-

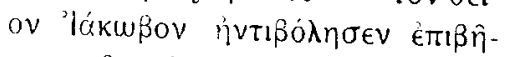

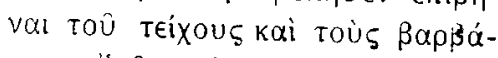

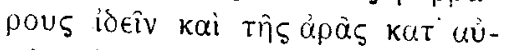

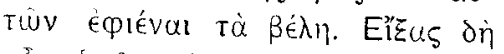

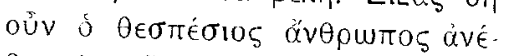

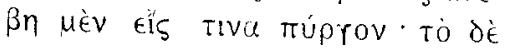

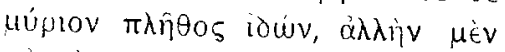

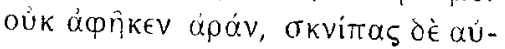

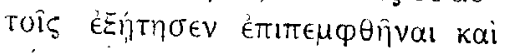

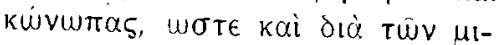

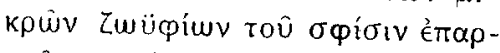

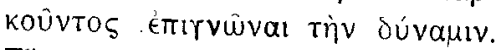

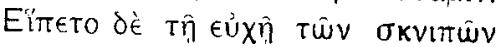

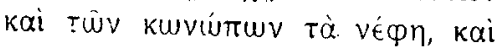

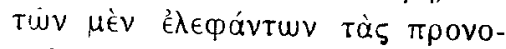

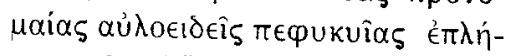

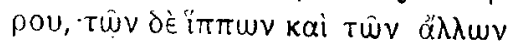

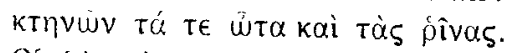
Oi dé pépeiv oủ duváuevol tûv Zwü

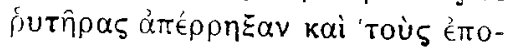

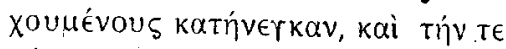

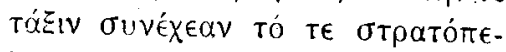

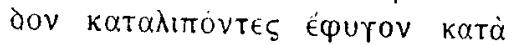

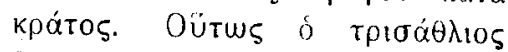

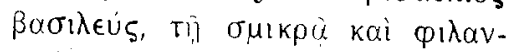

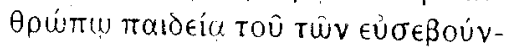




\section{Historia RELIGIOSA}

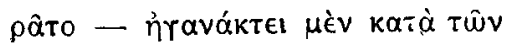

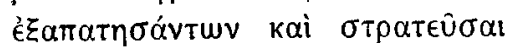

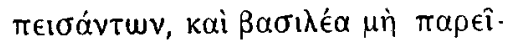

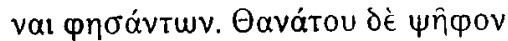

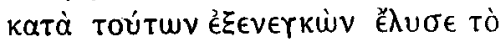

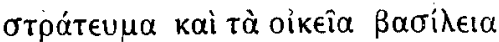

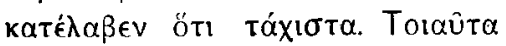

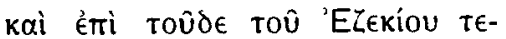

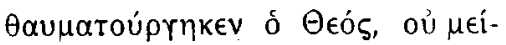

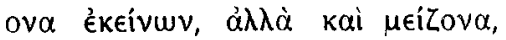

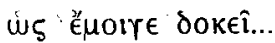

\section{Historia ecclesiastica}

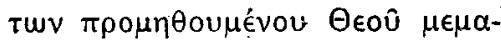

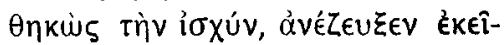

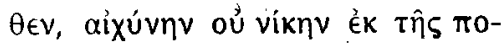

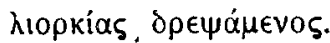

Il y a plusieurs divergences entre ces deux narrations : nous nous bornerons à indiquer les principales en négligeant les simples variantes verbales qui peuvent être imputées aux copistes; tel le nom du roi de Perse écrit $\Sigma a \pi u ́ p n s$ dans le

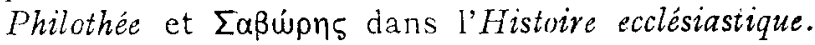

Dans la première rédaction, que nous appellerons la Vie de saint Jacques $(=\mathbf{V})$, l'action se passe très peu de temps après la mort de Constantin-le-Grand survenue en 337 ; dans la seconde, c'est à dire dans l'Histoire ecclésiastique $(=\mathbf{H})$, les faits sont reportés à la période qui suit les conciliabules de Rimini te de Séleucie en $359^{1}$. Telle est du moins la date qui ressort de la place où ils sont racontés, sans aucune forme de transition marquant un retour en arrière.

Dans V, la durée du siège est indéterminéc; - dans $\mathrm{H}$, le stratagème imaginé par Sapor est mis en cuvre après jo jours d'efforts inutiles.

D'après V, le fleuve - dont le nom propre est laissé à deviner - coule sous les remparts de la ville; - d'après H, le Mygdonios traverse la place.

Enfin, et ceci dépasse notablement la portée des variantes ci-dessus, il $y$ a entre les deux récits une différence assez grave dans l'enchaînement et par suite dans le caractère des taits qui amènent le dénouement. Selon $V$, Jacques, monté sur le rempart, fait apparâtre dans l'air une nuée de moucherons qui jettent le désordre dans les rangs ennemis. Sapor, témoin de cette débandade, aperçoit l'évêque qu'il prend pour l'empereur Constance, et cette vue achève de le plonger dans le dé- 
couragement. Selon H, Sapor ramenant ses troupes à l'assautt du rempart qu'il s'attendait à trouver démantelé, remarque sur le parapet de la muraille, relevée comme par enchantement, un personnage mystérieux en qui il croit reconnaître l'empereur. Ses officiers le détrompent et se rendant compte à luimême de l'inanité de son geste, il décharge sur l'apparition immatérielle sa-fureur impuissante. Alors Éphrem décide saint Jacques à monter sur l'escarpe - nouvelle preuve que dans $H$ ce n'est plus l'évêque en chair et en os que Sapor prend pour Constance - et les moustiques, appelés par la malédiction du saint, changent en déroute la confusion des assiégeants.

Tout compte fait, rien dans cette comparaison de variantes ne rend probable qu'entre le moment où il composait le chapitre I du $\Phi_{1 \lambda o ́} \theta \epsilon_{5}$ et celui où il achevait le second livre de son Histoire ecclésiastique, Théodoret ait mis la main sur quelque docủment nouveau concernant saint Jacques de Nisibe. Les seuls dét ails additionnels qui semblent marquer un certain progrès dans l'information de l'auteur sont les surnoms littéraires de Nisibe et de son fleuve: 'Avrióxela Murdovía et Murdóvios. Mais qui oserait affirmer que ces noms ne se lisaient pas déjà dans la source qui a servi à rédiger le $\phi_{1 \lambda o ́} \theta \in{ }^{\circ}$ ? Si l'on décide qu'ils ne pouvaient s'y trouver, puisque Théodoret ne les a pas reproduits, et que l'illustre écrivain a dû les apprendre dans un livre, après la publication de son premier récit, il y a plus d'une hypothèse laissée ouverte parces deux postulats également déraisonnables. Il est, par exemple, fort possible que Théodoret ait lu les harangues de Julien l'Apostat, où Nisibe et le fleuve qui l'arrose sont appelés de leurs noms héllénisants '. En tout cas, il avait mainte façon d'apprendre ces minces détails de nomenclature autrement que par un texte relatif à la personne ou à la vie de saint Jacques.

C'est peut-être aussi en lisant Julien qu'il aura remarqué la lourde erreur où il était tombé en plaçant immédiatement après la mort de Constantin le siège de l'année $35^{\circ}$, rendu célèbre par les travaux hydrauliques de Sapor. Mais il n'a réparé cette erreur que pour la remplacer par une autre, plus grave que la première: au lieu d'un anachronisme, sa narration remaniée en contient deux, et l'un de ceux-ci prouve que Théodoret avait oublié ou qu'il n'a jamais su que Jacques de Nisibe est mort en $33^{8}$. 
Ln autre passage du récit corrigé spécifie que la rivière de Nisibe traversait la ville par le milieu '. Ceci encore est loin de dénoter une connaissance plus exacte des lieux et des événements : saint Éphrem dit au contraire, en termes exprès, que le fleuve coulait en dehors de la ville ${ }^{2}$. Telle est aussi la disposition topographique qui est supposée dans le Chronicon Paschale et dans les descriptions de Julien, comme il serait facile de le montrer, si le sujet comportait de tels développements ${ }^{5}$. Quant aux autres différences des deux récits, elles n'ajoutent ni n'enlèvent rien à l'nnvraisemblance ou à la fausseté de la légende. Toute la question est de savoir où Théodoret a pris l'iciée de modifier sa première rédaction. Si l'on ne veut pas l'accuser d'avoir sciemment altéré les faits, la seule explication plausible est qu'il a suvi un document qui laissait place à plusieurs interprétations.

Or ce document, nous croyons en avoir retrouvé la trace. Ce même épisode du siège de Nisibe, tel 'qu'il est raconté pàr Théodoret, se lit également dans la Vie d'Éphrem avec des variantes qui se raccordent en partie à la leçon du Philotheos et en partie à celle de l'Histoire ecclesiastique. Mais il y a mieux. La Vie syriaque de Jacques de Nisibe, traduite, comme on l'a vu ", de l'Historia religiosa, se sépare ici de son origi. nal et relate l'épisode avec toutes les particularités propres à la Vie d'Éphrem. Le lecteur fera lui-même cette comparaison instructive. Voici les textes:

1. Voir ci-dessus, p. 297

2 Carmina Nisibena, XIII, I07-Io8; cf. Bickell, t. c., p. I4.

- D'après la description faite de visu par M. Sachau, la rivière pruncipale, (appelée aujourd'hui Džaghdjagh ou Dzaghdjagha), longe au sud l'emplacement de l'ancienne ville. Un autre cours d'eau, qui est proprement un ruisseau appelé Khnes le traverse un peu plus au nord. Le terrain de Nisibe et assez marécageux (E. Sachau, Reise in Syrien urd Mesopotamien Leizig, I885, p. 398-gr). La mêrne observation est déjà rapportée par Jāqūt (Geographisches Würterbuch, ed. WüstenfELd, t. IV, I869, p. 788). Si l'on tient compte de cette circonstance, le récit de Julien pạrait on ne peut plus nacurel. Sapor, à qui les marais du fleuve interdisaient l'accès de la place, a voulu tirer parti de l'obstacle en élevant le niveau de la nappe d'eau jusqu'à la rendre navizable.

4 Voir ci-dessus, p. 294. 


\section{Vita Ephraem}

Breri posi tempore vita functus est magnus et inclutus Constantinus; rex rictor, atque in eins potesiatem fulii eins successerunt. Elapsis porro diebus paucis, Sapor rex Persarum, filion Constantini iuventutem contemners contra Nisiben progressus est cum multis copiis infinitaque vi equorum et elephantorum. Copias suas divisit, (quae) se disposuerunt ad expusnandam urbem.

Iam per septuaginta dies eam (urbem) obsederut, cunn tandem fluctus amnis, qui urbên interluens meaiam dividit, a longe <interceptos > occhisit.Cumque murus, qui prae vehementia aquarum multarum consistere non poterat, labefactatus corruisset. existimavit Sapor nullo iam negotio se urbe potiturum ${ }^{1}$.

\section{VItTa IACOBI}

Aliquamain pastea zibta functus est Constantinus ille (vex) victor et in eints reynum filit eins successerunt. Tum Sapor rex Persarum, illorun invientuten contemnens, adversus urben Nisiben progressus est cum multis copiis, plurimisque equis et elephantis. et contra urben consedit ad eam expugnandam.

Iam per sephuagintu dies eam obsederat, alla plurima e regione muri constituerat, munitione (ur bent) concluserat, cunicula circum foderat, neque tamen eam capere potuerat. Tandem amnem, qui urbem interluens mediam dividit, a longe interceptum ex uiraque parte occlusit, aggerisque molem ita extulit. ut aquarum vehementiae resistere posset. Magnam igitur vim aquarum congessit: quaram cumulim, it supra aggerem summin propemodum exunaantem widit, repente insiar machinae cu. iusdam eas in mumum inmisit: qui murus, prae aquarum mole, illarum impetum ferye non potuit, sut racillarit atque comits at lapsu eodem mutrus perculsus est ex altera parte, qua est firminis exitus: quae eversa corruit. Quate cum ridisset Sapor, existimavit nullo negotio se urbe potiturum Requievit itaque die illo, neque perrexit at ingredienaam urbem, donec terra ex-

' Le texte est visiblement écourtá. 
VITA EPHRAFM

At domnus Iacobus episcopus et beatus domnus Ephraem, cum reliquo ecclesiae coetu, per totum opprugnationis tempus Deum obsecrati erant. Tandem episcopus equitibus ac reliquis civibus vires animosque auxit, murum aedificavit, tormentum balistamque in eo constituit, et quicumplue ad illum accedebant, prohibuit atque reppulit : quae omnia perfecit non muro appropinquans sed in templo divino Dominum universorum obsecrans.

Saporem vero non modo murus tam facile aedificatus obstupefecit, sed etiam visum ei porientum aliud conterruit: quippe visus est ei homo quidam regia veste circumdatus in summo muro consistere, cuius stola lucentibus radiis coruscabat. Quem, cum Romanorum regem esse crederet, minis invectus est in eos, a quibus audierat Antiochiae (tunc) esse regem Romanorum. Deinde hoc viso significatum intellexit Deum Romanorum pro illis pugnare. Excanduit igitur et in eos minas erupit infelix (homo), et iacula conicere coepit, ut qui incorporeum impetere se non intellegeret, iranque ac furorem suum effudit.

\section{VITA IACOBI}

siccaretur et fluvius aditum daret.

Sed cum tanden onnem exercutum suum ad urbem admovisset, ea parte se in eam ingressurum existimans qua murus corruerat, murum conspexit utrimque aedificatum inanemque comperit laborem suntn. Iacobus enim, vir divinus, orationum suarun ope equites incolasque urbis iirtute compleverat, murum aedificaverat, tormentum balistanque in eo col. locaverat, et quicumque ad illum accedebant dispersit ac reppulit. Quae omnia perfecit, non muro ipse appropinquans sed in interiore templo, Deum dominum universorum obsecrans.

Saporem vero non modo murus tam facile aedificatus obstupefecit, sed etiam visum ei portentum alind conterruit: quippe visus est ei homo (quidam) regia veste circumdatus in summo muro consistere, cuius stola et diadema lucentious radiis [al. sicut radii solis] coruscabant. Quem cum Romanorum regem esse crederet minis invectus est in eos [qui ei negaverant illum istic adesse. Illis antem contendentibus fide dignos eos esse ${ }^{1]}$ qui Constantium Antiochiae esse dixerant, portenta intellexit sibivisa, et dixit: "Deus Romanorum pro illis pugnat. = Et fremens (homo) miserandus, tela in aerem coniecit, non intellegens incorporeum a se non 'resum iri [al.

- Ces mots manquent dans l'un des manuscrits. 


\section{Vita Ephraem}

Tum Ephraem ille mirandus, de quo supra diximus, a donno Iacobo petiit ut sibi murum ascendere liceret ad conspiciendos barbaros atque maledictorum iacula in cos conicienda. Quio audito vir clarissimus, cum gratiae quae huic inerat confideret, propter miraculum antehac ab illo patratum'. permisit illi at ascenderet. Ascendit igitur in unan ex muri turribus. et ut illorum plurimam multitudinem conspexit. arrectis ad Deum oculis, eum precatus est ut sciniphes culicesque in illos immiteret, quandoquidem iel.per has bestiolas istos debellave posset, ita ut Dei virtutem asnoscerent. Porro, una cum beati oratione, exorta est nubes sciniphum et culicum, quibus elephanti oppleti sunt, quippe qui cutem glabram habeant et pilis careant, itemque nares et aures equorum aliorumque animantium quae (rex) secum habebat. Illa, cum divinae ultionis vim ferre non possent, disruptis frenis suis, equites eiecerunt, ordines perturbarunt et $e$ castris tumultuarie aufugerunt. Miseran. dus autem rex, Dei christianorum servatoris virtutem hac levi castigatione edoctus, inde recessit, vic-

\section{VITA IACOBI}

non intellegens miserandus se in incorporeum saevire]. Et furoris eitus aestus resedit.

Erat autem Ephraem, (vir) ille mirabilis, scriptor aptrime doctus et inter Syros celebratissimus. Qui a beato Iacobo petiit ut in murum ascendens barbaros con. spiceret et in eos maledictorum iacula coniceret. Cum igitur eum exaudivisset vir inclutus, ascendit in unam e muri turribus, et ut (illorum) pluvimam multitudinem conspexit, mulla alia exsecratione illos prosecutus Deum rogavit ut pediculos culicesque in eos immitteret, adeoque exilibus illis minutisque bestiolis, quae cos lácesserent, Dei virtutem docerentur. Porro una cum sancti oratione exorta est nubes pediculorum et culicum, quibus elephanti oppleti sunt, quippe qui cutem glabram habeant, et pilis careant; itemque nares et aures equorum alionunqus animantium. Illa. cum divinae huius uitionis vim ferre non possent, disruptis frenis suis, equites suos eiecerunt, [ordines perturbarunt $\left.{ }^{2}\right]$ et castra deseruerunt. Miserandus autem rex [Sapor $\left.{ }^{2}\right]$, Dei [fidelium seriatoris ${ }^{2}$ ] virlutem edoctus, inde recessit, e suo labore pudorem [non victo. riam '] reportans.

1 Allusion à un autre miracle d'Éphrem, que son biographe vient de rapporter.

${ }^{2}$ Manque dans l'un des manuscrits. 
Vita EpHraem

toriae loco ignominiam suo conatu assecutus. Sic igitur beati huius Ephraem oratu, civitatisalus facta est.

On peut recourir à des suppositions diverses pour expliquer la ressemblance de ces deux narrations entre elles et avec les deux textes de Théodoret. Mais à vouloir discuter toutes les combinaisons possibles en théorie, on ne ferait qu'embrouiller la question par amour de l'art. Le champ des hypothèses plausibles est notablement réduit par les observations suivantes :

Dans la Vie d'Éphrem (= E), et dans la Vie syriaque de Jacques de Nisibe $(=\mathbf{S})$, l'épisode est introduit par le même début que dans l'Historia religiosa. Puis, à partir du même point, les deux rédactions se rapprochent de l'Histoire ecclésiastique. On conviendra que cette rencontre est peu naturelle, et qu'elle ne l'est pas du tout si $\mathrm{E}$. et $\mathrm{S}$ ont opéré séparément sur le texte de Théodoret. E, pour ce qu'il connaît d'histoire générale et de chronologie, n'avait aucun motif d'aller couper. dans le Philotheos quelques lignes de transition et de les sub. stituer au début du récit qu'il traduisait. $S$ avait moins de raison encore de tronquer son original, juste après ces mêmes lignes, et d'y raboutir, par le même raccordement, le même texte emprunté par $\mathrm{E}$ '.

De plus, $\mathrm{E}$ et $\mathrm{S}$ s'accordent sur certaines variantes contre Théodoret. Par exemple: là où l'historien grec dit simplement que les moucherons de la nuée miraculeuse entraient dans les naseaux des chevaux et les trompt:s des éléphants, les deux Syriens, arrangeant à leur manière la zoologie, préfèrent écrire que les éléphants étaient infestés par ces bestioles $r$ is m dela am ris anarsa [S: «parce que leur peau est glabre et dépourvue de poil "2. Personne ne croira qu'ils aient, chacun pour soi, fait cette même observation renouvelée d'Ésope.

Leur source commune ne peut avoir été un texte grec, qu'ils

1 Rappelons qu'en toute hyputhèse le traducteur syrien aurait abandonné son original, puisqu'il s'écarte du Philotheos pour se rapprocher de l'Histoire ecclésiastique.

aEdjan, t. E., p. $27 \%$. 
auraient traduit séparément, par leurs moyens respectifs. Le syriaque de $\mathrm{S}$ ressemble de trop pres à celuj de $\mathrm{E}$; et cette ressemblance littérale s'étend aussi bien sur la section parallèle au Philotheos que sur la section parallèle à l'Historia ecclesiastica. Sauf le cas discutable où $S$ aurait puisé directement dans $\mathrm{E},-$ l'hypothèse inverse, $E$ copiant $S$, ne mérite pas examen, - il reste à dire que $E$ et $S$ sont tributaires d'une même rédaction syriaque. En d'autres termes, le traducteur syrien de la Vie de saint Jacques par Théodoret a pu lire ailleurs, en sa langue, l'épisode du siège de Nisibe.

Ainsi donc, antérieurement à la traduction de la vie de Jacques de Nisibe, il existait en syriaque une légende ou un document à prétentions historiques, apparenté d'une part à la Vie de saint Éphrem et d'autre part au Philotheos et à l'Histoire ecclésiastique. La question se pose maintenant de savoir quel est le rapport de ce document avec les sources de Théodoret.

Nous avons déjà sigualé plusieurs points de contact entre la Vie d'Éphrem et la Vie grecque de Jacques de Nisibe'. Quoi qu'il en soit'de ces indices, il faut bien reconnaitre que l'épisode du siège, considéré en lui-même, semble mettre la priorité du côté du syriaque. Le rôle que l'Histoire ecclésia stique prête à saint Éphrem offre toutes les apparences d'una adaptation maladroite. Ce n'était vraiment pas la peine de l'inventer pour le réduire à ces proportions insignifiantes. Le $\sigma u r-$

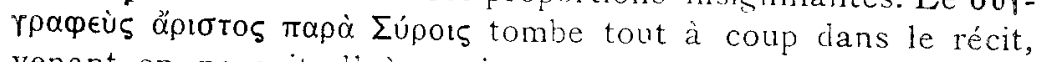
venant on ne sait d'où, uniquement pour presser saint Jacques d'appeler la malédiction divine sur l'armée des Perses. Dans le Philotheos, il n'était même pas nommé, et l'invitation adressée à l'évêque partait de'la foule anonyme. Pour que Théodoret se soit avisé d'introduire après coup dans son histoire ce personnage sans figure, il faut que lidée lui en ait été suggérée. Par qui ou par quoi? On ne peut guère songer ici qu'à une léçende épique, inventée dans un milieu où le souvenir de saint Éphrem était demeuré vivace. Il est peu croyable que l'auteur de l'anecdote primitive $y$ ait fait intervenir l' «illustre écrivain » uniquement pour lui donner ce rôle de comparse.

Si l'on se reporte à la Vie d'Éphrem, toute la mise en scène redevient naturelle. Éphrem partage avec saint Jacques

1 Ci-deśsus, p. 292-95. 
l'honneur d'avoir sauvé la ville. Il ne se borne pas à prier l'évêque de se monter sur le rempart; il lui demande la permission d'y monter lui-même, et c'est à sa prière que Dieu déchaîne sur l'armée ennemie le illéau qui la met en déroute.

Le texte syriaque de la Vie de saint Jacques est moins

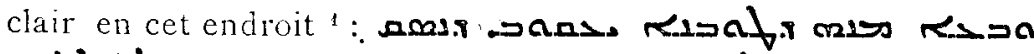

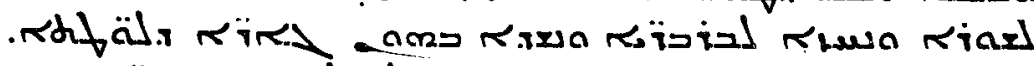

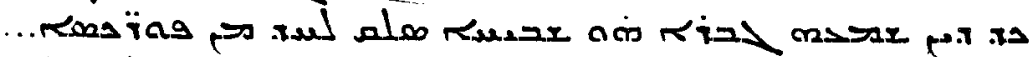

Au simple point de vue grammatical, ce tour de phrase contient une amphibologie, que notre traduction ${ }^{2}$ s'est attachée à conserver. Mais l'ambiguïté n'est que dans les mots. Le sens naturel, le seul qui vient à l'esprit du lecteur non averti, c'est qu'Éphrem a demandé et obtenu de saint Jacques la permission de monter sur la muraille.

C'est également la leçon suivie par Michel le Syrien ", abrégé à son tour dans la Chronique de Bar Hebraeus ‘. Quant au reste de l'épisode, pour tout ce qu'ils en rapportent, Miches le Syrien et son plagiaire s'accordent avec $\mathrm{E}$ et $\mathrm{S}$ contre Théodoret, sauf en un point assez caractéristique: ils connaissent les deux surnoms hellénisants de Nisibe et de son fleuve: Antiochia Mygdonia et Myodonios, que nos deux textes ne menLionnent pas.

En combinant tous ces indices, on est amené à suppośer que les événements du troisième siège de Nisibe, popularisés par la lettre de Vologèse, par les discours de Julien et sans doute encore par d'autres relations, écrites ou orales, ont servi de thème à une légende épique, dont les principales figures étaient l'évêque saint Jacques et cette autre illustration de Nisibe, le grand Éphrem ${ }^{5}$.

Cette légende. trop gravement inexacte pour qu'on y reconnaisse un reffet direct des faits et des lieux, semble avoir été dinspiration grecque. Elle fut traduite sinón composée en sy. riaque. Le rédacteur, ou plus exactement un interpolateur de

1 BEDJAN, t. c., p. 272.

2 Ci-dessus, p. 305.

¿Ed. J. B. Chabot, Chronique de Michel le Syrien (Paris, Igoo), texte, p. I34-35; trad., p. 266)

${ }^{4}$ Chronicon ecclesiasticum, ed Bedjan (Paris, r8go),p. 6r. Dans son abrégé arabe Bar Hebraeus ne mentionne plus en cet endroit que saint Éphrem (A.SALHANI,

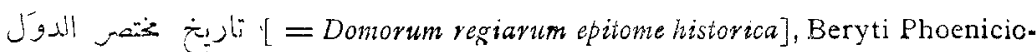
rum, I890, p. I37).

s Voir ci-dessus, p. 307. 
la Vie d'Éphrem, l'engloba dans sa rhapsodie '. Théodoret â son tour la rencontra, en grec ou en syriaque, il n'importe guère, car les deux sont possibles. Peut-être même, à une certaine hésitation dont témoignent ses retouches, serait-on plus. porté à croire qu'il utilisait une source syriaque ${ }^{2}$. Il inséra une première fois l'épisode du siège dans son Philotheos, au prix d'une adaptation'assez libre; puis, une seconde fois, avec des remaniements plus discrets, dans son Histoire ecclésiastique. De son côté, le traducteur de la Vie de saint Jacques trouva toute faite dans la légende syriaque une partie de sa version, et s'épargna la peine de la recommencer. C'est l'origine de la substitution de textes que l'on peut constater, sans conjecture cette fois, dans ce passage de la Vie syriaque.

Nous convenons sans détour que cette explication n'a pas le mérite d'une simplicité séduisante : le tout est de voir si elle s'adapte naturellement à la complexité du problème. D'autres lui reprocheront de mettre un brillant écrivain grec en posture d'imitateur sinon de plagiaire devant un obscur barbare; mais cette objection préjudicielle tombe devant le fait: Théodoret a connu la source syriaque où mous le soupçonnons d'avoir puisé.

Ce serait le moment d'examiner les parallélismes que nous avons relevés, sans en rien conclure, entre la Vie de saint Jacques de Nisibe et celle de saint Éphrem ${ }^{3}$. A la rigueur, en y mettant le temps et la place, il ne serait pas impossible de démontrer sur ces exemples que Théodoret est l'emprunteur. Mais en voici un autre qui rendra, croyons-nous, la discussion inutile.

Au chapitre $2_{4}$ du quatrième livre de l'Histoire ecclésiastique, Théodoret parle d'Ephrem en ces termes :

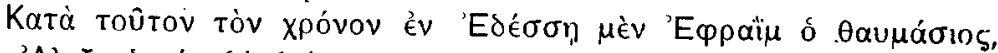

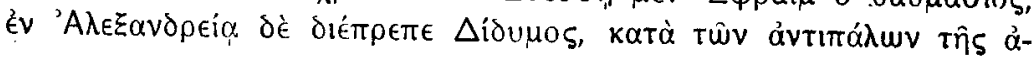

\footnotetext{
1 Des raccordements comme celui-ci : Ephraem ille mirandus, de quo supra diximus (cf. p. 305), suffisent à prouver que le passage n'appartient pas en propre à un récit dont Éphrem est le héros principal.

2 On peut de demander, par exempie, si ce n'est point par suite de l'amphibologie apparente du texte syriaque que Théodoret aura donné à saint Jacques le rôle que les documents parallètes attribuent à saint Éphrem, dans le cas rapporté ci-dessus (p. 308).

5 Cf. supr. p. 292 et suiv.

- Parmentier, t. c., p. 269.
} 


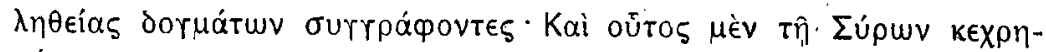

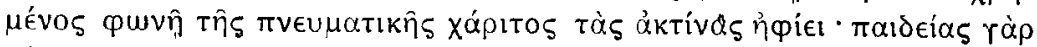

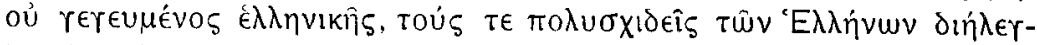

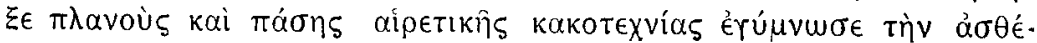

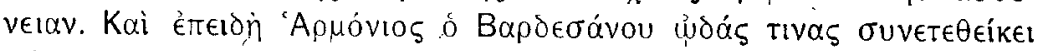

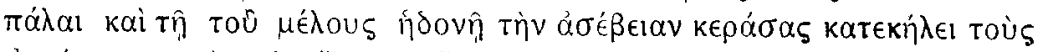

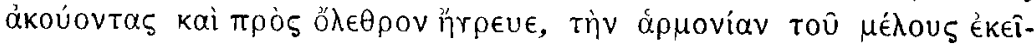

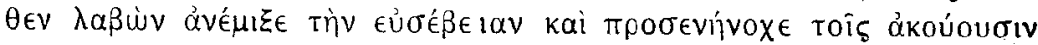

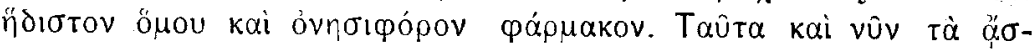

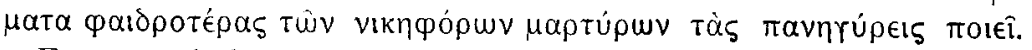

En regard de cette mention, il faut mettre le passage correspondant de la Vie d'Éphrem, c. $30^{\prime}$ :

Incidit quondam in eius manus liber ex abominanda Bardesanis doctrina, sicut dixit sanctus ipse; qui animo doluit, quod plenus esset (ille liber) daemonum ineptiis : "Voleban quidem aures meas mundas occludere, quas (ille) meatus fecerat sermonum blasphemiae plenorum. Et properavi auribus meis auscultandam dare praelectionem aliquam puram e sanctis divinisque libris. Audivi eum iustitiae eiusque compari gratiae conviciantem. Eius lectio animum pariter et corpus angebat, inter quae discidium inducebat, quo spes praecidebatur. Corpori resurrectionen et animae illius societatem ademit ${ }^{2}$.

Beatus igitur cum haereses istas comperisset earumque doctrinam impuram penitus persensisset " veritus est ne vulgus avidum blandis earum vocibus palliceretur; et alversus eas se armavit. Quippe sancti Spiritus splemdore illustratus populum " videbat titillatione

1 LAMY, t. c., p. 63-67.

2 Le discours mis dans la bouche d'Éphrem est formé des strophes 2 et 3 de l'hymne 5I des Carmina Nisibena. Dans l'édition de Bickele (t. c. p. I02), le texte est un peu différent: In Bardesanis librum incidi et aolore affectus sum quod (homo) loqtens (dx) perversa mundas aures meas polluit eas. que meatus fecit sermonis, qui blasphemiarum plenus ( $\left.\mathbf{u}_{\infty}\right)$ erut. Has igitur praelectione munda et pura ablueve properavi divinarum scripturarum. Ex illa quidem praelectione eum audivi institiaz conviciantem eiusque compari gratiae. Si enim corpus non resurgit, haec gratiae maligna contumslia est, quod illud veluti ad corruptionem creaverit, conviciumque in institian, quae illud quasi ad interitum proiecerit. Angit quidem lectio ista animam pariter ct corpus : corpori rasurrectionem adimit et unimae illius sucietatem; et dameun quod intulit serpens luçan Bardesanes appellat.

3 Le syriaque anad forme un jeu de mots avec le terme traduit par impurum (kolf, lire: $\| x_{6} ?$ ?) Voir ci-dessus, note 2, un autre jeu de mots par allitération: No. Ho.

4 Lire: : 
deceptum sermonum istorum qui perversitate pleni erant. Iam pridem enim Harmonius ', Bardesani filius, cum hymnos composuisset, in quibus patris sui perversitatem suavibus modis admiscuerat, audientes pellicere atque ad perniciem pertrahere solebat. De cuizus patre idem beatus dixerat: "Bardesanes carmina condidit et ad modos concinnavit. Psalmos composuit, Davidem imitari volens, qui centum et quinquaginta psalmos ediderat. Haud aliter et ille cantica item

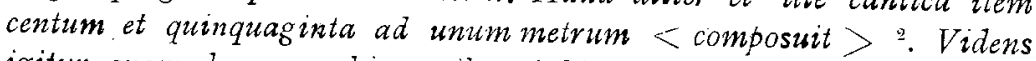
igitur quomodo error his vocibus inhiaret, vocis quidem musicesque concentum mutuatus divino timore infecit iucundumque simul concinnumque pharmacum audientibus praebuit : quae carmisa hodieque inclutorum martyrum festa laetificant. Sua igitur arte rhetorica

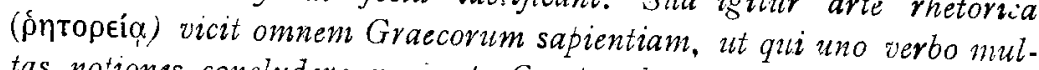
tas notiones concludere novisset. Comparabat quippe sibi armamenta. rium ad pugnandum contra illas, haereses, inquam, de quibus antea diximis. Omnibus porro virginibus sacratis, quae ad ecclesiam assidue descendere solent, scholam institutt easque carmina illa docuit': quae vespere et mane in ecclesiam convenientes ante sacra officia, et in commemorationibus martyrum, itidemque in defunctorum exsequiis cantica illa concinere solebant. Idem iis praestitit, quae extra urbern et iis quae in montibus habitabant. Iuvabat eum inter sorores stantem videre atque gratulationis voci concinentem. Scripsit porro earum causa libros multos, qui numerum excedunt, graeca etiam lingua; et fama eius per universum mundum circumvolitavit.

Nous osons dire que cette fois la question de priorité ne se pose même pas. L'hagiographe syriaque est ici sur son terrain; son style coule de source; sa pensée se meut dans un monde familier, et les citations qu'il emprunte aux poésies d'Éphrem achèvent de marquer sa narration au coin de la plus évidente originalité. Théodoret a donc connu la Vie d'Éphrem; les passages où la Vie de saint Jacques la rejoint sont des imitations ou des emprunts. L'épisode du siège de Nisibe est un de ces emprunts. A moins que l'on ne veuille absolument réserver à l'éloquent évêque de Cyr le douteux honneur d'avoir forgé cette anecdote et d'avoir, par une seconde super-

1 Texte : מasilon: Harmaqos.

2 Comparer l'hymne 53 d'Éphrem adversus haireses (LAMY, t. c., p. 65 , note I): Carmina condidit quibus modos aptavit. Cantica composilit, quere ad mumerum metrumqua concinnavit; voces distinxit et innocertibus anuritudinem suavitate temperavit. Aegroti ex (hoc) cibo non elegernt quae sana essent. Davidem invidioso studio suspexit, ut cius pulchritudine ornarctur ac similitudine decoraretur. Quinquaginta centum et ipse composuit cantica. 
cherie, modifié ensuite ses propres inventions, l'hypothèse la plus indulgente ou la plus équitable est encore d'admettre qu'il s'en est rapporté à un document dont la langue et la provenance lứ semblaient dén ter un témoin oculaire. Car il s'est vanté de n'en ávoir pas interrogé d'autres :

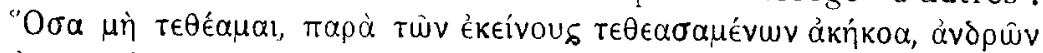

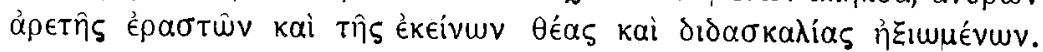

Si cette déclaration de l'auteur diu Philotheos dans sa préface n'est pas un simple mensonge en ce qui concerne la Vie de Jacques de Nisibe, elle nous invite à chercher une source orientale qu'il devait ou pouvait croire toute proche des événements.

9. Après l'épisode du siège, le récit se termine brusquement par quelques lignes incolores sur la mort de saint Jacques. Aucune date ni aucune circonstance ne sont indiquées. Quand Nisibe fut cédée à la Perse, la population, en se retirant, emporta le corps de son défenseur. On ne nous dit pas où il fut transféré.

Telle est la biographie de saint Jacques de Nisibe selon Théodotet. C'est par ce lissu incohérent de lieux communs, d'anecdotes démarquées et de fictions légendaires que s'ouvre un livre tout rempli de souvenirs personnels et d'observations prises sur le vif, l'un des plus attachants de toute l'ancienne hagiographie grecque. Il y avait dans un pareil début de quoi discréditer le reste de l'ouvrage. Ce fut le contraire qui arriva: la réputation du livre a sauvé des mains de la critique cette pièce disparate, et le centon de Théodoret, interprété, expliqué, excusé de ses pires erreurs, avec une indulgence volontairement aveugle, a créé en Occident l'illusion que saint Jacques de Nisibe a survécu dans l'histoire.

\section{$\S$ III. La légende orientale.}

Dans toutes les littératures dont l'inspiration dérive du Philotheos, l'auréole qui entoure le front de saint Jacques est d'avoir miraculeusement sauvé la ville de Nisibe. En Orient, le grand évêque est surtout le thaumaturge qui retrouva l'arche de Noé.

La plus ancienne attestation de cette légende remonte au commencement du Ve siècle. Elle est consignée dans le cha-

I P. G., t. c., p. I292. 
pitre de Fauste de Byzance, dont nous avons déjà parlé ${ }^{1}$ et que le moment est venu de citer textuellement?

Hoc tempore advent magnus Nisibenorum episcopus. admirabzis senex et in operibus veritatis impiger, qui nomen habebat Iacobum et pristino gentis nomine dicebatur Persa: qui vir a Deo electus, ex illa urbe ad Armeniae montes perrexerat, ad montem Sararad, in finibus principatus Airarat, pago Cordueno. Hic (igitur) vir gratia Christi plenus, adeo ut signorum ostentorumque prodigia manibus, eius fierent, flagrantissima cupiaitate (istuc) adductus, summis votis a Deo postulabat at salutarem arcam a Noe exstructam conspiceret; - in hunc enim montem in diluvio resederat. - Quippe omnia quae poscebat a Domino consequebatur. Itaque cum per abrupta aridaque saxa Sararat montis ascenderet, defatigatione et siti laboravit ipse et qui cum illo evant. Beatus igitur. Iacobus, fositis humi genibus, in orando Domino perseveravit; atque ex eo loco cui caput suum impresserat, scaturivit fons ex quo bibit ipse et qui cum illo erant : quem fontem Iacobi hodieque appellant. Ille vero in id incumbens ad quod conitebatur, sine cessatione Dominum precabatur ut quod optabat cerneret. Cum autem non procul a vertice (nontis) per ardua ascendere conaretur et admodum fatigatus esset, obdormivit. Ft advenit angelus Dei, qui dixit ei: "Iacobe, Iacobe! \Ille autem dixit: "Adsum, Domine. "Et dixit angelus : "Ecce preces tuas exaudivit Dominus, et quod postulas perfecit. Id quod prope caput tuum iacet, de ligno est arcae; quod inde tibi attuli, ubi est (illa); aliud enim ex ea non visurus es ${ }^{1}$, quoniam Dominus sic voluit. \laque nagno cum gaudio in pedes se erigens, plurima cum pietate Dominum adoravit. Et tabulam conspexit, quae securi videbatur ex ligno maiori decisa, exsecta et avulsa. Qua accepta, inde revertit cum gratifico munere,

1 Ci-dessus, p. 29 I.

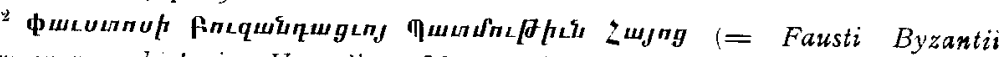
Armenorum listoria, Venetiis, 1862 ), l. I, ch. Io, p. 22-26. Fauste, qui écrivait avant la création de l'alphabet arménien a dû se servir d'une langue étrangère. Gelzer croyait pouvoir affirmer que cette langue était le grec (Die Anfünge der armenischen Kirche, dans Berilhte über die Ver. handlungen der k. sïchsischen Geselbschaft der Wissenschaften zu Leipzig, Phil. - histor. Cl., I895, p. I14-I6). Mais la question demanderait un plus mûr examen. On a quelque peine à comprendre, notamment, que le pitoyable traducteur qui a mis Fauste en arménien ait si régulièrement reconnu, sous la transcription des noms propres, des lettres sans équivalénts dans l'écriture grecque. Dans le passage qui nous occupe, plusieurs idiotismes et certains non-sens ont une couleur syriaque (cf. Revue des études arménientes, t. I, I920, p. I5, note I ; p. 2 r, note 5 ).

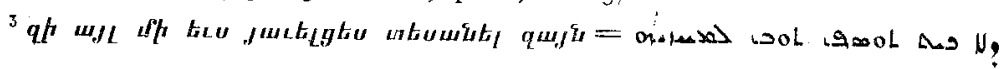


et qui cum eo venerant itineris socios, se illi adiunxerunt. Neque maiori laetitia magnus Moyses exsultavit cum e Sina monte descenderet, ne dicamus multo minori. Quippe vir ulle Deum conspicatus ulnis (gerens) mandata divinitus accepta et a Deo perscriptae monte descendsbat. Seil impius populus, qui dominicis (praeceptis) terga verterat et prostratus in faciem opus a se ipso excusum foedifragus adoraverat, legislatoris sui animum dolore ac maerore confecit. Confractae enim tabulae, euts qui has attulerat luctum indicarunt. At cum beato illo lonse aliter actum est. Quippe spiritali consolatione complebatur anino praecipiens paratam. voluntatem illorum qui (munus) Dii excepturi erant: qui (eins) itineris propositum coniectando praedicantes.", palam et occulte alius alii Omnipotentis gratiam cum universis terrigenarum gentibus communicabant.

Ut autem ${ }^{3}$ vir divinus advenit ferens opus divinum, terribile anspicium" poenae in onnia rationabilium et animalium genera edictae, mysterium " quod fuit ante saecula, specimen ${ }^{6}$ aviti laborıs. (quae erat) arca Noe; omnes ctrcumcirca pagi et civitates sine mora cum immenso gaudio et exsultatione ei obviam processerunt. Qui sancto circumfusi; perinde ac si Chrisii apostolum angelumve caelestem conspexissent, bonum pastorem suum guasi Dei oratorem intuebaniur;

1 Texte: eorum qui attuierant.

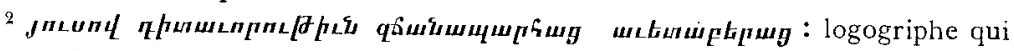
reprend un sens, lorsqu'on y remplace les mots arméniens par les mots

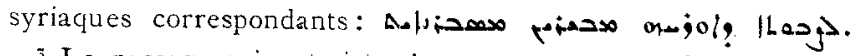

${ }^{3}$ Le passage suivant, jusqu'aux mots: non amplius pax fuit in illa terra, a été publié par L. Alishan sous le titrc: U • 3w4nuff Udpum ZuJpuntar to IJutumath [S. Iacobnes, Nisibis patriarcha, et Manadzirhus], a vec la rubri-

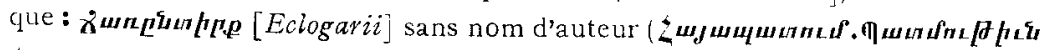
$\$ w_{\jmath} n g=$ Armenomnenon. Historia Ammeriae, t. I, Venetiis, Igor, p, 228-30). Le texte d'Alishan se distingue à peine par quelques variantes orthographiques d'avec celui de l'édition de Fauste.

4 Le texte, traduit littéralement, donnerait à péu près le galimatias que voici: divinum opus magnitudinum poenae consilii, quod in omnia cet. La traduction que nous proposons taute de mieux suppose que le traducteur arménien aura lullobs. miraculorłm, virtutum, prodigiorum, au lieu dellà.s. terriculae, formidines, cet. On trouvera une idée toute semblable, dans le passage parallèle de la Vie de Mār Augin cité en note à la' Vie arménienne, $\$ \mathbf{2 2}$.

"Proprement: signum, İzưisuul. La Vie de Mār Augin (voir loc. cit.), dans un contexte analogue, emploie le mot: 1,1, , «igne mystique $»$, mystère», etc..,qui signifie également «signe", au sens ordinarre.

"Littéralement: signum. Voir ci-dessus, note 5. 
eumque complexi, strenuorum officiosornmque pedum eius vestigia ' osculabantur, et allati sibi muneris gratiam cupido animo exceperuni. Atque ad hodiernum usque diem mysterium illud admirabile, lisnum ex arca Noe patriarchae, apud illos conspicue asservatur.

Deinde accepto nuntio e terra drmenia, admirabilis episcopus Iacobus digressus perrexit ad magnum dynasten, huius terrae principen, magnum clienten" regis Armeniae, Manadzirhum (inquam) Restunium, in cuius dicionem ire properavit'. Nempe eum audierat esse saevum et immitem, qui inutili ineptoque furore crudelis animi sui innmerabiles homines interemisset, atque ad eum docendum admonendumque venerat, ul Domini timore correptus, ad mansueios mores rewerterectur, et procul a se pessumdaret meniis feritien qua excaecatus erat. Sed ut eum vidit impius Manadzirhus, eum sprevit, (atque) virum, Dei, Iacobum episcopum, ludibrio et contemptui habuit. Et pro morum [suorum] saevitia, qua erat animo affectus, indionationem ei movere volens, octingentos homines, qui sine delicto in vinculis detinebantur, iussit ante illum adduci, atque carnifici cuidan praecepit "llilic eos una in mare proiceret, et eorum animas nulla culpa (reas) interimeret. Illum vero in rabiem actus cum irrisione iussit e terra sita expelli. Et dixit: * Vides quonodo, causa a te dicta, tibi honorem detulerim: illos a vinculis liberavi. Nunc adeo in mari natant.,

Inde ioitur digressus cilm summa maestitia, secundum praecepiionem mandati Domini sui, super istos pedum suorum pulverem excussit. Profectus autem ipse et qui cum eo erant, pervenit ad montem Fossorum ferri et plumbi, in Restunia : cuius montis vertex seorsum assurgebat, unde prospectus erat in pagos universos. Nomen huic erat Endzaqiar. Ut isitur ad huius montis radices pervenit, cum a multis iam diebus nihil omnino gustavisset, gravissinam sitem experius est. (Itaque) orando Domino se dedidit, senua posuit, caput ad terrani inflexit; et scaturivit fons, unde bibit ipse et qui cum eo erant. Quod secundum prins exemphum contigit : sicut enim egerat in Sararad monte, ita etiam egit ad radices montis Endzaqiar, in litore maris Restuniorum; et secundum prioris exemplum, hic etiam Iacobi fons appellatur ad hodiernum usque diem.

Porro ascendit hierarcha Dei Iasobus verticem montis Endzaqiar. Et huic terrae maledicens precatus est ut, loco Dominicae pacis, cui

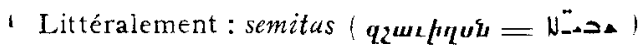

? Littéralement : servum.

"Littéralement : evasit anfugtt (17uthogu, au sens propre: efluxit; cf. toig). 
morem non gesserant, a perturbatione non vacaret (illa) usque ad extremum. Et sanctus evangelista idemque episcopus domum reditt. Verum in pago illo, postquam inde profectus est, duobus elapsis diebus, periit Manadzirhi uxor cum septem filits suis. Deinde mala morte et ipse abreptus + inter magnos cruciatus decessit e terra. Et secundum verbum quod dixerat sanctus, inde ab illo die non amplius pax fuit in illa terra.

Porro Iacobus ille summa, prodigia opcrabatur. Aaiit autem ad magnam Nicaeae synodum, quae habita est tempore Constantini Romanorum imperatoris, in qua irecenti decem et octo episcopi convenerunt propter exsecrandan havesim Arii ab Alexandria, quae est in Aegypti provincia. Iam vero considebant illic omnes episcopi coram Constantino, aderatque ex Armeniis Aristaces, filius Gregorii portentosi (viri), prini calholici Armeniae maioris. Huic porro Iacobo regis ilius admirabilis opera miraculorum signis a Spiritu sancto patefieri coepta sunt. Nempe Constantinum imperatorem sub purpura et regia chlamyde cilicio indutum vidit angelumque custodem ei ministrantem. Rei admiratione permotus Iacobus episcopus ad alios multos ex episcopis concilii de hoc angelo rettulit: qui rei fidem non adhibuerunt. Ille autem asseverans (cum iis) argumentabatur, et dixit: " Quandoquidem vos novistis res occultas, primum aperite quid sit illud quo imperator indutus est sub chlamyde sua. "Ipse vero in medio donsistens, Spiritus sancti virtute restimenti humilitatem patefecit, qua regis Constantini pietas in Deum significabatur- Et re coram omnibus explorata, demonstravit eum sub purpura cilicin interius indutum esse, propter fidem ardentissimae caritatis quam adversus Christum habebal. Deinde vidit et (ipse) rex Constantinus, angelum qui coram Iacobo ministrabat ${ }^{2}$. Et procidens ad eins pedes summis honoribus muneribusque illum affecit, eiusque solium extulit supra (solia) multorum, qui synodo hivic intererant.

Porro eius reliquiae Amidensium civitati donatae sunt a Nisibenis superstitibus ${ }^{3}$, cum isti ex ista (urbe) in illam migrarunt, saeviente bello inter regem Graecorum regemque Persarum.

Pour n'avoir pas à y revenir, nous ferons immédiatement remarquer que ces dernières lignies concordent avec une affir-

- Littéralement: perforatus, guLnutiwl.

${ }^{2}$ Littéralement : angelum Iacobi faciei ministrum (vuluuuen? tptoum : asN ,

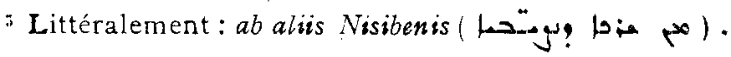


mation de Théodoret et la précisent. Le traité par lequel Jovien livra Nisibe au roi de Perse stipulait que la ville serait évacuće par ses habitants '. Au dire du pseudo-Denys de Tell-Mahré ${ }^{2}$, la population émigra vers Amid, et c'est aussi ce qui paraît ressortir de la Vie d'Ephrem *. Que les réfugiés de Nisibe aient emporté avec eux les ossements vénérés de leur premiêr évêque, il faudrait le supposer même si aucun texte ne le disait positivement. Le témoignage de Fauste est donc en parfait accord avec l'histoire. Il est doublement instructif, parce qu'il suppose une communication orale ou écrite entre son auteur et ce milieu syriaque homogène qu'ćtait alors la communauté chrétienne d'Amid.

Dans son exil posthume, saint Jacques de Nisibe ne semble pas avoir joui d'une hospitalité très attentive. M. Baumstark, qui a réuni avec une érudition consciencieuse tout ce que la tradition nous apprend des églises ou des sanctuaires chrétiens de la vieille métropole mésopotamienne. n'a pu relever aucune mention rappelant distinctement la mémoire de l'évêque de Nisibe . Amid possédait cependant une église de Sairt-jacques, qui passe, dit M. van Berchem ", pour contenir les reliques de Jacques de Saroug. Cette attribution est de la plus extrême invraisemblance. Jusqu'à preuve du contraire, il est permis de conjecturer que le nom du célèbre évêque de Batnan se sera substitué, clans le cours des siècles, à celui de Jacques de Nisibe, retombé dans l'oubli

En $975^{\circ}$, au cours de sa victorieuse expédition à travers la Phénicie et la Syrie centrale, Jean T Limiscès retrouva à Nisibe et emporta à Constantinople les reliques de saint Jacques, ainsi qu'il le raconte lui-même dans une lettre à son compa-

1 Ammien Marcellin, 1. XXV,ch. 7, 9 (ed. V. Gardthausen Leipzig, 1875, p. 50); ct. O. SeEcK; article Lovianus dans la Real-Encyclopädie de Pac. LY - Wissowa, t. XVIII (IgI6), col. 2009.

2 F. NAU, Revue de l'Orient Chréticn, t. II (1897), p. 58.

3 LAMY, 't. c., p. 24-25. Il n'y a aucun fond à faire sur l'assertion emphatique de Gennade, au dire duquel Julien l'Apostat curait fait enlever de Nisibe les restes de saint Jacques. (Voir ci-dessus, p. 287).

'Die altchristlichen Kirchen von Amida, dans M. van Berchem et' J. STrzy. Gowski, Amida (Heidelberg, t9ro), p. I63-67.

"Dans Baumstark, t. c., p. I97.

- Voir G. Schlumbergir, L'épopie byzantine à la fin au $X^{c}$ siècle. Fean Tzimiscès. Les jeunes années de Basile II le Tueur de Bulgares (Paris, 1896), p. 275 et suiv. 
triote, le curopalate As̆ot d'Arménie ${ }^{1}$. Il les retrouva ou crut les retrouver, mais rien ne nous oblige à le croire comme lui. $\mathrm{Si}$ le redoutable vainqueur. se voyant à Nisibe, se mit en tête d'exiger les ossements du thaumaturge qui avait illustré cette ville, on ne pouvait manquer de les lui découvrir aussitôt. Il faudrait une autre preuve pour démontrer qu'ils n'étaient plus à Amid ou qu'ils n'y auraient pas été transférés.

Réserve faite du renseignement qu'il nous donne sur la sépulture de saint Jacques, le chapitre de Fauste est composé de trois récits sans liaison entre eux: Io l'invertion de l'Arche $;-2^{\circ}$. le rôle de saint Jacques au concile de Nicée, et - $3^{\circ}$ sa mission au pays des Reštouniens.

1. InVEntion DE L'ARChe. Nous n'essaierons pas de rechercher les sources de cette légende, puisque Fauste lui-même en est le plus ancien témoin aujourd'hui connu. Mais, en attendant qu'un heureux hasard permette de remonter plus haut, il est possible de déterminer avec une entière certitude où cette légende a dû se former. L'identification des noms géographiques relatifs à l'histoire du déluge est un de ces thèmes à perspectives indéfinies, sır lesquels aimait à se déployer, il y a un demi-siècle, l'érudition aventureuse mise à la mode par les premières découvertes de l'assyriologie ${ }^{2}$. Nous nous garderons bien d'aborder ce domaine réservé de la haute science, sauf par l'étroite lisière où les Actes de saint Jacques le rencontrent et le prolongent. Il est établi, en dehors de toute hypothèse, que dès avant l'ère chrétienne, une tradition d'origine babylonienne, désignait comme l'endroit où l'arche avait abordé après le déluge, la chaîne du Qardu, aujourd'hui le Gabal al-Güli, dont les cimes se dressent à $4000 \mathrm{~m}$. d'altitude, sur la rive gauche du Tigre. en face de Gazirat-ibn-

- Conservée par l'historien Matthieu d'Édesse (19umL

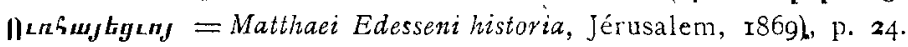

${ }^{2}$ La simple bibliugraphie du sujet s'enflerait vite au delà de toute 'mesure. On sera mis sur la voic de toutes les données essentieiles par les deux articles Ararat (A. H. SAYCE) et Flood (F. H. Woods) 'dans le Dictionary of the Bible de J. Hastings, t. I et II (Londres, Igoo); cf. l'Encyclopadia Biblica de 'T. K. Cheyne (t. I. Londres, I899), aux articles Ararai (C. P. Tiele et W. K. Kosters) et Deluge (T. K. Cheyne et J. S. BLACK). Voir aussi J. MARQUART, Osteuropäische matastatische Streifzüge, LLeipzig, I903), p. 286-92. 
'Omar, dans la Cordyène des Girecs. Josèphe, qui relate cette croyance, appelle en témoignage Bérose, Jérôme l'Égytien. Mnaséas et maint autre '. Le texte de Bérose, qu'il nous

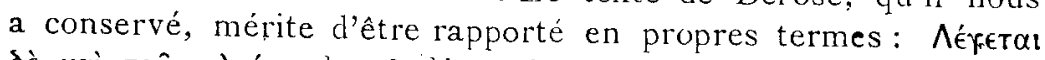

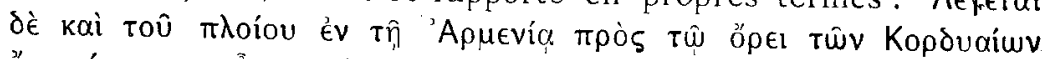

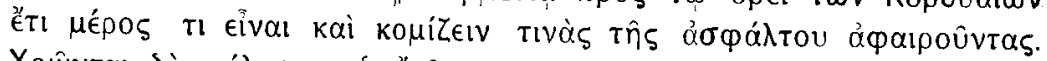

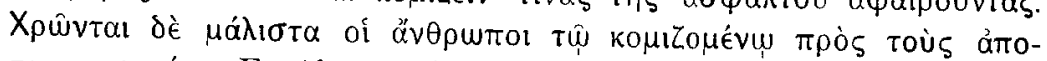

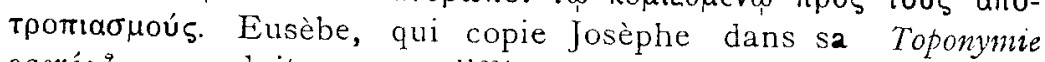
sacrée $^{2}$, reproduit un peu différemment, dans sa Chronique, la même citation de Bérose, d'après Alexandre Polyhistor ${ }^{3}$. Mais, sur le fond des choses, les deux versions sont d'accord.

C'est le mont Qardu qui est désigné, comme point d'atterrissage de l'Arche, dans le targum d'Onkelos, dans la version syriaque de la Bible, et dans les apocryphes de l'Ancien Testament, à commencer par les livres des Jubilés '. De là il a passé dans les légendes chrétiennes de la Mésopotamie. Sur l'une.des cimes du Qardu, s'élevait le couvent de l'Arche,

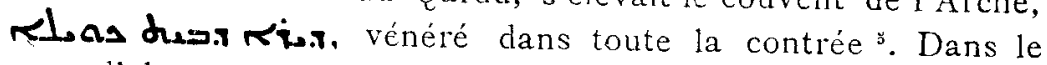
pays d'alentour, d'autres lieux saints rappelaient chacun quelque souvenir du déluge. Dä̈r Abbun ou Dä̈r Abbiun, près de Burz Mihran, gardait le tombeau de Noé "; Thamānōn, "la cité des huit âmes avait été bâtie par les huit personnes débar-

1 Antiquilates, 1, I, 92-94; ed. S. A. NABER (Leipzig, I888), p. 19-20.

2 Eusebius Onomastikon der biblischen Ortsiamen, ed. E. KLOSTERManN (= Die griechischen christipchen Schriftsteller der ersten dei fahrhundertc. Eusebius, t. III, Leipzig, I904), p. 4.

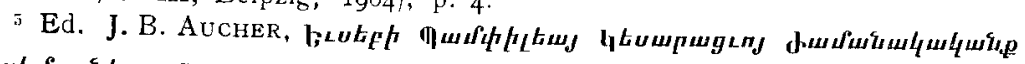
tphlfuututuy. Eusebii Pamphili Caesariensis episcopi Chronicon bipartitum, $t$. I Venetiis, $18 \mathrm{I} 8$ ), p. 36-37. Le texte grec de Polyhistor, conservé dans Georges le Syncelle, porte par. une erreur évidente Kopkupaiuv au lieu de Kopdvaiwv (Georgins Syncelltus et Nicephorus C. P. ed. G. Dindorf, Bonn, I829, p. 55).

4 C. BEzoLd, Die Schatzhoilhle, t. II (Leipzig, I888), p. 97-98; trad. ibid., t. I (I883), p. 23. C'est cet apocryphe qui paraît avoir inspiré le passage correspondant du commentaire d' Hippolyte sur le Targum. (Hippolytus der Ausleger des Targums. Fragmente zur Pentateuch, ed. H. Acicelis, dans Die griechischen christlichen Schriftsteller der erston drei fahrhunderte. Hippo. lyius, t. I, 2, I\&97, p. 90.9I\%. La paraphrase qui fait suite à ce fragment dans la chaîne arabe est de trop basse époque pour mériter l'attention.

s Assemani, Bibliotheca Orientalis, t. II, p. 113 et pass.; cf. Jăqūi, ed. WüsTENFELD, t. II (1867), p. 653 .

6 Jāoūt, ibid., p. 460 . On le montre aujourd'hui au village de Hassana, aux environs du mont Güdi (cf. J. Gorex, dans le Correspondant, ro sept. Igrg, p. 909). 
quées de l'arche*; ou Gurdakil, et a la haute montagne surnommée Barathken»,

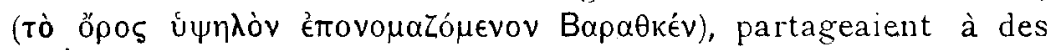
titrés différents la même célébrité, - si toutefois ces noms, malaisés à vérifier, ne font pas double emploi ${ }^{2}$. En voyant, dans un même voisinage, cette constellation de sanctuaires bibliques, tous illustrés par un souvenir ou une relique du déluge, comment se dérober à la conclusion évidente que toutes ces légendes ont germé sur place, l'une poussant l'autre, du sol même où on les trouve implantées ${ }^{3}$ ? Et quand un auteur nous raconte que l'arche fut découverte en Cordyène, par un évêque de Nisibe. cet auteur fût-il un Arménien écrivant une histoire d'Arménie, son récit porte une marque d'origine à laquelle on ne saurait se tromper: comme les autres " traditions * du même cycle, celle-ci est un produit du terroir syriaque ${ }^{4}$.

1 Egressae sunt ex arca octo animat; et pagum Thamanon aedificarunt, sic dictum ab octo animis; quae hodie sedes episcopalis est in eparchia Soba (SAlomon DE Bassorat, The Book of the Bee, ed. A. E. Wallis Budgr, Anecdota Oxoniensia. Semitic Series t. I, I; 1886, p. 33; trad. p. 32). Sobā n'est autre que Nisibe, la $\Sigma_{\imath} \beta a \pi \pi \lambda_{l} \varsigma$ des Actes de sainte Fébronie. M. Marquart, après M. Hartmann, croit que Thamānon serait le village kurde de Bc̄tmānīn, situé, dit-on, derrière le Ğabaì Ğ̉idî, à douze heures environ de Nahrawān (Hand's Amsorya, art. cit., p. ISI).

2 Cf. G. Hofpmann, Auszïge aus syrischen Acten persischer Mürtyrer, dans Abhandlingen für die Kunde des Morgenlandes, t. VII, 3 (Leipzig, I880), p. I75.

${ }^{3}$ La tradition islamite s'est greffée sur la légende judéo-chrétienne. Dans la sourate XI du Coran, verset 46 , il est dit que l'arche se posa surle Gúdi أسثوت على الخودي , Mahomet semble croire que le Ğūdi était situé en Arabie; mais les Arabes ont transporté ce nom au Qardu, qui l'a gardé jusqu'à nos jours (MARQuart, d'après NöLdeke, dans Hundes Amsorya, art. cit., p. I 8 I). Rabbi Benjamin de Tudèle, qui passa à Ğazīrat ibn-'Omar, entre les années II60 et II73. ajoute un nouveau trait à la légende du Qardu, qu'en sa qualité de Juif il identifie avec le mont Ararat: 'Omar ibn-Khațtāb (le khalife Omar I, 634-544) aurait fait démolir l'arche et $\mathrm{en}$ aurait employé le bois à construire une mosquée sur le même emplacement (Travels of Rabbi Benjamin of Tudela, trad. B. Gerrans, Londres, 1784, p. 92). Aujourd'hui encore, le mont Ğũdi est couronné par une ájj ou sanctuaire vénéré, et tous les ans, au mois d'août des milliers de pèlerins chrétiens musulmans, et yézidis y montent célébrer la fête de Noé /Gorer, Corresondant, art. cit., p. 9ogl. Chez les Yézidis actuels, le Ğüdi est une montagne sacrée. Ils y rendent à l'Arche un culte emblématique (cf. F. NaU, Revue de l'Orsent chrétien, $2^{e}$ sér., t. X, I9I7, p. 255).

4 Ceci a été parfaitement reconnu par M. F. MURAD dans une brochure écrite pour soutenir la thèse indéfendable que nous rencontrerons dans un 
La littérature syriaque a du reste conservé un récit de l'Invention de l'arche indépendant du livre de Fauste. Ce récit se lit dans la Vie de Mār Augin, dont nous aurons bientôt à reparler. Il est manifestement greffé sur une légende antérieure, que l'hagiographe a exploitie sans scrupule au profit de son héros. Malgré la criante évidence du démarquage, ce rôle taillé à Mãr Augin dans les Actes de saint Jacques s'est fait accepter des biographes de ce dernier et, dans l'épisode de la découverte de l'arche, le compilateur de notre Vie arménienne, qui a lu Fauste et qui s'en inspire ou même le copie, s'en est tenu à la narration frelatée de la Vie de Mār Augin.

Par une exception dont il est peu d'autres exemples, cette légende complètement ignorée de la tradition gréco-latine a pénétré dans le martyrologe hiéronymien. A la date des ides de juillet, les manuscrits de Berne et de Wissembourg portent la mention que voici :

Iacobi epi Niciuis, qui in corpora [W: corpore] multa signa fecit et arcã noe [W: arcanoe] solus uidit in monte. Nullus alius de his qui cum eo perrexerant uidere est pernissum." Cette notice, que Fiorentini soupçonnait déjà d'être interpolée ${ }^{2}$, a dérouté également l'auteur d'une monographie un peu ambitieuse sur les martyrologes. Après avoir émis l'hy. pothèse qu'elle pourrait remonter à l'une des sources orientales de l'hiéronymien, $H$. Achelis la declare sonst unbekannt ${ }^{3}$. C'est une de ces affirmations comme le laborieux érudit pouvait s'en permettre sans avoir conscience de parler à la légère. Il s'en serait peut-être épargné l'imprudence, s'il avait pris la peine de consulter le commentaire, bien vieilli pourtant, de Cuperus sur saint Jacques de Nisibe".

instant (Ararat und Masis. Studien zur armenischen Altertumskunde und Litteratur, Heidelberg, Igor).

1 Act. SS., Nov. t. II., p. [aI].

2 Vetustioris occidentalis ecclesiae marlyrologium D. Hieronymo tributum (Lucae, I768), p. 663.

${ }^{3}$ Die Martyrologien und ihr geschichtlicher Wert dans Abhandlungen der $\mathrm{kgl}$. Gesellschaft der Wissenschaften zu Göttingen, Phil.-hist. Klasse, N. F. t. IIl, 3 (1900), p. 157. cf. Anal. Boll., t. XIX, p. 44I-44.

4 Act. SS., Iul. t. IV, p. 29-3r. Eb. Nestle, répondant à l'assertion d'Achelis, a cité comme l'une des * sources > de la légende en question, ia Vie de Mār Augin rappelée ci.dessus (Zeitschrift für Kirchengeschichte, t. XXVI, 1905, p. 24I). 
Une fois transplantée en Arménie, la légende devait fatalement s'adapter à cette nouvelle ambiance. La montagne où saint Jacques s'en va à la découverte de l'arche, est appelée par Fauste le mont Sararad ( $/ \boldsymbol{m} \boldsymbol{m} \boldsymbol{m} \boldsymbol{m} \boldsymbol{\eta})$ ou Sararat; elle est située - sur le territoire (ou à la frontière) de la princifauté d'Aïrarat, dans la province de Cordyène $s$. A travers cet assemblage incohérent et contradictoire de noms hétéroclites, on aperçoit en raccourci toute une évolution de la légende. Le fond primitif de la source syriaque est représenté par la mention de la Cordyène. Car c'est bien du mont Qardu que Fauste veut

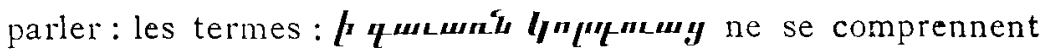
pas autrement, et, pour achever d'en fixer le sens, l'épisode qui fait suite à la découverte de l'arche se passe dans le canton de Rštuniq, de la province du Vaspurakan, limitrophe de la Cordyène.

Sararad est une leçon estropiée de la bible arménienne (Gen.

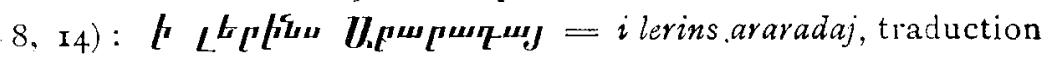

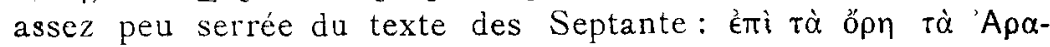
$\rho a ́ \tau$. Le -ś final du mot levins aura été joint au nom suivant. Cette explication, qui paraît difficile à écarter, suppose que l'erreur de lecture a été commise par celui qui a pris le nom Ararad dans la Bible pour l'introduire dans la légende de saint Jacques. Pour ce motif déjà, il est arbitraire de mettre la forme Surarad sur le compte des copistes ${ }^{1}$. De plus, ce vocable bizarre, que notre texte répète par trois fois, se retrouve dans un passage de la Vie de sainte Rhipsimé, où le pseudo-Moise de Khoren s'est visiblement souvenu de Fauste $^{2}$. Comme, d'autre part, il n'est pas possible que ce dernier,

1 Langlors, Historiens de l'Amménie, t. c., p. $2 \mathrm{r} 8$, col. 2, note a. - M. J. Marquart, tout en reconnaissant le fait évident que Sararad est.une corruption du toponyme biblique Araraț, n'a pas cherché à expliquer d'où est venue la méprise et dans quel texte elle s'est d'abord produite (Sïdarmenien und die Tigrisquellest nach griechischen und arabischen Geographen, dans Handes Amsorya, t. XXVIII, I9:4, p. I80). .

* Abiit (sancta Rhipsime) in mediam Corduenen ad montem Soloph [0nqnu] in anoena provincia. Ferunt autem Syri, cum aquad diluvi residerent, in huius montis vorticen, qui mons est Sararad, arcan appulisse, interiectumque serram cetum navem detinuisse: cui pago nomen datum est Themnis [ [opifupu = Thamānön!, quod octo animae ex arca egressae sint (1rnelubutr pontiumgenJ

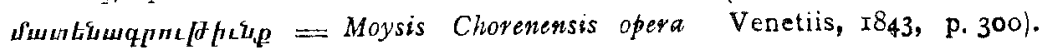
cf. H. HüBschmanN, t. c., p. 334, n. I. 
ait déjà pu lire la Bible en arménien, il est assez probable que Sararad est une trouvaille du traducteur.

Mais ce n'est pas tout. Après avoir affublé le Qardu de ce nom d'emprunt, on l'a transporté dans la provine e d'Aïrarat. Pour apprécier la portée de cette improvisation géographique, il faudrait rappeler toutes les vicissitudes de ce nom d'Airarat, en remontant, c'est le cas de le dire, jusqu'au déluge et par delà. Mais, fort heureusement, cette histoire hérissée de questions abstruses et en partie insolubles peut se ramener à quelques points à peu près certains.

Sous le nom d'Ararat, qui répond à l'assyrien urarț, le texte hébreu de l'Ancien Testament désigne proprement une région de l'Arménie septentrionale comprenant le bassin de l'Araxe jusqu'aux lacs de Van et d'Urmiah et parfois aussi, au sens figuré, tout le pays arménien dans ses mouvantes frontières ${ }^{1}$. Lorsque la Vulgate dit que l'arche s'arrêta super montes $A r$ meniae, elle reste donc assez près du sens original et littéral; et, pour le dire en passant, le mont Qardu peut fort bien être compris dans cette désignation, puisque la Cordyène fut, à certaines époques, rattachée au royaume d'Arménie. La traduction

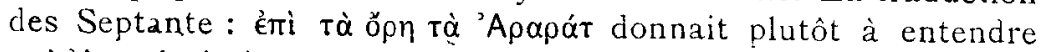
qu' 'Apapát était le nom d'une chaîne de montagnes et, par lì, elle a contribué à répandre, si elle ne l'a créée, une tradition rivale de celle du mont Qardu.

Chez tous les peuples qui lisaient l'Ancien Testament en grec, il fut admis que l'arche s'était posée sur la cime du «mout Ararat». Quant à la question de savoir où était situé le mont Ararat, les opinions ont très longtemps flotté à la débandade. Quelques exemples suffiront, car trop souvent, il faut renoncer à découvrir la réalité géographique cachée sous ce nom, qui pour beaucoup d'auteurs n'était qu'un nom. Saint Épipha-

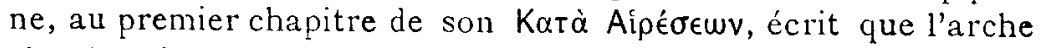

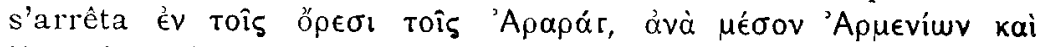

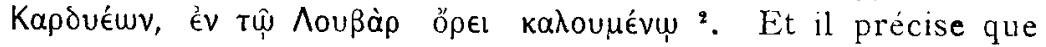
les descendants de Noé, partant ảmò toû ヘoußà ópous kaì

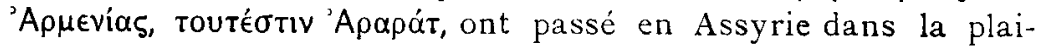
ne de Sennaar '. Il faul ajouter qu'un peu plus loin, au chapitre XVIII de ce même ouvrage, le même saint Épiphane rapporte que les reliques de l'arche se voyaient encore év Tĥ

1 Voyez Encyclopaedia Biblica, 2rt. cit.

\# Ed. L. Dindorf (Leipzig, I859), p. 283.

3 Ibid., p. 284-85. 


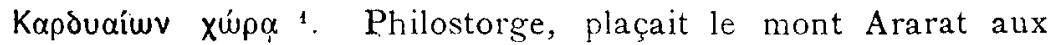
sources de l'Euphrate ${ }^{2}$. Au VII' siècle, Jean d'Antioche rappelait que Josèphe et d'autres mettaient l'Ararat biblique en Ar-

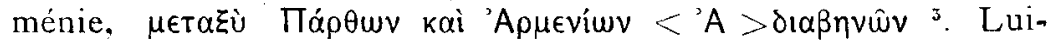

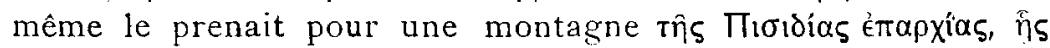

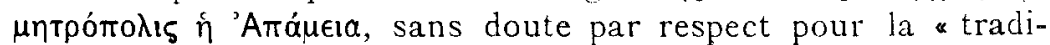

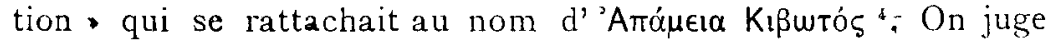
quelle consistance et quelle précision pouvaient avoir les dires d'après lesquels Philostorge avance que de son temps il restait des pièces de bois et des clous provenant de l'arche sur la montagne que les Arméniens continuent d'appeler Ararat ${ }^{*}$.

De ce témoignage si nettement fabuleux, on serait tenté de retenir pourtant une indication toponymique. C'est trop encore: cette indication est fausse comme tout le reste. Jusqu'à l'époque moderne, il n'y a jamais eu en Arménie de montagne appelée Ararat par les Arméniens. Même aujourd'hui, ce nom n'a cours chez eux qu'à titre de forme savante et exotique le vulgaire ne l'emploie ni ne le comprend. C'est à tort que, pour lui trouver une origine archaïque, des érudits ont prétendu "le rattacher au nom de Sararad, autre forme livresque, deux fois étrangère à l'usage indigène : et parce que celui-ci ne l'a jamais adoptée, et parce que le lettré qui l'a forgée sans le savoir l'avait prise pour un vocable synonyme du mont Qardu.

Sur leur montagne qu'ils n'appelaient pas Ararat, les anciens Arméniens ne vénéraient pas non plus les reliques de l'arche, car ils ne croyaient pas les posséder. Le premier d'entre eux qui les mentionne raconte qu'elles furent découvertes en Cordyène par un évêque syrien; et, plusieurs siècles plus tard, un autre Arménien, le pseudo-Moïse de Khoren, répète le dire de Fauste sans avoir conscience de démentir une tradition nationale. Lazare de Pharpi, au Ve siècle, ne se doutait pas non

I Ibid., p. 324.

2 Philostorgius Kirchengeschichte, ed. J. BıDEz, dans Die griechischen christlichen Schriftsteller der ersten drei Fahrinuderte (Leipzig, Igr3), p. 37.

¿Ed. C. Mülcer, Fragmenta historicorum graecorum; t. IV (Paris, I85I), p. 54 r.

- Cf. Hirschfeld, i.v. Apameia 6, dans Pauly-Wissowa, Realencyclopädie, t. I, 2, col, $2664-65$.

"Brdez, l. c.

"Voir notamment la dissertation de M. Murad, citée plus haut (p. 320, note 4 . 
plus qu'il l'infirmait par son silence dans sa description lyrique de la province d'Aïrarat ${ }^{1}$.

Dans la dernière rédaction d'Agathange, au VIIIe siècle, les titres bibliques du Massis ne sont pas seulement ignorés, ils sont méconnus et, peu s'en faut, niés par une autre légende. Le roi Tiridate gravit la montagne, qui n'était pàs encore inaccessible. Il en atteint le sommet, après une ascension de sept jours, sans àvoir été arrêté par aucune puissance surnaturelle, et redescend chargé de huit blocs de pierre, qu'il encastre dans les murs de la chapelle des saintes Rhipsimiennes². A qui fera-t-on croire qu'il n'aurait pas rapporté plutôt, avant saint Jacques, un morceau de l'arche, si Agathange * avait su qu'elle s'y trouvait?

On le voit : la tradition qui, dès cette époque, tendait à se former hors de l'Arménie ${ }^{3}$, était encore inconnue des Arméniens. L'ancienne littérature épique, reflétéc par les vieux historiens du pays, ne s'occupe de Noé que pour rattacher à la famille du patriarche la dynastie de Haik: elle ignore complè. tement qu'il ait débarqué sur les montagnes du Haïastan.

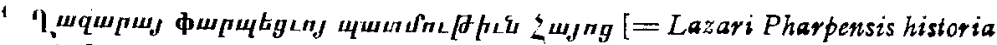

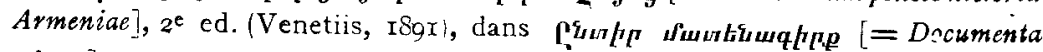
selecta], t. VII, p. 24-34. Lazare nomme au désigne deux fois le mont Massis (p. 426-27), sans faire la moindre allusion aux grands souvenirs que ce nom aurait rappelés.

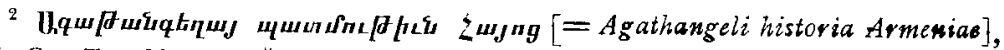

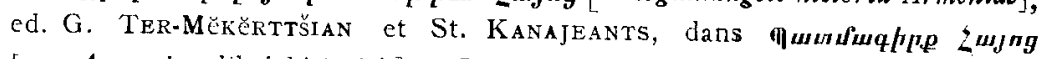
[= Armeniae libri historici], t. I, 2 (Titlis. Igog), 567, p. 398 .

- Pour établir que la c tradition arménienne s était déjà connue des Babyloniens, on a tiré argument du texte d'Abydenos rapporté par Eusèbe (Praeparatio evangelica, I. IX, c. I2), et par Cyrille d'Alexandrie (Contra

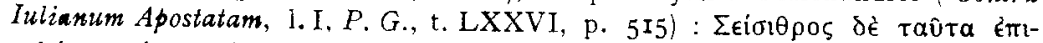

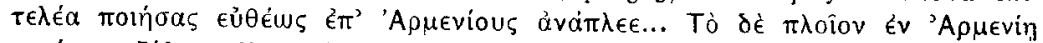

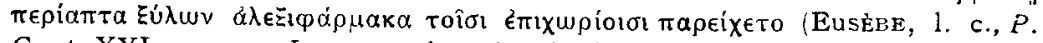
G., t. XXI, p. 700. Le texte de saint Cyrille présente quelques variantes rédactionnelles). L'argument est sans force, puisque le mont Qardu était

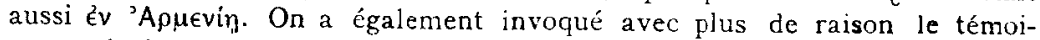
gnage de Nicolas de Damas, enregistré par Josèphe (Antiq. I, 6,94; NaBER, t. c., p. 2o), et par Eusèbe (Onomasticon; KLosTekmanN, t. c., p. 4) : "Eoriv

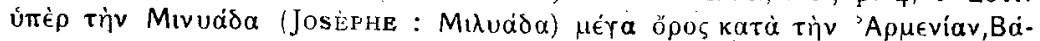

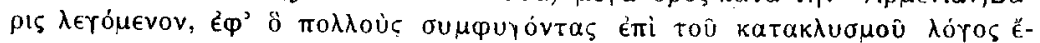

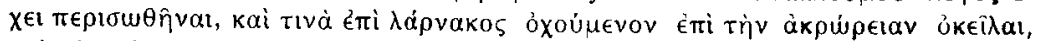

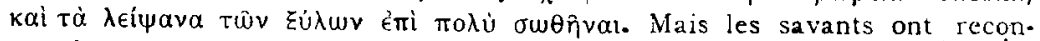
nu dans Mivuás le nom assyrien de Manzu, la contrée située au S.-S.-E. du lac d'Urmiah, et dans Báplৎ un élément du nom iranien de l'Elbuiz. (Voir Encyclopaedia Biblica, t. c., art. Ararat, col. 289). 


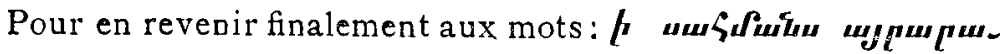
mbmi m5 mmL/Atwm, in finibus dicionis Airarat, ils ne se lisaient assurément pas dans la légende' syriaque primitive. Ils ont dû être ajoutés dans la recension arménienne; mais quand et par qui ? Fauste n'ê̂t jamais commis pareil non-sens; et le traducteur ou le copiste qui a forgé le mot Sararad est tombé dans cette erreur tout justement pour n'avoir pas songé au nom arménien de la province d'Aïrarat. On observera enfin que la mention : $\boldsymbol{f}$ ми

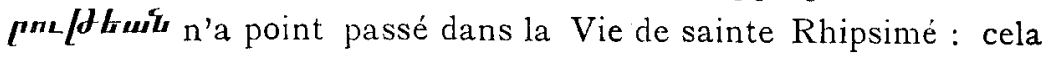
permet de supposer qu'à cette date, elle n'avait point encore été introduite dans le texte de Fauste. Mais il est possible aussi que le pseudo-Moïse en ait remarqué la trop évidente absurdité.

D'autre part, elle n'a pas été insérée pour mettre la légende de saint Jacques en concordance avec la tradition arménienne, puisque, nous venons dele voir, cette tradition n'existait pas encore. Toute autre explication faisant défaut, il reste à considérer ces trois mots comme une glose empruntée au document par excellence, que chacun d'evait se rappeler à propos de Noé et du déluge. Un copiste ou un reviseur arménien, qui avait lu, correctement cette fois, le verset de la Genèse $(8,4)$, se sera avisé que l'Ararat du texte biblique correspond au nom de la province d'Aïrarat, et, pour l'honneur de son pays, il aura intercalé son observation dans le texte de Fauste, sans égard au contraste deux fois choquant qu'elle y fait avec le nom de Sararad et celui de la Cordyène.

Cette interpolation était destinée à une singulière fortune. Elle devançait et peut-être inaugurait une tradition nouvelle, qui devait finir par éclipser, non seulement en Arménie mais dans tout l'Occident, la renommée du Qardu. C'est dans la province d'Aïrarat qu'est situé l'un des points culminants de l'Asie antérieure, la haute montagne que les Arméniens et, avant eux, les aborigènes appelaient depuis toujours le Massis. Le Massis n'est pas nommé dans le texte actuel de Fauste; preuve encore, et preuve décisive, qu'à la date correspondante il n'était pas encore regardé comme la montagne du déluge biblique. Mais à partir du jour où il fut admis que l'arche était venue s'échouer dans la province d'Airarat, il ne pouvait plus échapper à cet honneur. Son altitude, la majesté grandi- 
ose de son aspect, le voisinage du sanctuaire vénéré d'Edšmiadsin, tout le prédestinait à devenir le second berceau du genre humain et le centre du monde. Et voilà sans doute pourquoi, dans la géographie universelle, le Massis s'appelle aujourd'hui le mont Ararat.

L'ancieane tradition ne se laissa pourtant pas déposséder sans résistance. En Arménie même, au $\mathrm{X}^{\mathrm{c}}$ siècle, l'historien Thomas Ardsruni écrit encore que l'arche s'arrêta s sur les montagnes des Kardouq ". Mais, lentement et persévéramment, l'exégèse populaire fit son ouvre. Les vallées basses, les contreforts et les abords du Massis, à défaıt de son inaccessible sommet, devinrent en l'espace de quelques générations, le siège de souvenirs multiséculaires, dont l'origine se perdait ailleurs que dans la nuit des temps. Oñ découvrit à Arnoítn l'endroit où Noé avait séjourné au sortir de l'arche "; au village d'Akori, aujourd'hui Agori, celui où il avait planté la vigne " ${ }^{3}$. La ville de Thamănon elle-méme fut transportée quelque part dans la plaine de l'Araxe, aux environs du Massis “. Nakhičevan" crut

1 Histoire des Ardzrouni, trad. M. Brosset, dans Collection d'historiens aymériens, t. I (Saint-Pétersbourg, I874): p. I4.

2 J. Saint-Martir, Mémoires historiques ei géographiques sur l'Armérie, t. I (Paris, I8I8), p. 266.

- De là serait venu le nom du village (uqnnp pour umín nunp : vineam sevii), d'après une étymologie rapportée par le Synaxaire Arménien (L. ALISHAN, I.,/rupums $=$ Airarat, Venise, I89o, p. 47I-72).

" Voir ci-après le texte de Guillaume de Ruysbroeck.

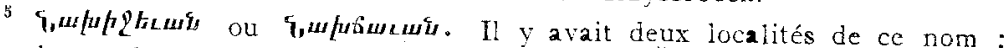
une bourgade à peine connue, dans le canton de Sirab, et la ville du Vas. purakan (plus tard de la Siunie), dont il est question ici. Nalibičevan est la Nazouáva de Ptolémée. On a cru reconnaître dans ce nom le mot h gurut, station", “auberge», etc., qui a paru concorder avec le texte célèbre de

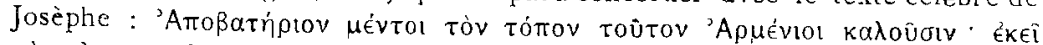

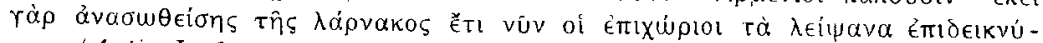
ovor (Antiq. I, 6, 92; NAlis. t. C., p. 2) ). Hübschmann a pris la peine de réfuter cette étymologie, dont le seul titre sérieux était d'avoir été adimise par Saint-Martin (Mémoires sur l'Arménie, t. I. p. 267-68; cf. HüisscrIAan, Altarmenische Ortsnamin, p. 45j). Nous nous bornerons à faire observer que la * tradition » de Nakhicevan ruine celle du Massis $\vdots$ à moins que l'on ne compte pour rien une distance de quelque $100 \mathrm{~km}$. en ligne droite. Au siècle dernier, Ics habitants de Nalhíevan montraient encore le tombeau de Noé, non loin de l'Araxe, sur la irontière persane. Le lieutenant Julius Kästner en a lait, en $1 \delta_{5}$, un dessin d'après nature, qui forme la fl. xvili d'un album appartenant au Musée Asiatique de Moscou (M. Brosset, Les ruines d'Ani, capitale de l'Arménie sous les rois Bagratides, aux Xe et XIe s., Ie partie, Saint-Pétersbourg, I860, p. 9). 
posséder le tombeau de Noé et Marand, dans l'Adherbaïdžan, celui de sa femme ${ }^{1}$. Toutes ces créations artificielles de l'archéologie locale sont de trop fraîche date pour offrir aucun intérêt ", mais nous devons mentionner celles qui touchent de plus près à la légende de saint Jacques.

Un épisode original, inséré dans l'une des deux versions arméniennes de la Vie des Pères du désert, parle d'un ermite

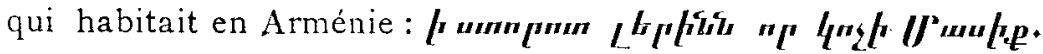

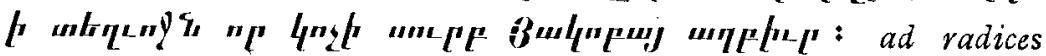
montis qui dicitur Massiq(Massis), loco cui nomen est Fons sancti Iacobi ${ }^{3}$. Cette fontaine, est il besoin de l'ajouter? était celle que les larmes de saint Jacques avaient fait jaillir. Dans la suite, elle

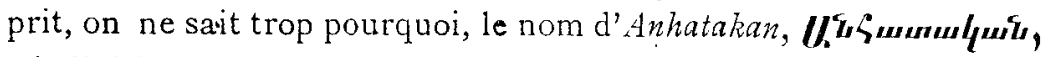
«indivisible $»$ ou a inépuisable . Elle était surmontée d'une chapelle et jouissait d'une vénération qui s'étendait au loin. Son eau passait pour avoir la propriété miraculeuse de multiplier les oiseaux destructeurs de la sauterelle ".

Un peu en contrebas de la fontaine s'élevait le monastère

1 Voir la Géographie de Vardan, ed. SaInT-Martin (Mómoires sur l'Arménie, t. II, Paris, I8I9), p. 422, et les considérations de Saint-Martin lu: même, ibid., t. I, p. 266-68 ; cf. Hübschmann, Ortsnamen, p. 45r. Vers la fin du XVIIe siècle, Chardin se laissa conter ou crut entendre que Noé lui.même était enterré à " Marant * (Voyage de Paris à Ispahan, t. IV, dans Nouvelie bibliothèque des voyages, t, XXXIII, Paris, I83o, p. I25).

2 Au rapport d'Élisée Reclus, les carrières de sel gemme de Koulpi

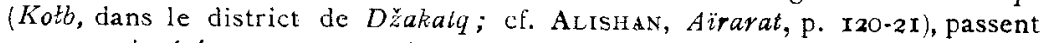
pour avoir été ouvertes par Noé en personne, et «les Arméniens montrent même l'endroit où lc patriarche commença son travail de mineur * Géographie universelle, t. VI, L'Asie russe, Paris, I88ז, p. 247). Ici, la tradition localc ne paraît pas avoir d'attestation ancienne.

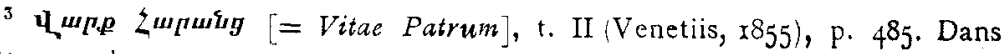
cette anecdote se trouve mentionné le couvent de Maqenotz en Siunie. Le monastère de Maqenotz aurait été fondé au VIIl siècle. Alishan en conclut avec raison que l'historiette du solitaire de Saint-Jacques n'est pas très ancienne (t. c., p. 470). La limite chronologique ainsi marquée est encore antéricure, de plusieurs siècles probablement, à la date réelie. Nous noterons cependant que l'historien Étienne de Siunie parle d'un monastère de Maqenotz qui fut incendié par le Perse Boban, prince de Siunie, lors de la conquête de l'Arménie par les Arabes, sous Marwan, en 727 (1)

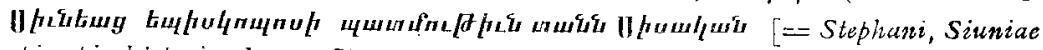
episcopi, historia domus Sisacanue, ed. I. B. EmIN, Mosquae, I86I, p. II6).

'Alishan t. c., p. 470. En 5473 , elle est, pour cette raison, mentionnée dans les Annales Vénitiennes sous le nom diatre de Lagusta. 
de Saint-Jacques. Lorsque Parrot, l'explorateur de l'Ararat, y séjourna en $\mathbf{1} 829$, l'archimandrite Karapet lui assura que le vocable de Saint-Jacques appartenait à une petite chapelle située à mille pieds plus haut dans la montagne, - éridemment l'édicule de la source dont il vient d'être question ". Cela n'empêchait pas le couvent de porter le même nom, comme en témoigne une inscription datée de I288, que Parrot y lut et y copia :. Plus tard, la stradition prétendit même que le monastère possédait la tombe de son fondateur et patron ${ }^{3}$. Le couvent de Saint-Jacques fut détruit avec le village d'Akori par le tremblement de terre du 2 .juillet $1840^{\circ}$.

Dans son nouveau cadre topographique le récit de la découverte de l'arche ne parait pas avoir subi d'altérations essentielles.

Le franciscain Guillaume de Ruysbroeck, ambassadeur du roi saint Louis auprès du khan de Tartarie ", s'arrêta à Nakhičevan ${ }^{6}$, en revenant de Karakorum, à la Noël de I253. Écoutons-le narrer en son latin ce qu'il y entendit raconter par des hôtes, notamment par un évêque venu d'un monastère des environs (Edšmiadsin), pour les funérailles d'un prêtre arménien :

... Prope civitatem predictam sunt montes in quibus dicunt quod requievit archa Noe; et sunt auo, unus maior alio; et fluit Araxes ad radices corum; et est ibi una villa que dicitur Cemanunn ${ }^{7}$,

1 Ch. KoHLer, Recueil des historiens des croisades. Historiens arméniens, t. II (Paris, rgo6) p. 562, note.

2 Alishan, t. c., p. 470-7I, analyse brièvement les inscriptions d'Akori traduites par Dubors de MonTPERreux, Voyage autour du Caucase. t. II (I833). Il ne s'y trouve aucune inscription datce de 1288 , et le vocable de SaintJacques ne figure pas dans le résumé. Mais l'auteur ne semble pas le mettre en question.

- Voir J. Leclerce, Voyage au mont Ararat (Paris, I892), p. II2-I4; cf. p. 90.9r.

${ }^{4}$ LeClerce, t. c., p. 9I-97. Lne vallée et, semble-t-il, un glacier du versant $N$. portent encore aujourd'bui le nom de Saint-Jacques.

"La relation intitulée Ininerarium Willelmi de Rubruk a ćté publiće par d'Avezac, avec le concours de Fr. Michel et Th. Wright, dans le Recueil de voyages et de mémoires de la Société de Géographie, t. IV ('aris, 1839 ), p. 213-396. Ce texte d'un intérét peu commun mérilerait les bunneurs d'un édition critique.

"Les mss. portent Vaxuan, Maxuan, Naxuam. L'éditeur semble avor une préférence instinctive pour les plus mauvaises leçons.

'Edit. Cenauium; var. : Comaurum, Cemanunn. Voir cl-dessus. p. 327. 
quod interpretatur octo, quam dicunt sic nominatam ab octo personis que exierunt de archa et edificaverunt illud super maiorem montem. Multi tempiaverunt ascendere et non potuerunt. Et dixit michi ille episcopus quod quidam monachus fuit valde sollicitus, et apparuit ei anorelus afferens ei lingnum de archa, dicens ei ne amplius laboraret. Illud lingnum habebant ipsi in ecclesia sua, ut michi dicebat ${ }^{1}$. Nec est mons ita altus secundum apparenciam ${ }^{2}$ quin bene possent homines ascendere. Et quidam senex dixit wichi rationem satis bonam quare nullus debeat illum ascendere. Illum montem vocant Massis, et est feminini generis secundum linguam eorum " : Super Massis, inquit, nullus debet ascen. dere, quia est mater mundi *. .

A travers ce résumé, où elle est réduite à sa plus simple expression, toute l'anecdote de Fauste de Byzance demeure reconnaissable. Il n'y manque que le nom de saint Jacques. Celui du Massis, ou de la Massis, puisque l'auteur tient à cette différence illusoire, caractérise la recension arménienne à l'état natif, avant les traductions européennes. Guillaume de Ruysbroeck connaît pourtant le nom d'Ararat; mais voici à quoi il l'applique: Venit etiam per illam planiciem Araxes, qui venit de maiori Hermenia recte de jinter meridiem et occidentem, a quo dicitur terra Ararat, que est ipsa Armenia ${ }^{3}$ : unde in libro regum dicitur de filii<s> Cenacherip. quod interfecto patre fugerunt in terram Armenorum; et in Ysaya autem dicitur quod fugerunt in terram Ararat ' . Il est remarquable que ces mots aient été écrits dans la plaine même du Massis, ou d'après des souvenirs rapportés de là, en $\mathbf{2} 253$.

Vers la même époque, ou plutôt quelques années auparavant, notrelégende avait déjà été résumée en ces termes par Vincent de Beauvais :

1 Cette relique de l'arche, un morceau de bois pétrifié, est encore gardée précieusement dans le trésor de la cathédrale d'Edšmiadsin (J. LEcLEkcQ, t. c, p. 240).

* A la distance de passé roo $\mathrm{km}$. à vol d'oiseau.

"Se rappeler que l'arménien n'a pas de genre grammatical!

- Recueil de voyages, t. c. p. $386-87$.

;Ruysbroeck aura lu saint Jérôme: Ararat autem regio in Armenia campestris est, per quam Araxes fuit, incredibilis ubertatis, ad radices Tauri montis, qui usque illuc extenditur. Ergo ct Arca... non ad montes generaliter Arneniae delatu est, quac appellutur Ararat, sed ad montes Tanti alissmos, Q'i Avarat imminent campis (In Isaiam, 1. XI, c. 37, v. 36).

iLid. p. 383 . L'un des quatre mss. employés par l'éditeur Cambridge, Corpus Christi cod. LXVI) porte deux fois Araxat. 
In Armenia est civitas nobilis quam Ani vocant, ubi sunt mili ecclesie ac centum milia familie seu domus inhabitate, quam Tartari ceperunt in duodecim diebus, et etiam ibi prope eam mons Arach. Ibi requievit archa Noe, et in pede montis illius est prima civitas quam edificavit ibi Noe, et vocatur hec civitas Laudumie. Circa illam defluit fluvius Arathosi, qui fluit per medium Mongam, ubi sunt in hyeme Tartari, usque in mare seruaxicum. Estautem mons iste, videlicet Arach, excellentissimus, neque unquam illuc ascendisse dicitur homo, nisi monachus unus. Ille siquidem quodam devotionis, ut dicitur, ardore commotus, propter archam Noeque ibi requievit, multotiens illuc ascendere, quibus potuit, conatibus attemptavit. Cumque aliquam montis partem ascenderat et membra corporis fatigata quieti dabat, semper post quietem euigilans in pede montis se inueniebat. Tandem vero Dominus eius affectui condescendens einsque uotum et orationes exaudiens, per angelum suum eum nonuit ut semel ascenderet. Ita tamen ut de cetero ascendere nullatenus attemptaret. Tunc ergo securus ascendit et postea descendens inde secum ex archa unum asserem detulit. Tunc in. montis pede monasterium edificauit in quo eumdem asserem tanquam pro sacris reliquiis deuote

Les érudits qui ont remarqué ce curieux passage se sont empressés d'y corriger Arach en Ararat ', comme s'ils trouvaient toute naturelle cette faute commise deux fois coup sur coup dans un nom transcrit de la Vulgate et reproduit par. tout ailleurs avec une remarquable fixité ${ }^{3}$. Avant de toucher à ce terme géographique, il conviendrait au moins de se demander ce que signifient ceux dont il est environné. Le fleuve Arathosi, le mare Seruanicum et la ville appelée Laudunie présentent, à première vue, une apparence, il faut le dire, assez suspecte. Mais s'ils sont de pure fantaisie, il s'ensuivrait logiquement que tout ce chapitre de Vincent de Beauvais doit être regardé comme une élucubration pédantesque d'érudit occidental, écrivant d'après une source littéraire. Or cette conclusion n'est pas seulement douteuse; elle est insoutenable. Il y a dans cet aperçu géographique des traits qui dénotent une information directe. La ville d'Ani est bien la célèbre capitale des Bagratides, et ses mille églises: sont un lieu commun de l'historiographie arménienne. Mongam doit dési-

1 Speculum historiale, 1. XXXI, ch. 97. (Nous citons l'édition de Venise,
$\hat{I}_{4} 83$ ).

2 Ainsi ont fait Fiorentini, Cuperus et d'autres à leur suite.

"Le texte de Guillaume de Ruysbroeck suffirait à le prouver. 
gner la plaine de Moughan ou de Moghan, au sud de l'Albanie, près de-l'embouchure de l'Araxe dans la Caspienne, où les chroniques du temps mentionnent en effet, à plusieurs reprises, le passage des Tatares et précisément durant l'hiver '. Voilà bien de quoi mettre en défiance. Il conviendrait d'y regarder à deux fois avant de prétendre biffer ou corriger les noms propres de ce passage, y compris celui du mont Arach.

Sauf meilleur avis, voici notre explication, puisque, de toute manière, il en faut une. Laudumie est complètement inacceptable comme transcription phonétique d'un nom arménien. Dans l'orthographe flottante de l'époque, il répond au mot lautu-

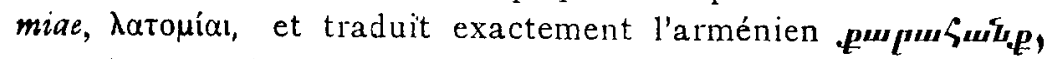
- carrièress. Ce nom désignait et, semble-t-il, désigne encore un quartier de la ville d'Érivan ${ }^{2}$ : rien ne prouve qu'il n'ait jadis été employé en concurrence avec celui d'Érivan, dont la plus ancienne attestation certaine est du IXe siècle. Érivan a gardé jusqu'au siècle dernier et, sans doute, jusqu'à nos jours la prétention d'avoir été bâti par Noé ${ }^{3}$. La ville est baignée par un affluent de l'Araxe, qu'un géographẹ du moyen âge pouvait fort bien prendre pour le cours supérieur du fleuve. Cette rivière, appelée aujourd'hui Zangi. était autrefois connue sous le nom de Hurastan, Hurazdan, Hrazdan ou Hraztan, qui, vaguement confondu avec celui de l'Araxe, peut, au prix de quelques fautes d'orthographe, avoir donné Arathosi en transcription latine: Le Hraztan prend sa source dans le $G o g$ - Ca $a \ddot{i}$, immense nappe d'eau, située à $1925 \mathrm{~m}$. d'altitude au S.-E. d'Alexandropol et que les Arméniens appelent tantôt mer de Gełam (Kegham, Kelam) tantôt mer de Sevan ou de Seranga: c'est le mare Se[r]uanicum. Ici la ressemblance des noms est complète; mais Vincent de Beauvais, répétant et broullant les dires d'un voyageur, aura oublié par quelle extrémité de son cours le Hraztan-Araxe touche au mare Sevanicum. La bévue n'est d'ailleurs pas plus grossière que serait

1 Hayton O.F. M. (Héthoum, frère du roi d'Arménie; † peu après I3r4), La flor des estoires de la terre d'Orient, I. I, ch. Io; 1. III, ch. 9 et 48 ; ed. Ch. Kohler, itistoriens des croisades, t. c. pp. I3̇o, 156, 216). Comme formes latines on trouve: Mogan, Mogam, Monga, Mugon, Mogat, Mogay.

2 Alishan, Airarat, p. 315 .

"Chardin, Voyage en Perse,. t. III (Nowv. Biblioth. des voyages, t. 32,

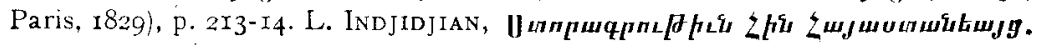
Itb $2 u j \rho[=$ Descriptio veteris Armeniae. Armenia maior], (Venetiis, 1822), p. $454-5.5$. 
celle d'avoir pris le nom du lac de Sevan pour celui de la mer Caspienne.

Sortons du domaine des hypothèses. Notre texte dit que le mont Arach est voisin d'Ani. Or, sur l'horizon de cette ville se dresse, au S.-E., le massif de l'Ala-Göz, dont le nom arménien est Arugads, H.purquod, ou plutôt Arakadis dans la prononciation du XIII siècle. Si Laudumie désigne Érivan, les mots : in pede montis illius donnent une indication concordante, car les dernières ondulations du versant oriental viennent s'arrêter au N.-O. d'Érivan. L'Arakads, dont les pics se dressent à passé $4000 \mathrm{~m}$., peut prétendre au titre.de mons excellentissimus ${ }^{1}$; et sur l'un de ses contreforts orientaux, se trouvait

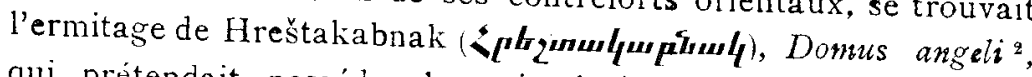
qui prétendait posséder la main droite de saint Jacques de Nisibe ${ }^{3}$.

La conclusion paraît assez naturelle. De tous les noms géographiques mentionnés dans ce chapitre, ceux qui sont clairs par eux-mêmes (Ani, Moughan, Sevanga) désignent des localités de la région de l'Arakads, et tous les autres, interprétés suivant le fil du contexte, rentrent sans effort trop violent dans le même cadre. On ne contestera pas que le nom de l'Arakads ressem. ble lui-même d'assez près à ce nom d'Arach, qui révient deux fois dans le corps du chapitre. Deux hypothèses se présentent ici : ou bien Vincent de Beauvais aura lu la légende de saint Jacques dans une version arrangée par l'un de ses confrères, les missionnaires dominicains de Géorgie, à qui le pays de l'Arakads devait être plus familier que la province d'Aïrarat. $\mathrm{Ou}$ bien il faut croire qu'en Arménie mème, quand Ani était encore dans sa splendeur, la «tradition, avait quelque temps hésité entre l'Arakads et le Massis. Les origines revendiquées par Érivan et plus encore la relique de Hrestakabnak prétent au soupçon que, là aussi, le patriotisme régional avait convoité l'honneur de posséder la montagne du déluge.

1 Malgré sa grande hauteur, l'Arakads (comme du reste le Qardu), n'est pont une montagne à décourager les grimpeurs. Mais la légende n'y regarde pas de si près. Aux yeux des Arméniens, le Massis a continué d'être inaccessible rnême après que plusieurs expéditions en avaient atteint le sommet.

2 On se rappellera, que, dans notre légende, un ange apparaît à saint Jacques pour lui apporter une planche de l'arche et lui déconseiller de poursuivre son ascension.

- Voir la Geographie de Vardan, éd. Saint-Martin, (Mémoires sur l'Arménie, t. II, p. 4I6-18). 
De même que le récit de Ruysbroeck, celui de Vincent de Beauvais a le mérite de nous représenter la légende redevenue vivante sur les lèvres du peuple. Il porte la marque de l'observation clirecte, comme les anecdotes, les traits de mœurs, les détails biographiques ou historiques qui donnent au Speculum historiale la valeur d'une source originale pour l'histoire et l'ethnographie de la Géorgie au XIIIe siècle.

Depuis lors la tradition n'a plus varié. Le bienheureux Odo. ric de Pordenone, traversant l'Arménie pour se rendre en Asie centrale, en $133^{\circ}$, passa, entre Erzeroum et Tauris, par une montagne dont les copistes, traducteurs et éditeurs de sa relation, ont estropié le nom à qui mieux mieux ${ }^{1}$, mais non assez pour qu'on n'y reconnaisse celui de Surmari-Qala'at:

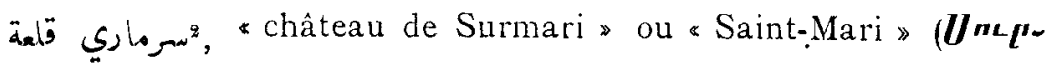

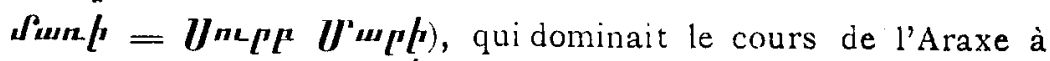
l'entrée de la plaine d'Érivan. Le bienheureux dit à ce propos :

In hoc territorio est mons in quo archa Noe requievit. Hunc libenter ascendissem, si me voluisset mea societas praesto'ari. Cum tamen illuc ire voluissem, dicebat gens illa, quod nullus umquam uscendere potuit, quia hoc dicitur Deo altissimo non placere ${ }^{3}$. Derrière ces quelques mots, on devine le reste de l'histoire qu'Odoric aura entendue de ses guides s'il lui prit fantaisie de les interroger. La montagne désignée est, de toute évidence, le Massis. On notera que le bienheureux non plus que son confrère Ruysbroeck, ne la connaît encore sous le nom d'Ararat ${ }^{4}$.

1 L'édition princeps de nos anciens (Act. SS., Ian. t. I, p. 986), porte: Sarbi Sarboio. Ailleurs on trouve: Sabisorbolo, Sobissacalo Sovisalcalo, Sollisaculo, Sarbisaculo, Buỏis Sachalo, Subissa Colloasseis... (Cf. H. Cordier, Les voyages en Asie au XIVe siècle du bienheurcux Frère Odoric de Pordenone, dans Recueil de voyages et de documents pour servir à l'histoire de la géographic, t. X, Paris, I8gI, p. 6). Toutes ces formes où l'on reconnaît le mot

sour (sourb = unıp, * saint *) et le mot qala'at, ä, " château *), gravitent autour du nom Sermessaculo, mentionné vers 1350 par Pegolotti dans son Itinéraire d'Erzeroum à Tauris (Condier, t. c., p. 15, qui identifie Sermessacalo avec Hassan:Qaleh, près d'Erzeroum).

z JāQūt, ed. WüstenfeLd, t. III, p. 82.

3 Marcellino da Civezza, Storia universale delle Missioni Francescame, t. III (Roma, 1659), p. 741-42; cf. Act. SS., t. c., p. 986-87.

4 La version française d'Odoric par Jacques Lelong, porte, il est vrai; Pres de la est le mont Harach sur lequel est l'arche Noel (CORDIER, t. c., 
Nous n'avons à mentionner ici que pour l'exclure, le pseudoJean de Maundeville, voyageur en chambre et mystificateur, qui a brodé sans vergogne, d'après Vincent de Beauvais, un récit nouveau de la découverte de l'arche'. Pour constater la suite continue de la tradition orale, sans prétendre en marquer tous les jalons certains, on peut s'en rapporter au témoi. gnage de Chardin, un explorateur authentique celui-ci. A la fin du XVII siècle, Chardin entendit raconter à Érivan la légende $\mathrm{du}$ «Macis" 2. Ce miracle qu'on lui dit "être arrivé à un moine

p. 6). Mais ce nom de Harach ne se lit dans aucun exemplaire de la rela. tion latite originale, ni dans aucune autre version connue $/ G$. Golvbovrch, Biblioteca bio-bibliografica aella Terra Santa e dell'Oriente Francescano, t. III, Quaracchi, IgIg; p. 387). Lclong, qui en a intercalé d'autres dans le texte du bienheureux Odoric, aura pris celui-ci à Vincent de Beauvais. Dans sa version italienne, Giambattista Ramusio, au milieu du XVIe siècle, supplée encore le nom de Monte Gordico (Cordier, l. c.), qui fait coup double contre la atradition, de l'Ararat.

1 The Marvellous Adventur's of Sir Foln Maundeville, ed. Arth. LAYARD (Westminster, I895), p. I80-8I. Maundeville est censé avoir écrit au XIVe siècle. Il convient égaiement de se méfier, au moins en cet endroit, du recueil de Mirabilia mis sous le nom de Jourdain de Séverac, O. P. évêque dé Colombo, au XIV siècie (éd. Copuebert-Montbret, dans Recueil de voyages et de mémoires, t. IV, p. 37-64). Ce titre de Mirabilia est un premier avertissement, que la suite ne dément pas, bien au contraire. Ce petit livre, qui ne ressemble en rien à une relation de voyage, ne dénote guère plus l'observation personnelie. Si Jourdain de Sévérac, qui a réellement passé par l'Arménie vers r330, est bien l'auteur des deux pages qui prétendent résumer les curiosités de ce pays (t. c., p. 38-39), il faudiait en conclure qu'il a été chercher ses souvenirs dans les livres - notamment dans un légendier latin - ce qui du reste est arrivé à d'autres voyageurs. Le paragraphe de Armenia commence par une description fantaisiste du mont super quem dicitur arca Noe requievisse. Pas de nom; mais à la fin du chapitre, après une énumération de choses mémorables, presque toutes empruntées à l'hagiographie latine, l'auteur revient par un détour à son point de départ: Ibi est locus quidan, in pede praejati montis magni ubi fuerunt ntartyrisati $X$ milia martyres (sic) in quorum martyrio fuerunt facta omnia signa quae in Passione Christi; eo quod omates iidem pro Christo fuerunt crucifixi; et vocatur pars illa montis Ararat; et fuit ibi civitas una, quae Semur vocabatur, magna valde, quae per Tartaros fuit destructa. Ego fui per totan terram istam fere. (Cf. Act. SS., Iun. t. IV, p. I82-87.) A noter que la légende des dix mille crucifiés de l'Ararat n'a jamals été connue en Arménie.

${ }^{2} \mathrm{Ce}$ nom est à noter. «L'Écriture-Sainte-c'est Chardin qui parle, - ne lui donne point de nom particulier > (au Massis). "Elle dit simplement que l'arche de Noé s'arrêta sur la montagne d'Ararat, qui est l'Arménie, comme l'on dit. Ce sont ces montagnes qui sont si célèbres dans les auteurs grecs et latins, qu'ils disent être partie du mont Taurus, et qu'ils appel- 
d'Echs-Miazin, nommé Jacques, qui fut depuis évêque de $\mathrm{Ni}$ zibe ${ }^{1} \gg$, correspond trait pour trait à l'anecdote du Speculum historiale: Près d'un siècle et demi plus tard, Parrot recueillait exactement la même histoire au couvent de Saint-Jacques d'Akori '.

2. Saint Jacques de Nisibe et Manadžirh.

L'épisode de saint Jacques et de Manadžirh prince des Rštuniq, nous retiendra moins longtemps. Il se passe, comme on l'a vu ${ }^{3}$, dans le nord de la province du Vaspurakan et devait se rattacher au récit d'une expédition de saint Jacques en Perse : peut-être celle dont Théodoret aussi a gardé un souvenir confus ". Ce Manadžirh n'est pas autrement connu; ce que le pseudo-Moïse ${ }^{\text {s }}$ et, au XIc siècle, l'historien Étienne Asolik de Taron ", copiant Moïse, racontent de lui est emprunté à Fauste ou doit être allégé des détails qui dépassent la narration de Fauste. D'après ces deux écrivains, Manadžirh, général du roi Chosroès II d'Arménie, commandait l'armée du Sud et des troupes ciliciennes qui furent envoyées en Assyrie pour dompter la révolte de Bakour, bdeškh ${ }^{7}$ de la province d'Arzanène ${ }^{8}$. Au cours de cette campagne, le prince des Rštuniq aurait fait, daṇs la région de Nisibe, un grand nombre de prisonniers, parmi lesquels huit diacres du clergé de saint Jacques. C'est ce qui aurait donné lieu au conflit qui se dénoua par le châtiment miraculeux de Manadžirh et de tout le pays des Rštuniens. Mais il suffit de replacer cette histoire dans son contexte pour se convaincre que toutes ces indications flottent dans le vide. Moïse ne connaît que par

lent Gordiens, Cordéens, Cordunéins, Cardiens, Curdes et Carduches, chaque auteur changeant ainsi le nom, en le voulant tourner seion l'inflexion de sa langue $\gg($ Nouv. Bibl, des voyages, t. IV, p. 22).

1 Ibid., p. 422-23.

2 Cf. Kohler, Historiens des croisades, t. c., p. $5^{62}$, note.

-Ci-dessus, p. 322 .

- Cf. supr., p. 292 et $A \S 15$.

5 Histoire d'Arménic, l. III, ch. 6-7, t. c., p. rgI-93.

6 I. B. Еmin, Весобцая петорія Степ̆аноса Таронскаго, Асох'ика по прозванію [= Historia universalis Stephani Taronensis cognomine Asokh'ik], (Mosquae, $x 86_{4}$ ); 1. II, ch. I, p. $43^{4} 44$.

7 Sur ce titre, voir Anal. Boll., t. XXXII, p. 302, note I.

8 En arménien: Atdaniq, au S.-O. du lac de Van. (Voir Hübschmann, Ortsnamen, pp. 248-5I, 305-22.) 
Fauste ${ }^{1}$ la révolte et le châtiment de Bakour et par Fauste encore le différend de saint Jacques et de Manadžirh 2. L'épisode qui nous occupe reste donc sans attestation parallele, et les circonstances ajoutées par Moïse ne rendent pas plus facile de le raccorder à aucun événement connu.

Sur la rive sud du lac de Van existe encore aujourd'hui.un village du nom d'Endzaq. Il est assis sur une hauteur appelée en turc, $A k K u l$, plus anciennement Kaput Got (ou Gabud Gogh), et qui doit être le mont Endzaqisar ou hauteur díEndzaq, mentionné dans, notre récit ${ }^{3}$. Le versant $\mathrm{S}-\mathrm{E}$. de la colline porte un monastère de Saint-Jacques. On y gardait le petit doigt du saint et un morceau de l'arche de Noé, qui furent volés par les Kurdes, vers le milieu du siècle dernier". A l'ouest du couvent, près d'une chapelle en ruines, une fontaine reçoit l'eau d'une source jaillissant du coteau. Il est inutile d'ajouter que cette source est celle où saint Jacques renouvela lè miracle du mont "Sararad»". Elle semble avoir aujourd'hui perdu son nom, après l'avoir passé au monastère que sa légende a fait surgir. Cette fondation a une histoire, qu'on lira en appendice à la Vie arménienne.

3. Saint Jacques de Nisibe au Concile de Nicée.

Il est établi par les listes des Pères de Nicée ${ }^{6}$ que sain Jacques était présent au concile. On ne sait rien de la part

1. L. III, ch. 9 .

2 Cf. supr., p. 3I5-I6.

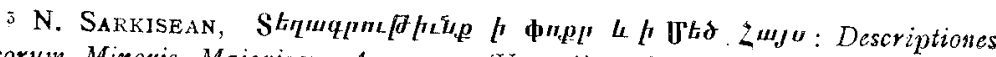
locorum Minoris Maiorisque Amemae (Venetiis, 1864), P. 25 I cf. HüBschManN, Ortshumen, pp. 429, 439. Lynch cité par Hübschuann écrit le nom du village moderne: Endzakh,

4 Sarkisean, t. c., p. $25^{\mathrm{T}-52}$.

3 Cf. supr., p. 3I5, et SARkisean, t. c.; p. 25I-52. Comme s'il devait être démontré une fois de plus que les " traditions 》 de ce genre manquent rarement de susciter des traditions rivales, celle. de Saint-Jacques d'Endzaqisar eut sa réplique non loin de là, au célèbre monastère de Narek en Rśtuniq, fondé au Xe siècle par des moines arméniens émigrés d'Asie Mineure. Là, on prétendit ou l'on crut posséder un pouce de saint Jacques de Nisibe (Indjidjian, Descriptio Veteris Armeniae, t. c., p. r72, d'après un manuscrit inédit de la Géographie de Vardan. La rédaction publiée par Saint-Martin ne dit rien de semblable, Mémoires sur l'arménie, t. II, p. 428 ).

iVoir ci-dessus, po 285. 
qu'il $\mathrm{y}$ prit, et le rôle éclatant que la légende lui prête prouve seulement que les chrétiens de Mésopotamie ont tenu à posséder en sa personne l'un des chefs de l'illustre assemblée. Il est significatif que les Arméniens aussi se soient mis en frais d'imagination pour exalter l'évêque de Nisibe ; car l'historiette rapportée par Fauste a une couleur bien arménienne et n'a aucun rapport avec celle qui court sous le nom de Théodoret. Langlois a déjà fait remarquer qu'elle se rattache à un texte

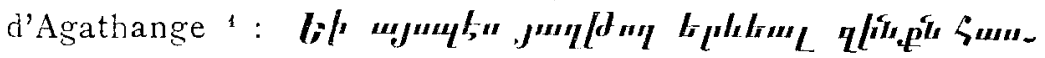

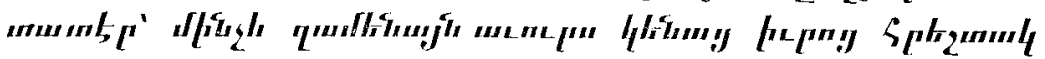
"

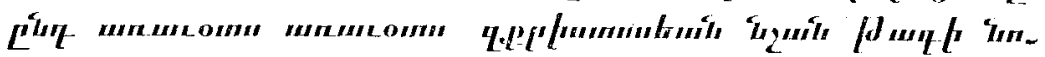

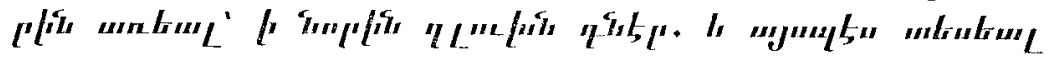

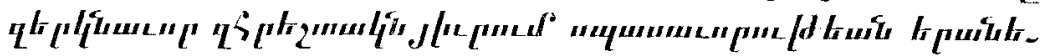

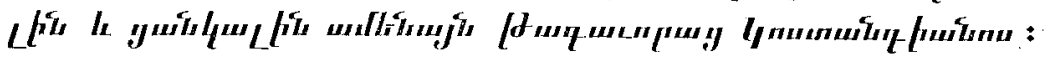
OI le q

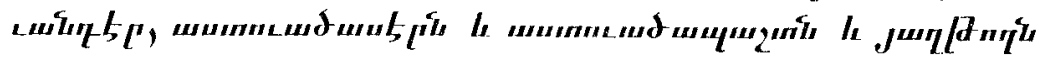

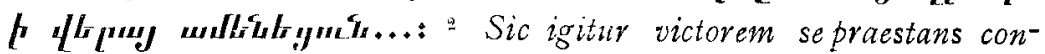
frmabatur, adeo ut singulis diebus aetatis suae angelus e caelo apparens ad eius obsequia por totum dim assistebat: qui cottidie sub auroran assumbium ilius coronae cluristianum signum in eius caput imponebat. Hunc in modum beatus et inter omnes exoptatissimus rex Constanti[a]nus caelestem angelum sibi ministraxtem cernebat; idemque reviam suam purpuram Christo commendabat (vir) Deum amans et colens atque victoria clarissimus unus...

Aucun doute n'est possible: l'ange familier, qui' remplissait auprès de Constantin les fonctions bien arméniennes de cham-

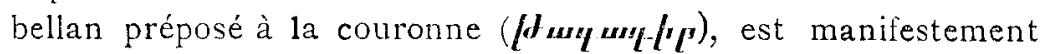
celui dont saint Jacques révéla la présence aux, pères de Nicée. Et, en regardant de pris le contexte, peut-être découvrirait-on ici, sous la pourpre royale, un bout du cilice que l'évêque de Nisibe montra à ses collègues ”. Il reste seulement à savoir si Agathange a pris son inspiration dans Fauste, ou bien

1 Historiens de l'Arménie, t. I, P. 220, col. I, note 2.

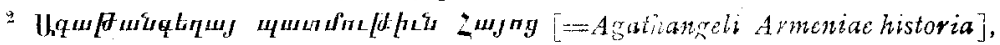

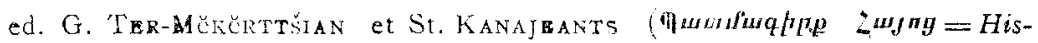
torias Armeniae, I. I, P. I, IItis, I909), § 87 I, p. 458-59.

3 CE. supr., P. 316. 
Fauste dans le précurseur d'Agathange, ou si tous deux sont tributaires de quelque témoin disparu.

\section{§IV. Le cycle de saint Jacques de Nisibe.}

Théodoret pour l'Occident, Fauste de Byzance pour l'Orient sont les deux sources de l'histoire légendaire de saint Jacques de Nisibe. On ne peut donner ce nom de source, même dans le sens le plus impropre, aux textes de basse époque dont nous avons maintenant à parler. Mais, en ces compilations informes, apparaissent pour la première fois certains épisodes dont saint Jacques est le personnage principal. Nouvellement poussés sur l'ancien fonds ou transplantés d'ailleurs, ces récits représentent une arrière-floraison de la légende; ils appartiennent à une variété distincte de la tradition, et, comme nous le verrons par la Vie arménienne, plusieurs de ces anecdotes ont servi à interpolér les textes dont elles étaient a l'origine une imitation ou un prolongement séparé. Il n'est donc pas permis de les traiter comme une quantité négligeable.

De ces éléments nouveaux l'apport le plus considérable par la masse, on ne dira point par l'intérêt, appartient à la Vie syriaque de Mār Augin. La critique de cette rhapsodie a été faite de main de maître par M. l'abbé Labourt '. Il suffira d'y ajouter, de notre point de vue spécial, quelques observations complémentaires.

Saint Jacques de Nisibe tient dans la Vie d'Augin une place importante, au point que l'on peut, par instants, se demander lequel, de l'évêque ou du moine, est le héros principal. S'il est permis d'invoquer les vraisemblances à propos d'un écrivain qui les brave toutes, il est inadmissible que le biographe ait introduit dans son récit, l'illustre thaumaturse de Nisibe, sans autre dessein que de dresser à côté d'Augin une figure plus imposante, qui l'éclipse ou du moins le diminue. La vérité est qu'il n'avait pas le champ libre. Il lui fallait tenir compte de la renommée qui était déjà en possession de la crédulité populaire. Ne pouvant attribuer à l'archimandrite du mont Izlā une place déjà prise, il l'a, par un artifice commode, associé à la gloire du premier occupant. Augin aide saint Jacques à construire l'égli-

1 J. LABOURT, Le Christiantisnie dants l'empire perse sous la dynastie sassamide (Paris, Ig04 ; dars la Bibliothèque de l'enseignement de l'histoire ecclé-
siastique), p. 302 et suiv. 
se de Nisibe; il assiste à ses miracles et les opère de moitié avec lui, ou bien il s'efface volontairement pour lui laisser le rôle qu'il ne pouvait ni s'attribuer ni partager. Invité par Jacques à l'accompagner dans son expédition à la découverte de l'arche, il s'excuse et se déclare empêché '. De la sorte, les droits acquis sont saufs, la tradition aussi, et le contrefacteur ne risque pas de soulever aucune revendication malencontreuse.

C'est encore, en partie du moins, la Vie de saint Jacques qu'il copie en copiant celle de saint Milès. Milès ou Melès est l'évêque martyr de Beth Lapaț (Suse), mentionné par le synaxaire de Constantinople au I3 novembre ${ }^{2}$. Sa personnalité historique est garantie par le martyrologe syriaque de $+12^{\circ}$ et par les Actes du synode de Dadišo en $4^{2} 4^{4}$. Une Passion syriaque, que Sozomène paraît avoir lue ${ }^{3}$ et qui fut dans la suite dénaturée par des interpolations ineptes ${ }^{6}$, le fait passer par Nisibe, au retour d'un pèlerinage à Jérusalem. Là, il trouve saint Jacques occupé à bâtir son église; il l'encourage de sa pieuse admiration, et, après l'avoir quitté, il continue de lui venir en aide par une généreuse aumône. Le biographe de Mār Augin s'est emparé de cette fiction et l'a encadrée dans ses propres inventions: contrefaçon d'un faux et plagiat au second degré.

Un autre exemple de ce même genre de racicordement postiche nous a été conservé, en syriaque encore, par la Vie de saint Eusèbe de Samosate '. Une noble dame romaine nommée Syncletica ${ }^{8}$ offre à Eusèbe les ressources nécessaires pour bâtir une église. Tandis qu'il délibère sur cette proposition, saint Jacques de Nisibe est averti par une vision d'ailer lui

1 Bedjan, Acta martyrum et sanctorum, t. III, p. 436. L'épisode du siège de Nisibe a été arrangé d'après le même procédé (p. 453 et suiv.)

- Syrax. Eucl. CP., p. 220-21 ; cf. p. 965.

3 Acta SS., Nov. t. II, p. [Lxiv].

$4 \mathrm{~J}$. B. Chaвot, Synodicon Orientale. Recueil des Actes synoduux de l'Église de Perse, dans Notices et extrats aes mamuscrits le la Bibliothèque Nationale, t. XXXVII (Paris, rgoz), p. 46, trad. p. 290 ; cf. LABOURT, t. c., p. 22-23, note 4 , et $\mathrm{p} .70-72$.

L. II, ch. I4, I-3; ed. Husser, P. $150-5$ I.

6 BHO. $772-773$.

' Brdjan, Acta martyrum et sanctormm, t. VI(Paris, 18g6), p. 355-77. Nous etudierons prochainement un curleux passage de cette Vie.

\& Voir le martyrologe de Rabban Șibä au quctobre; Anal. Boli., t. XXVII, p. $x 63$, n. 4 . 
porter secours. Il se rend à Samosate; il décide Eusèbe à se mettre à l'cuvre; il le seconde dans son entreprise, et, l'édifice achevé, il se retire pour échapper à l'honneur d'en célébrer la dédicace ${ }^{1}$.

On remarquera avec que le insistance revient ce thème de saint Jacques bâtisseur d'églises. Bien que ces attributs légendaires soient sujets à se former clans le vide, on peut se demander si celui-ci ne reposerait pas surr une réalité historique. L'église de Nisibe fut, dit-on, élevée par saint Jacques". Elle aura été l'une des premières que la province transeuphratésienne vit surgir après la paix de Constantin ${ }^{3}$. On s'expliquerait donc que sa fondation ait eu farmi les chrétiens d'Orient un retentissement durable et que, dans leurs traditions, l'évêque de Nisibe ait pris la figure épique prêtée par la tradition occidentale a saint Silvestre érigeant la basilique du Sauveur. A quelle date et par quelle voie ce souvenir idéalisé a pénétré dans la biographie de saint Eusèbe, il faut renoncer à le deviner. Il ne reste ni vestige ni trace, même littéraire, des anciens monuments chrétiens de Samosate, et nous ignorons jusqu'à l'âge possible de l'église dont la construction aura, quelques siècles plus tard, servi de prétexte à l'épisode dont il s'agit.

Grâce à tous ces écrivains peu. scrupuleux, qui lui empruntaient son illustration pour d'autres personnages, saint Jacques de Nisibe était donc devenu le héros d'un cycle hagiographique. Cycle est sans doute un grand mot; mais il caractérise assez bien ce développement continu d'une légende, qui se propage et s'amplifie par des prolongements poussés à l'intérieur d'autres légendes.

1 Bedjan, t. c., p. $350 \cdot 60$.

2Voir ci-dessus, p 29o, le texte de l'Histoire des métropolitains de Nisibe.

`Au moment où ces pages nous reviennent de l'imprimerie, nous apprenons, par un prospectus de libraire, que MM. Fr. SARRe et E. HerzFELD viennent de publier, au t. II de leur Archüologische Reise im Eupirat- und Tigrisgebiet, ch. VIII (cf. Amal. Boll., t. XXXII, p. 85-87), une étude sur les antiquités de la région de Nisibe. Un baptistère de Mār Ja'qüb daté de l'an 359 et dont un croquis de M. C. Th. Brodführer reconstitue l'aspect primitit, y est indiqué comme le plus ancien monument chrétien de la Mésopotamie. S'il a loujours été le premier en date et ne l'est pas caevenu par la disparition d'une autre église plus ancienne, on voit sans peine ce qui a dû. se passer. La légende aura pris pour une construction de saint Jacques un édifice élevé à sa mémoire, peu de temps après sa mort. 
Il serait long et fort peu intéressant d'analyser en détail ces episodes parasites. On en trouvera lesthèmes principaux dans la Vie arménienne. Ces inventions monotones appartiennent au roman d'édification : elles n'ont plus même une apparence de lien avec l'histoire, ni avec aucune tradition prétendue historique '.

Quant à la source exclusivement littéraire qui pourrait les avoir inspirées, il faudrait la chercher dans la biblłothéque de quelque monastère jacobite de Nisibe ou du Tur-Abdin. Le rédacteur qui allait $\mathrm{y}$ abreuver sa lourde imagination était un homme du pays, écrivant pour les gens du pays, en syriaque probablement, et ses élucubrations n'auraient peut-être jamais dépassé les limites de leur lieu d'origine, sans le concours fortuit d'un traducteur arménien.

\section{$\$$ V. La rédaction arménienne de la Vie de saint Jacques.}

Le document dont il doit maintenant être question a été publié dans le recueil des Mékhitharistes de Venise : $\prod_{\mathbf{a}} \boldsymbol{w} \boldsymbol{\mu} \boldsymbol{\boldsymbol { p }}$

1 Il se pourrait toutefois que, çà et là, quelque souvenir topographique se fût conservé, par exemple, dans la Vie de saint Abraham de Káškar, qui habitait c au lieu appelé Mādrā,$j_{+\infty}$, dans la grotte de saint Jacques de Nisibe léd. F. Nad, Revile de l'Orient chreatien, ze sér., t. I, IgI8-IgI9, p. 164; cf. Die Hanilschriften-Verzeiclunisse der kgl. Bibliothek zu Berlin, t. XXIII. Verzeichniss der syriscizen Handschriften von E. SACHAU I899, p. 559). Dans la basse hagiograpbie arménienne, saint Abraham le juste (Abraham Qjdunājā) cst aussi devenu un disciple de Jacques de Nisibe (cf. J. Dashian, Catalog dor armenischen Handschriften in der Mechitharisten-Bibliothek zu Wien, Vienne, 1895; part. armén. p. 65).-Enfin, il est impossible de ne pas mentionner ici la prétendue lettre écrite par saint Jacques à Mār Pāpā de Séleucie, pour protester contre l'opposition faite par une partie du clergé de Perse à son métropolitain (O. BRAUn, Der Briefwechsel des Katholikos Papa von Seleucia, dans Zeitschrift fïr katholische Theologie, t. XVIII, r894, p. I67-68). Cette pièce apocryphe n'a aucune espèce d'attache avec la Tie de saint Jacques. Lorsque le parti de Mār Păpā entreprit de réhabiliter sa, ménoire, il parut tout simple d'invoquer parmi les témoins à décharge, le grand évêque de Nisibe, ami, survant la légende, de ce même saint Melès, qui avait été le porte-parole des adversaires de Pāpā au synode de Séleucie (cf. Revue des études arménientes, t. I, I920, p. 28). C’est sans dolite par un artifice du même genre, quoique d'une intention moins transparente, qu'il faudrait expliquer l'attribution des homélies d'Aphraates à Jacques de Nisibe. La biographie, vraie ou fausse, du saint n'a rien de commun avec cette fraude littéraire. 


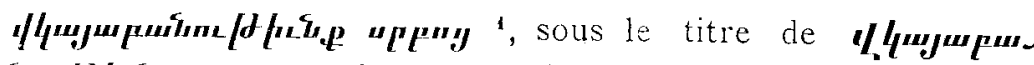

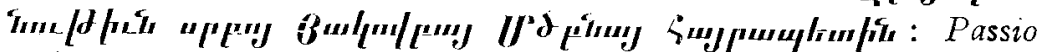
(sic) sancti Lacobi Nisibis patriarchae. Aucun avertissement n'étant joint à l'édition, nous en sommes réduit à identifier le texte par conjecture.

Une Vie de saint Jacques réponclant de point en point aux caractéristiques de la pièce en question se lit dans deux manuscrits et partiellement dans un troisième de la bibliothèque des Mékhitharistes de Saint-Lazare à. Venise?.

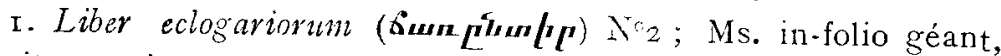
écrit en minuscule du XIe-XIIe s., par les copistes Sargis, Hajrouck, Stefanos et autres. Fut renouvelé et relié à neuf par des acquéreurs qui l'avaient en leur possession en l'année 855 de l'ère arménienne ( $1_{40} 4_{-1} 4_{0} 5$ de J. C.). Intitulé de la Vie:

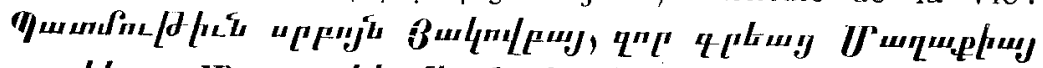

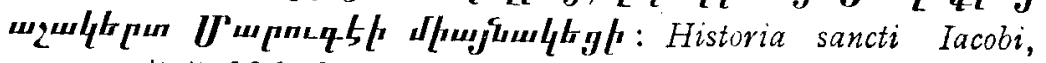
quam scripsit Malachias discipulus Marugae solitarii.

2. Liber eclogariorum $\mathrm{N}^{\circ} 5$, calligraphié en onciales au couvent de Saint-Jacques à Jérusalem, en l'an r2r5, sous le roi Léon d'Arménie. Intitulé de la Vie: T/um

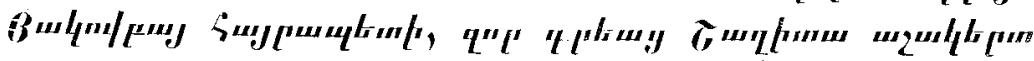

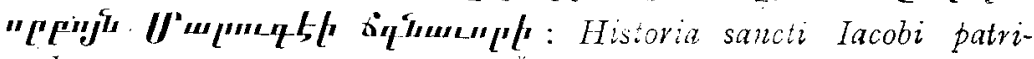
archae, quam scripsit Salitas (Śatità) discipulus sancti Marugae ascetae.

3 Liber eclogarionum $\mathrm{N}^{\circ} 6$, écrit à une date ancienne mais inconnue, en belle minuscule et en mauvaise onciale, par plusieurs copistes du désert de Maškevor. Ne contient qu'un extrait ou des extraits de la Vie, sans titre à ce qu'il semble ${ }^{3}$.

1 Vitae Passionesque sanctorlum (Venetis, 1874), p. 83-107; cf. BHO. 408.

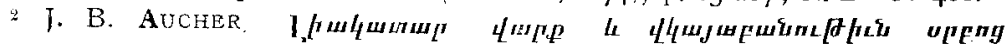
$[=$ Pleniores Vitue Passionisyle sunctonum $]$, t. X, Venetiis, $18 \mathrm{r} 4$, p. $55-57$; cf. t. XI : Supplementum; ibid, $18 I_{4}$, p. Fu_ f $F$.

" Par un second contretemps, qui est. comme le premier (cf. supr.; p. 34I, note 2 ) une des menues conséquences de la guerre, nous' venons à peine de recevoir une brochure du R. P. N. Akinian, parue en I9I4:

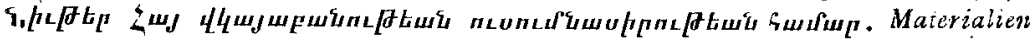
zum Studium des armenischen Martyrologiums (Vienne; extrait de la revue Handes Amsorya). Elle contient (p. $54-5^{6}$ ) un fragnent de la Vie de saint Jacques de Nisibe, retrouvé sur des feuillets de garde, remontant au XeXIIe siècles (cf. p. XI). Pour des raisons pratiques, il nous a fallu renoncer à en utiliser les variantes dans notre traduction. 
Il y a tout lieu de supposer que la Vie a été publiée d'après les deux premiers manuscrits. L'éditeur aura départagé Malachie et Sałita en biffant leurs noms à tous deux.

Salita-Malachie ne dit pas expressément qu'il a été disciple de saint Jacques et qu'il est l'un des gardiens de son tombeau; mais il emploie sa grosse ruse à le faire croire '. Son œuvre est un centon hétéroclite, dont il est impossible de débrouiller la composition autrement qu'avec le texte intégral sous les yeux. On y retrouve, enlacés dans un faux ordre chronologique, des lambeaux arrachés à Théodoret. à Fauste de Byzance et à la Vie de Mār Augin. Comment tout cela tient ensemble, le lecteur en aura céjà une première idée, s'il a pris garde au tableau comparatif des passages parallèles à la Vie grecque *. Le reste de la pièce est agencé d'après le même procédé. On pourra juger du détail par les références jointes à chaque paragraphe de notre traduction.

Un point demeure obscur: le compilateur arménien a-t-il opéré directement sur le texte grec de Théodoret ou sur la version syriaque? La question demanderait un examen assez minutieux, et l'on nous excusera d'avoir pensé qu'elle ne vaut pas un si grand effort.

Ainsi travestie et maquillée, la légende de saint Jacques n'était pas encore au terme de ses transformations. Un autre rédacteur arménien entreprit de la reviser et de la compléter ${ }^{3}$. Voici le prologue de cette recension, qu'il faudrait lire dans le style amphigourique de l'original; aucune analyse ne saurait mieux caractériser la manière et l'intention de l'hagiographe:

Lectio historixe de sancto Iacobo, cuius adumbrationem novo Sinaï daturi sumus, probterea concinnata est, quod ii qui vitam sancti Incobi notam perspectamque fecerunt, (postquam) aemulatione capii (einsdem) vicendi genus secuti sunt eiusque consortes fuerunt, aspectu Domini cum eo disnati sunt. Quidam porroprioribus dictis obstiterunt reticendo illum fuisse de genere Arsacidarm, sive sororis filim patris sancti Gregorii: quoi nos liquido demonstratum comprobatumque repperimus in libris Syrorum. Id qui infitiati fuerint, suae sententiae morcedem ab eo accipiant; nos autem vera dicemus

\footnotetext{
1 Voir la Vie armćnienne, $\$ 25$.

$\because$ Ci-dessus, p. 29 I et suiv.

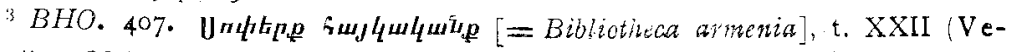
netiis, $\mathbf{8} 86 \mathrm{r})$, p. $5-63$.
} 
atque $a b$ eius iudicio immunes erimus, quandoquidem et Iudaei de Christo dixerunt eum esse fabri filium ${ }^{1}$.

Si ce langage n'est pas clair, la prétention qu'il pense cacher l'est parfaitement. L'auteur veut se donner l'air dlavoirécrit peu de temps après la mort des compagnons de saint Jacques, et pour les successeurs mémes de ces témoins disparus. Il s'adresse aux habitants du a nouveau Sinaï, nom inconnu dans la géographie religieuse de l'Arménie, mais qui désigne, sans précision compromettante, un endroit de la montagne d'où saint Jacques est descendu, portant le bois de l'arche, comme Moïse portant les tables de la Loi. Les bons lecteurs entendront sans peine cette image empruntée à Fauste de Byzance "2, et ne songeront pas à se demander pourquoi ce « nouveau Sinaï n'a pas laissé d'autres souvenirs. Comme il s'agit de leur présenter une généalogie de saint Jacques ignorée de toute l'historiographie arménienne, le faussaire prend soin de leur marquer qu'il remet en honneur la tradition primitive, retrouvée par lui dans les livres des Syriens. S'ils en doutent, ils ont toute facilité d'y aller voir.

Sur la foi de cette référencè érudite, notre homme se met donc à raconter l'enfance de saint Jacques, neveu par sa mère du père de saint Grégoire l'Illuminateur, frère de lait de son cousin, emporté avec lui par leur nourrice dans sa fuite en Cappadoce (lors du massacre de la famille d'Anak), élevé à Césarée, puis demeuré «au pays srec», quand le petit Grégoire fut ramené en Arménie. Ce conte, digne en tous points de la grossière supercherie quil'a fait accepter. n'est lui-même qu'un artifice pour transformer saint Jacques en saint national arménien. Aussi ne faut-il pas s'étonner d'en retrouver la trace dans le synaxaire de. Grégoire Dserents ".

La recension qui nous occupe en ce moment a été publiée d'après deux manuscrits, dont l'un doit être le lioer Lclocsariorum No r, de la bibliothèque de Saint-Lazare a Venise: in-folio du plus grand format, écrit en onciales, parle scribe Thaddée, au désert du Saint-Illuminateur, en $\mathrm{I} 22_{4}$ ". On en connait encore un autre exemplaire, écrit in $\mathrm{r}_{42} 8$, par le moine Kara-

1 T. c., p. 5-6.

2 Voir ci-dessus, p. 314.

5. 3ujurturmulp, 2e éd. (Constantinople, I730), p. 246-49; Antonelli, S. Iacobi Nisibeni sermones, t. C., p. xxxir-xxxıx; cf. BHO. 409. isu.

- Aucher, Pleriores Vitae sanctorum, t. X, p. 54.; cf. Supplementum, p. 
pet dans le ms. 224 de la bibliothèque des Mékhitharistes de de Vienne. A en juger d'après le sommaire qu'en a donné le P. Dashian, il a été remanié avec une extrême liberté. La légende $y$ est arrivée à ce point d'inconsistance où elle n'est plus qu'un thème à variations indéfinies ". Ces exercices littéraires n'offrent pas un intérêt proportionné à la place qu'il taudrait pour les traduire in extenso. Seulement, comme il a été dit plus haut, nous donnerons en appendice à la première Vie arménienne, le paragraphe final de la seconde Vie, où est racontée la fondation du monastère de Saint-Jacques d'Endzaqisar, parceque ce récit, tout dénaturé qu'il paraît être, est, croyons-notas, le seul témoignage restant de la tradition locale.

P. P.

\section{Passio sancti Iacobi Nisibis patriarchae'.}

1. Moyses divinus legislator qui mare Rubrum aperuit, qui traduxit populum per aridam solitudinem, aliaque miracula permagna patravit, quae singillatim perscripsit, cum priscorum sauctorum vitas narrare institueret, non tradita sibi ab Aeg- 5 gyptiis disciplina <id fecit>, sed infusa Dei gratia, quae in ipso illo tempore data fuit. Ego vero unde idoneus fiam qui de aliorum sanctorum vitis exponam : de fortitudine Abel, aut de religione Enoch ', aut de fide Abraham eiusque acceptc sacrificio? Itaque paucis et breviter vobis exponam sanctorum ro vitam <qui paulo ante nos nustrave hac aetate claruerunt ${ }^{2}>$ et gratias ${ }^{3}$ quae illis inerant ${ }^{4}$; atque eorum sanctorum nomina ${ }^{5}$ litteris mandabo; quippe forsitan me iuvabunt et ad portum me perducent.

Lemma. ${ }^{1}$ Cod. eclog. 2 : Historia sancti Iacob;, quam scripsit Malachias discepulus Martorae solitarii. Cod. eclog. 5: Historia sancii Iacobi patriar-

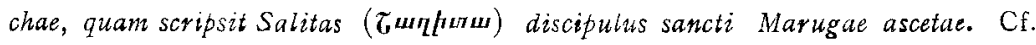
supr. p. 344 .

1. Cf. Theodoreti Historia veligiosa, P. G., t. c., p. I293, A-C. - 'A Ai. : Enos.

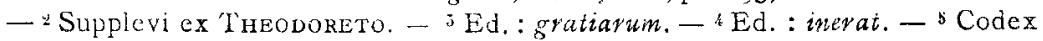
AUCHERII :... illo tempore data fuit. Ex quo enim alio (fonte) didicit fortitu.

1 Dashiax, Catalog der armewischen Handschrifteng partie arménienne, 2. 573 . 


\section{$<$ INITIUM $^{\circ}>$ SERMONIS DE SANCTO IACOBO.}

2. Nisibis urbs fuit in confinio Romanorum Persarumque sita; quondam enim haec urbs in potestate Romanorum erat. Illic beatus Iacobus vitam solitariam primum amplexus erat : 5 in vastitate solus habitabat et in vertice montiun sedem suam constituerat. Ver, aestatem autumnumque sine tecto traducebat, unumque caelum pro tabernaculo illi erat; hiberno tantum tempore habitabat in exigua quadam spelunca, cuius spatium interius vix corpus eius capiebat ${ }^{2}$. Cibis corporalibus non ro utebatur, quibus homines vesci solent, sed Spiritus sancti gratia alebatur. Montanarum arborum collecti fructus ei satis erant. Ad usum enim sui corporis ignem sibi prorsus interdixerat. Pallio indutus erat e pilis caprinis. Quippe huiusmodi castigatione corpus suum nutriebat, vario et multiplici asperiI5 tatum genere, futura semper ante oculos habens, sicuti fert Pauli oraculum: "Quasi in perspicuo speculo <gloriam Domini $>\mathbf{2}$ Cor. cernimus.» Et orationes eius semper atque perpetuo divina meditabantur, eiusque facies splendore collucens transformabatur a clarilate in claritatem. tamquam a Domini spiritu ${ }^{5} .2$ Cor. 2o.Propter admirabilem eius vivendi rationem portenta non pauca ab eo fiebant, et Deus, quidquid ille poscebat, sine mora ei concedebat. Prophetarum charismata ei data sunt, et antequam eveniebant, arcana nuntiabat. De Spiritus sancti gratia illi datum est, ut portenta ederet curationesque operaretur. 25 Itaque paucis perscribam signa quae patravit et asperum eius vivendi genus, iis qui nesciunt, aperiam.

3. Hoc tempore vita functus est Nisibis episcopus et in civi-

dinem Abcl, aut religionem Enoch, aut institiam Noe, aut sacerdotium Melcitisedech aut fidem Abraham acceptumque sacrificium eius? Proinde et ego patucis et breviter exponam sanctorum vitam, et gratias Spiritus sancti, qui in illis erat, atque corum nomina...- "Supplevi ex Aucherio. Ed.: ad fortum me per ducent sermonis de-sancio $l$.

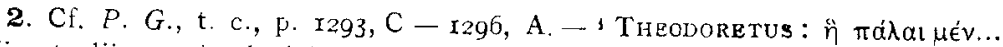
Hic et aliis passim locis armenium interpretem lapsum crederes in ambigua illa particula syriaca: ? (.. 地 vix eius corpus intus consistere poterat. - 3 Var. : tanquam a Domino et a Spiritu sareto.

3. Cf. Vit. Aug. (Bedjan, t. III, p. $392 \cdot 95$ ). 
tate suffragio scitum est ${ }^{1}$ quis sede episcopali dignus. esset. Erant autem homines quinque, quos nonnulli dignos esse dicebant; multaque contentio erat in civitate de hominibus illis, quis eorum prae ceteris ad sedem patriarchalem eveheretur: alius enim hoc nomen pronuntiabat alius illud, neque ex dis- 5 sensione ad concordiam pervenerunt. Tum viri, qui optimates erant civitatis, sanctum Marugam in eius solitudinem adire constituerunt, ut eius sententiam explorarent. Ad cuius cellae ianuam cum pervenirent, sanctus Maruge, more suo, orationi vacabat. Discipulus autem eius (ad eos) egressus dixit : a Ite ad eccle- ro siae vestibulum, donec absoluta oratione ad vos veniet. Porro tribus ante diebus sanctus Iacobus ad sanctum Marugam venerat; qui ei vaticinatus fuerat his verbis : \&Hodie te ut solitarium osculor; at brevi te ut praesulem atque gregis tui pastorem osculabor. Cui sanctus Iacobus dixit: "Parce mihi, I5 frater; non enim opere dignus sum, quod dicis. "Itaque sanctus Maruge, ad populum egressus, eos exspectantes repperit, singulis turmis seorsum in vestibulo considentibus. Qui, ut beatum conspexerunt, assurgentes illi obviam processerunt; erat enim aspectus eius sicut angeli. Ille turbae innuit ut parum. 20 per conticesceret ", dum ipse in ecclesia precatur. Postquam oravit, illi apud beatum convenerunt: qui i̧nter eos stabat innixus baculo, et turba pedes manusque eius osculabatur. (Sanctus) eos considere suaque verba diligenter auscultare iussit. Et dixit illis: "Cuius rei causa congregati huc advenistis? , Illi autem 25 dixerunt: "Propter quaestionem de episcopatu. \$ Dixit vero illis : Quem vultis in episcopali cathedra considere? Et aliis 22. 24. aliud nomen pronuntiantibus, orta est contentio inter eos. Ille eos selavit et dixit: "Scio vos praesulis vestri morte afflictos esse; ex hominibus autem quos elegistis nullus est dignus epis- $3^{\circ}$ copatu. Verum surgite, et Amidam 3 itote : illic enim coetus est episcoporum, in quo adest et Antiochiae patriarcha; ibi, per hunc + aperiet vobis Spiritus sanctus quem ad obtinendam sedem episcopalem destinavorit. . Illi, eius dicta quasi ab

1 Var.: sacerdotum suffragio sciium est. $-{ }^{2}$ Var. : consideret. $-{ }^{3} \mathrm{Ed} .:$ Amith; var.: Emth. - Var.: per hos. 
angelo Dei excipientes, surrexerunt et in urbem suam reverterunt.

4. Post aliquot dies ad episcoporum coetum se contulerunt, iisque data salute, consederunt; (qui) interrogaverunt eos dicentes : 5 *Quem poscitis praesulem? * Illi verba is rettulerunt, quae dixerat sanctus Maruge: "Spiritus sanctus vobis praesulem dabit. "Quod verbum isti considerantes, dixerunt: „Deo supplicationem hodie peragamus; qui nobis (hominem) cathedra dignum indicabit. $\gg$ Itaque media nocte universa multitudo cum ro catholico' supplicationem exorsa est cum psalmis, benedictione et canticis spiritalibus, negotium illud inter lacrimas Deo vehementi flagitatione commendans. Quoniam ${ }^{2}$ vero voluntatem timentium se facere et deprecationem eorum exaudire solet Dominus catholicus (repentino) stupore oppressus est, veluti somno quo$15 \mathrm{dam}$, et videre sibi visus est formosum quemdam iuvenem, qui di. xit : - Sanctus Iacobus est homo ille. \#t indicavit ei quo loco ille habitaret: nempe eum anachoretam esse (et) thaumaturgum ${ }^{3}$. Ut angelus sursum elatus est, catholicus expergefactus est, et consurgens Deo laudes egit, ut qui spiritalia somnia videre solitus esset. 20 Et confestim surgens in ecclesiam descendit, missoque nuntio advocavit episcopos et eos qui Nisibi advenerant; quibus visum sibi angelum rettulit, qui sancti Iacobi nomen sibi indicasset. Omnes igitur uno animo consurgentes Nisiben descenderunt. Episcoporum coetus, communi sententia, epistulam conscripsit 25 missisque viris fidelibus (sanctum) ad consilium arcesserunt. Ut autem ad illos advenit, negotium ei significarunt. At sanctus rei iam ante certior factus erat et patriarcham Nisiben advenisse noverat: - Spiritus enim sanctus id eum docuerat. Veritus est (igitur) mandato Christi resistere, eo magis quod 30 a sancto Maruga saepe audiisset : \& Futurum est ut apostolicam dignitatem obtinea's. * Itaque admonuit eum Spiritus sanctus ut ad concilium descenderet, quandoquidem illic collecta esset fre-

4. Cf. Vit. Aug., p. 395, I. I3-398. - 1 Var.: multitudo et patriarcha. - ${ }^{2}$ Ed. : Qui (Domenus)... - ${ }^{3}$ Cf. Vit. Aug., p. 376 : " homo ille quem a Domino nostro exposcis." Et indicavit ei locum ubi ilie habitatiat, cundemque esse ascetam per quem multa prodigia operaretur Dominus noster. 
quentia civium et adventum sancti praestolaretur: omnes enim noverant mores sancti ${ }^{4}$. Qui inter patriarchas ingressus eos salutavit. Catholicus eum sedere iussit. Dixit illis sanctus : "Quid causae fuit cur me istuc advocaretis? "Dixerunt illi : "A Domino significatum est te dignum esse qui sedem episco- 5 palem in hoc civitate obtineres. Ille autem iis dixit: * Non sum dignus hoc munere. " Populus vero patriarcham urgebat, neque (sancto) plura fandi copiam dedit. Patriarcha igitur extemplo consurgens, assumpto Iacobo, (cum aliis) ecclesiam ingressus est, et consecrationis episcopalis ritus super illo per- ro fecerunt. Ut autem sanctus Iacobus ordinatus fuit episcopus, ingens gaudium in civitate ortum est; et Domino Deo gratias laudesque egerunt, qui sanctum Iacobum is pastorem praesulemque constituerat.

5. Elapsis porro diebus aliquot, in die dominico', sanctus I $_{5}$ Maruge cum multis fratribus suis descendit, ut sanctum Iacobum episcopum salutaret et $a b$ eo benediceretur. Salute invicem data redditaque, sanctus Maruge Deo gratias agere coepit, quod ecclesiae suae vigilantem pastorem praefecisset. Hoc ipso die paralyticus aliquis, exarefacto corpore, prostratus 20 iacebat in ecrlesiae vestibulo, (iam ab) annis quindecim, cuius

Cf. Vit. Aus, p. $398: \ldots$ descendit cum illis ad coetum patrum episcoporum, cum interea civitas untversa congregata, una cum frequentissima multitudine, e regione suburbana exspectaret quandonam sibi pastor futurus esset domnus lacobus: omnilus enim perspecta erat viri excellentia. Quapropter...

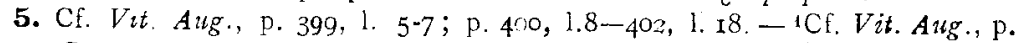
599: Rursus inter eos quaestio incidit undenam domni lacobi donus genusque ducerentur: non enim erat qui hoc novisset; atque civitatis multitudo inter gratubationes sic (ab eo) sciscitabatur: "Ex quanan prosapia oriundus est dommus < var .: lacobus> pater noster? * Ille auten id eos docere noluit. Ut adfuit dies dominicus, descendit sanctus domnus Augin, cum clarioribus e coetu fratribus, ut episcopum salutarent. Postquan igitur, die dominico sub vesperam ad episcopum universtumque coetum ingressi salutem iis dedernnt, coepit sanctus domnus Augin Deo gratias agere, qui ecclesiae suae tam vigilantem strentumque pustorem constituisset, simul uqviversae civitatis mulitudini (haec) aiens: - Gaudete, dominumque nostrum landate, quva civitati vestrae principem ac moderatovem destinaverit dommum lacobum, qui domo et gente ad genus pertinet suncii domni lacobi, fratris Donini, illizs qui apostolorum aetate episcopus fuit Hierosolymorum. " Id quippe senex donnuss Augint revelante Spiritu sancto didiccrat; verun sanctus domme lacubus se ipse manifestare nolwerab, ne ad suam glorian id cederet. 
soluta erant omnia membra. Ut autem ad sacra riysteria (facienda) descenderunt domnus Iacobus et sanctus Maruge, sacratum illud par, sanctus Maruge hominem conspicatus paralyticum, qui iacebat prostratus, dixit domno Iacobo : \& Veni; 5 oremus pro paralytico illo, ut Dominus eius misertus eum sanet. » Tunc diaconis praeceperunt ut illius faciem ad orientem converterent ; et cum se inclinassent, genuflectentes cum lacrimis sic fati sunt : "Domine Deus virtutum, qui hanc urbem dignam fecisti in qua praedicaretur nomen sanctum tuum inter Iudaeos roet idololatras - et cognoverunt te solum esse verum Deum, et crediderunt nomini dilecti Filii tui Domini Iesu Christi, quae portenta perfecisti per manus sanctorum apostolorum tuorum, eadem et nunc perfice per manus pusillorum servorum tuorum, ut praedicetur virtus tua, - gloria afficiatur nomen I5 tuum atque attollatur virtus sanctae crucis tuae. Et sicut Hierosolymis signum tuum luculenter edidisti per manus sanctorum apostolorum, ita ut Iudaei inter se murmurarent dicentes : - En prodigium quod in hac urbe factum est! (adeo)que isti pudore afficerentur, evangelium tuum laetificaretur, 2o splendesceret sancta crux tua, atque attolleretur cornu sanctae ecclesiae tuae ad gloriam tuam; ita etiam nunc, benefice Domine, exaudi flagitationes servorum tuorum ; sana hunce paralyticum; occlude os eorum, qui sanctae cruci tuae conviciantur, quae est gloria ecclesiae sanctae tuae; et fac nobis25 cum signum tuum (in) bonum, ut videant qui oderunt te et confundantur. Postquam autem (ambo) suam orationem absolverunt, dixit domno Iacobo sanctus Maruge : "Accede illiusque membra dominica (cruce) signa. " Dixit ille: "Accede tu.» Dixit sanctus Maruge : a Te oportet decetque illi manus im30 ponere ${ }^{2}$ atque precationem facere, quippe qui episcopali dignitate praeditus sis. " Tunc dixit domnus Iacobus : "Ego ad dextram, tu ad sinistram. * Et apprehenso illi dixerunt : * Heus tu, homo; age, surge, in nomine Domini nostri Iesu Christi. "Et extemplo surrexit ille; constitit in pedibus suis 
et confirmata sunt membra eius. Manus suas sursum protendit et Dei gloriam praedicavit. Turba autem, ut haec prodigia conspexit, procidens adoravit Dominum, et (omnes) clara voce Deum benedicebant dicentes: «Benedictus es tu, Christe, qui omni tempore exaudire soles eos qui tibi placeant, et ad vocem ser- 5 vorum tuorum miracula operaris, ut attollatur atque celebretur nomen tuum sanctum. Tu quippe solus es Dominus Deus, tibique (sit) gloria in aeternum. Amen. D Dixit tunc sanctus I,r7. Maruge paralytico : \& Surge, indue te tunica tua, accinge renes tuos, et Dei virtutem praedica, quae per manus servo- ro rum eius in te operata est. Iudaei autem, (his) auditis, prodigia admirabantur quae divina virtute per sanctum Iacobum facta erant, cum fidelibus contendentes, qui propter miracula, quae inter eos evenerant, Dei gloriatn praedicabant.

6. Post haec omnia, prodiit homo quidam nomine Cedron ", I5 qui Marcionis magi disciplinam sectabatur, et christianis infensus erat. Ortus hic erat e terra Pontica " et locum obtinebat hand ignobilem apud Constanti[a]num regem. Eius frater in regio exercitu stipendia merebatur, et apud regem gratiam inierat. Dixıt ei rex: Facies tua decora est aspectu; tute 20 (ipse) admodum es idoneus; unum in te desideratur, quod Deum non novisti, qui fecit caelum et terram et creaturas quae in iis sunt. Proinde fac cognoscas Deum verum, et Christi sigillum accipias, atque inclutus fies et honorabilis: te principem creabo atque in Mesopotamiam mittam, ad Nisiben civitatem. > 25 Respondit homo et dixit: «Deo credo, quem tu mihi praedicasti et notum fecisti. , Itaque gaudio percitus imperator eum protinus baptizari iussit summisque dignitatibusauctum ad Nisiben urbem eum honorificentissime misit. Porro frater eius, qui in civitate conspicuus et opulentissimus erat, idola impurosque zo daemones adorabat, quorum domum auro, argento pretiosisque

6. Vit. Aug., p. 402, 1. 19-404, 1. I4. Narratio partim contractior, partim explicatior. - 1 Var.: Cerdon. - ${ }^{2}$ Vit. Aug.: Erat autem homo [var. paganus] quidam ex asseclis Marcionis viri ncfarii, qui in gentem cinristianorum vehementer efferebatur. Hic e regione Ponti [var. : Pehstos, wascong] genere oriundus erat... 
gemmis ornaverat. Beatus Constanti[a]nus Cedronem, eparchi fratrem, persaepe rogaverat ut illum baptizari (curaret); at iste (illuc) adire noluerat, quia Marcionis magi errore deceptus fucrat. Porro Cedronis filius erat paralyticus natus, 5 cuius crura instar lori alterum alteri complexa erant a planta pedum usque ad genua; membra eius exaruerant, iacebatque in lectulo stratus. Erat autem vultu formosus, cincinnatus, et decorus aspectu. Cedron, ut audivit paralyticum qui in ecclesiae vestibulo prostratus iacebat, sanatum esse a sancto ro patriarcha Iacobó, per nuntium arcessivit hominem qui sanatus fuerat, ut ab eo (rerum) veritatem exploraret. $Q u i$, ut ante Cedronem adductus est, iste eum interrogavit et dixit: \& Quis te curavit? Dixit ille: a Quindecim sunt anni, ex quo paralyticus factus eram, sicut vos probe novistis, et me sanaverunt I 5 servi illi Dei. > Dixit Cedron: «Cuius nomine hoc in te prodigium operati sunt? > Dixit ille: - Iesu Nazareni. "Quae cum audivisset Marcion, indignatione percitus dixit : *Asseveranter tibi dico: haec te christiani docuerunt. Non eras paralyticus; mentiris. Quae ut audivit paralyticus, acerbe tulit et iracundia 20 percitus dixit: a Fraudator et impie; tute ipse mentiris. Superstitionis tuae fallacia Domini nostri Iesu Christi nomine cohibe. bitur et pater tuus Satanas puciore afticietur; tu vero mala nece pereas. Et nisi sancti (haec) me praedicare iussissent, nulla prorsus responsione dignus esses. Verum, quae a sanctis ius25 sus sum, his refero, qui audiant, et animo excipiant. *

7. Cedron autem aures praebebat et dicta libenter auscultabat. Rursus ille Marcioni dixit: "Scio equidem bonum sapientemque fratrem tuum eparcium, qui me huc arcessivit, constituisse, ut (rei) veritatem expioraret, propter filii sui cu30 rationem ${ }^{2}$. Qui profecto, cum (rei) veritatem, et morum vestro-

7. Vit. Aug., p. 404, 1. I5-499, 1. 4: (narratio in multis discrepansı.1 Var. : Marciano. -2 Locus itidem interpretis armenii errore vitiatus. Cr. Vit. Aug. : te quidem / Marcionemmi responsione non distalurus eram, nisi cartum exploratumque mihi fuisset, me a viro probo ot sapienti, cparchi fratre, lute arcessitum esse. ut reil veritatem a me rescisceret, quippe qui de pueri curatione sollicitus sit. 
rum tenebricosum errorem dignoverit ${ }^{3}$, evangelium salutis suscipiet, quod errorem vestrum ex hac urbe expulsurum est., Tum a mago faciem avertens, Cedroni dixit: "Audi, domine mi Cedron, quandoquidem voluntatis tuae arbitrior in domum tuam arcessitus sum, profecto decet me praedicare re- 5 gnum Christi. Ego vere paralyticus fui, prout omnes persaepe me conspexistis in vestibulo, paralysi atrociter laborantem, ut dixi. Itaque, domine Cedron, si credis nomini Domini nostri Iesu Christi, qui natus est e sancta Virgine Maria et ad servos suos appropinquavit, profecto per illos sanabitur filius tuus. \ Io Quae cum a paralytico audiisset, miratus est atque animo haesitavit; at re melius considerata, mentem suam a Marcione mago avertit et ad evangelium Christi aspirare coepit, sic secum animo dicens: *Qui filio meo curationem exhibuerit, is est Deus verus. Tum Marcion magus ei dixit: Cur pecto- $₫ 5$ ri tuo dubitatio movetur de fide, in qua fuisti a puero, adeoque perversa loqueris "? Ad haec Cedron cachinnum edidit et magi verba contemnens ait: * Proinde veritatem explorare volo et a mendacio recedere. $\$$ Et protinus consurgens cum familia sua, ad ecclesiam se contulit; ad quam accedentes sanc- 20 tum Iacobum et Marugam monuerunt dicentes: . Cedron, eparchi frater, ad ianuam vestram astat vosque videre cupit. » Et bona venia eum ingredi iusserunt. Aderat autem ibi et illius frater eparchus. Cedron ad sanctos ingressus eos pronus peramanter salutavit: iam tum quippe cogitationes eius a pris- 25 tino errore"se removerant. Et salute illis data, erectus stetit coram is atque clara voce is dixit: \&quidem ad hodiernum usque diem, clomini, veritatem me sectari arbitrabar, non errorem. Er persaepe a regia maiestate me defendi "ne me baptizaret Constanti[a]nus rex, sicut fratrem meum. In duas vias abeunt $3^{\circ}$ cogitationes meae consiliaque mea neque novi rectum iter. Pa-

5 Var: : qui cum (rem) perspexerit, procul dubio ervorem moresque tenebricosos deserat... - ${ }^{4}$ Sic var. ; ed. : apristina consuetudine. - Verbum e verbo: prohibitus (sum). Idoneam sententiam praebet $V$ it. Ang.. in varia lectione: Persaepe a regia ctian maiestate me removi: Gtob as lace fide alionum me fieri volebant; cf, supr. \& 6, p. 352-53. 
ralytici huius curatione spes mihi data est. (Nempe) si precibus vestris curabitur et filiolus meus, sicut ille curatus fuit, mens mea in vera fide stabilietur; Marcion autem qui negat Christum carnem induisse et ex sancta Virgine natum esse, 5 neque ullam futuram esse resurrectionem pudore afficietur. Num autem reapse, sicut aiunt, Nazarenus ${ }^{6}$ ille natus sit ex Maria virgine, crucifixus sepultusque sit, (num) resurrexerit tertio die, atque resurrectionis mo:tuorum spem confirmaverit, cum in his anceps haeream, nullam aliam iudicandi notam habeo ı praeter filioli mei curationem: qui aridam hanc carnem sanaverit, is verus est Deus idemque et meum corpus et (meum) animum postea sanabit. *

8. Porro Marcion, convocatis discipulis suis, auscultabat ea quae dicebat Cedron, et in furorem actus dixit: a $\mathrm{Ne}$ audias I5 Galilaeos istos : claudum curare non possunt neque paralyticum sanare. $D$ Tunc sanctus Iacobus ${ }^{\prime}$ coram universo coetu dixit: * Nos inutilia verba non loquimur; sed (loquimur) in nomine Domini nostri, qui natus est e sancta virgine Maria, (qui) ad tormenta crucis propter nostram salutem accessit, in 20 sepulcrum descendit, et Adamo omnibusque posteris eius resurrectionis spem fecit; (qui) destruxit mortem eiusque potestatem dissipavit, tertio die resurrexit a mortuis et secum nostram naturam suscitavit; (qui) per quadraginta dies cum discipulis suis versatus est, iisque dixit: "Vado parare vobis locum; Ioh. 25 et graviter eos prohibuit Hierosolymis exire donec Spiritum sanctum accepissent, iisque praecepit ut docerent omnes gentiles $e_{i}^{i}$ baptizarent eos in nomine Patris et Filii et Spiritus sancti, $<$ aiens > : Qui crediderit vivet, et qui non crediderit con- Mar demnabitur. * Et dixit: "Qui credit in me, opera quae ego facio Ioh. I

1) Var. : ... sicut aiunt Nazareni, natus ille sit ex Maria. - Cf. Vit. Aug.: Utrum autem, sicut praedicat Cedron et, eo duce, Marcion..... an; sicut praedicant Nazaroni, ille carnem induerit et ex virgine natus sit, adeoque mortui resurrecturi sint, equidem hodie, utpote inscins, in alterutram sententiam inclinabor nullo alio discrimine usus, quo veram fidom agnoscam, nisi curatione huius pueri...

8. Cf. Vit. Aug., p. $409,1.5-4 \mathbf{1}$, 1. I2 (ut supr.). - 1. In Vitu Aug., orationem habet non Iacobus sed Augin. 
et ipse faciet. Nos igitur et ei credimus, et in eo confidimus : quodcumque ab eo postulamus dat ille nobis, et in eius nomine draconis caput impavidi conculcamus. - Deinde sacrificulis dixit : - Si fidem idolis vestris habetis, o sacrificuli, falsos deos vestros obsecrate: qui si (hac) virtute pollent, vos exaudient et pue rum 5 istum sanabunt. Sin autem eum non sanaverint, profecto idem vobis accidet quod Romae Simoni mago (accidit). Iam vero nos Deo confidimus atque pueri huiusce curationem flagitamus, haud nostra causa sed propter istam multitudinem hominum, qui credunt nomini eius. Marcion, fracto animo et fusca voce ro dixit: *Neque nos eum sanare possumus, neque tu (potes).. At sanctus Maruge irridens ei dixit: * Equidem a Deo vero et Filio (eius) consubstantiali et Spiritu sancto confidenter spero quidquid poscimus, sine mora omnino perfectum iri ${ }^{2}$; et prop. ter nomen Domini nostri Iesu Christi fore confido ut iste, I5 postquam sanctus patriarcha Iacobus eum baptizaverit, consanatus exeat ex isto lavacro. Quippe sacratum illud par in Domino suo stabilitum erat, sicut sancti Apostoli.

9. Respondit tunc Cedron et dixit: "Uno (eodemque) tempore baptizari voluissem cum universa. familia mea. Attamen 20 primo loco baptizate filiolum hunc meum, ac deinde me et familiam meam. Dixit sanctus Maruge domno Jacobo : a Manda alicui e presbyteris tuis ut lavacrum disponat. , Renuit Cedron et sancto dixit: * Filiolum meum nemo baptizabit nisi sanctitas tua. 》Itaque, disposito lavacro, sancti consurgentes 25 genu flexerunt, et precationem persolverunt, alter ad dexteram lavacri, alter ad sinistram, dicentes: c Domine Deus, creator universi universorumque domine, qui filios hominum vis vivere, supplicem vocem servorum tuorum exaudi, 85. I7. preces nostras respice, et fac in nobis signum tuum bunum, 30 nomenque tuum inter Iudaeos et gentiles extolle in civitate ista, adeoque te cognoscant esse unicum Deum virtutum, et ti-

: Pressius : eum (Deum) id perfecturum esse.

9. Cf. Vit. Aug., pp. 4II, l.12-4I4, 1. Io (narratio multo prolixior); et rursus, post aliam eiusdem argumenti historiunculam, p. $4 \mathrm{r} 7$, 1. I6 -418 , 1. 3, aliis verbis, rebus et ordine. 
bi debitam esse gloriam in saecula. Amen. " Tum ab oratione consurgentes, in lavacrum demitti iusserunt puerum, qui annos octo natus erat, assumptoque oleo sancto totum corpus eius inunxerunt, et baptizaverunt eum in nomine Patris et Fi5 lii et Spiritus sancti. Et attollentes eum diaconi e lavacro eduxerunt. Sanctus Iacobus eius crura protendi et alterum ab altero separari iussit, apprehensumque manu puerum erexit et incedere iussit. Turba autem, ut puerum incedentem vidit, Deo laudes gratesque agere coepit propter miracula quae Io fiebant a sancto patriarcha Iacobo: Deus enim glorificantes se Cf.I Re glorificat. Porro Marcion, ut vidit quae a Christo fierent, eorum pavore correptus est. (Circumstantium) autem multitudo alius cum alio conflictabat ut puerum viderent. Tunc Marcion eiusque erroris asseclae, mutato habitu per tumultum evadentes ex urI 5 be aufugerunt : ad quos sequendos immissi eos non reppererunt. Et extemplo Cedronem universamque multitudinem (sancti) baptizaverunt; fuitque numerus eorum qui eo die baptizati sunt tria milia et trecenti. Sanctus vero Maruge in suum coenobium magno cum gaudio abiit Deoque gratias egit prop20 ter omnia illa - miracula. Eodem die, Cedron ad domum suam se conferens cum cruce facibusque arderitibus, ipse omnisque turba eorum qui ad baptismum convenerant, magnum festum egerunt. Cum autem sanctus Maruge ad coenobium suum rediisset Cedron aegre id ferens per nuntium eum arcessivit. 25 Eius domum ingressus, dixit sanctus Maruge: * Afferte libros magicos Marcionis. , Et mandatum illius exsecuti, ignem accenderunt ut istos libros comburerent.

10. Singulis porro diebus multi ad sanctum Iacobum adibant, ut Christi discipuli fierent. Quare sanctus Iacobus magnam $3^{\circ}$ ecclesiam aedificare constituit. Hoc enim tempore, Christiani erant pauci et exigua ecclesia.

11. Cum igitur sanctus Maruge ad coenobium sum ascendere vellet, dixit ei Paulus, qui antea vocabatur Cedron - hoc

10. Cf. Kit. Aug., p. 4 r8, 1. $3-7$.

11. C. Vit. Aug., p. 418, 1. $8-421,1$. 3. Narratio procul a nostra nonnihil vagatur. 
quippe nomen ei datum fuerat in baptismate, Cedroni Paulus, et filio eius Iohannes - : Domine, quandonam ad coenobium tuum ibimus, ut benedicamur a coetu fratrum?" Ille vero dixit: «Nihil omnino vos prohibet; quandocumque vos libuerit, venite. \Itaque, elapsis circiter diebus decem, Paulus con- $\mathbf{5}$ surgens cum familia famulisque suis et cum uxore, quae Maria dicebatur, ac filio suo, ascendit ad Marugae coenobium, ut ab ipso fratrumque coetu benediceretur. Hac ipsa nocte, evenit ut puer in morbum incideret mortiferum, qui morbus (ab) illa aetate Iacobi morbus appellatus est. Continuo in iumen- ro tum imponi.iussit omna quae parata erant, et dixit: "Iter hoc suscipite vos quidem. Ego vero et uxor mea (istic) manebimus ut videamus quid de puero futurum sit. " Perfecerunt famuli, quae $a b$ eo iussi fuerant. Puerulum autem magis magisque opprimebat vis morbi. Paulus igitur sic in animo reputavit: I5 «Haec diaboli vexatio et artificium est, qui nos prohibere vult quominus ad sanctum adeamus. Puerulum igitur assumptum iumento imposuit; ipsi vero equos suos conscendentes, iter ingressi sunt. Interea pater, cum puerulum morti proximum videret, Deo gratias, agebat dicens: "Sive vivit, 20 $\mathrm{I}_{4}$, 8. Domino vivit ; sive moritur, Domino moritur. $»$ Et servis suis praccepit ut ire properarent antequam puer moreretur. Iam illi ad coenobium succedebant, cum prope fuit ut puerulus e vita migraret. Qui aquam petiit, nec bibere potuit, adeo artatae erant fauces eius. Et continuo eiecit animam. Erant autem 25 nonnulli qui hoc id veneficis factum dicerent; alii autem eum ista nocte vinum bibisse dicebant, in quo venenum inesset: utrum isto an illo modo res acciderit, nescio: a Satana profecto acta est. Famuli ad urbem confestim redeundum esse censebant ut puerulum sepelirent; sed huius pater dixit: * Ante- 30 quam sanctum Marugam et fratres videro, non revertar. \& Et ex equis descendentes Paulus eiusque uxor pedibus iter perrexerunt. Praecepit autem ille uni ex famulis ut puerum deferret in ulnis suis: quem coram sancto Maruga allatum deposuerunt et dixerunt: «Ecce, digni non fuimus qui ad vos cum 35 puerulo nostro gaudentes veniremus. Iam vero eum manibus 
tuis commisimus, et novimus Deum, quidquid eum petieritis, vobis largiri solitum.» At sanctus Maruge nihil respondit: quippe miserebat eum recentium confessorum, quod iterum haec opportunitas data esset maligno, alienigenis haereticis et impio 5 venefico Marcioni.

12. Deinde sanctus Maruge beatum Iacobum misso nuntio (invitavit) ut ad suum coenobium veniret puerulum sanaturus, ut cui Dei charismata data essent ad eius (modi) morbos curandos. Sanctus vero Iacobus, ut audivit pueri (casum), conIo surgens festinanter (illuc) adiit cum eparcho, qui erat princeps civitatis, idemque frater Pauli ; cum quo et alii optimates civitatis $<$ se contulerunt $>$ ad exsequias pueri. Ut advenit sanctus Iacobus, signum pulsari et religiosos congregari iussit, puerumque in sanctis ulnis suis assumptum deposuit in ambonis 15 gradum. Ipse vero, inclinato corpore, genua flexit, (et) in precationem institit dicens: "Domine Iesu, medice bone et redintegrator aegrotantis naturae nostrae; nos, qui in ferali lectulo strati iacebamus, a lapsu erexisti vitamque immortalem nobis pollicitus es. In sepulcrum Lazari vocem edidisti ; morti 20 praecepisti ut quatriduanum e mortuis dimitteret, eumque vitae restituisti. Eia, Domine, exaudi hndie obsecrationes infimi servuli tui atque hunce puerulum in vitam restitue. Quod per Elisaeum et Eliam egisti, (idem) nobis hodie largire, non propter merita nostra sed propter nomen sanctum tuum, ut gloria 25 istud afficiatur, ut extollatur ecclesia tua, et crux tua sancta praedicatione coruscet inter omnes gentes, populos et linguas, adeoque omnes qui decepti sunt et aberraverunt, te verum Deum esse discant, qui occidis et das vitam, deducis Deut. 3 ad inferos et reducis. Fac hodie ut puerulus iste salvus sit et Tob. : $^{\prime}$ $3^{0}$ vivat. Domine Deus, exaudi obsecrationes servi tui.

13. Et cum has preces absolveret, lacrimae prosilierunt ex oculis sancti, adeo ut solum madefacerent ante aram sacram. Assumensque lutum istud, quod ex illius lacrimis factum erat,

12. Cf. Vit. Aug., p. 421, 1. $4-422,1.8$.

13. Cf. Vit. $A u g .$, p. $422,1.9-424$, l. 13. (Narratio contractior in qua, primas partes modo Iacobus agit, modo Augin). 
in pueruli fauces istud. imposuit. Agitavit puer manum supra pectus sum. Et sanctus Iacobus pueri manum-apprehendit di3,6. cens : "Iohannes filiole, age, surge, in nomine Domini nostri Iesu Christi." Et extemplo puer, apertis oculis suis, sanctum turbamque intuitus est, et in gradu (ambonis) consedit. Ipse 5 quidem laetabundo pectore Deo gratias agebat, et laudes gloriamque praedicabat largitoris tantorum beneficiorum. At eparchus universaque turba, ut conspexerunt quae evenerant, ingenti pavore correpti sanctum verebantur intueri, quippe qui non homo sed Dei angelus iis esse videretur. Exclamaverunt ro

6, 3. una voce et dixerunt: "Sanctus, sanctus, sanctus Dominus virtutum. Plena est omnis terra gloria tua. \& Et apprehendens manu puerum (sanctus) eum dedit patri matrique suae. Qui rogaverunt eum ut puerum sibi adiungeret; at ille dixit: «Non expedit puerum hunc apud me relinquere, quoniam ad- I5 huc tenellus est. Educetur iste et ad iuvenilem aetatem perveniat. » Egerunt autem die illo festum magnum ingentemque laetitiam; et totum diem ieiunarunt nihil omnino gustantes. Postridie ecclesiam ingressi sacrificium obtulerunt et salutari mysterio communicarunt. Post sacrificium, praecepit illis sanc-20 tus Iacobus ut sale tantum et pane vescerentur, quandoquidem ex eorum mentibus non exciderant prodigia quae conspexerant '. Tunc a sancto Maruga eiusque fratribus benedictionem acceperunt Paulus, uxor eius eorumque filius, quem Dominus a mortuis per sanctum Iacobum suscitaverat. Et consur- 25 gens sanctus Iacobus et eparchus cum turbis ad urbem profecti sunt. Horum vero prodigiorum et suscitati pueri fama per omnes pagos increbuit urbi vicinos; et qui procul erant (haec) audientes Deo benedicebant tantorum beneficiorum largitori. Appropinquantibus illis ad urbem, uno agmine obviam pro-3o gressi sunt viri et mulieres, senes et pueri, in varias turmas gregesque collecti. Et omnis generis aegroti ante pedes eius

1 Vit. Aug. : sanctus (Augin) cos considere promiscuisque cibarits vesci iussit. Et dum comedunt in cogitatione defixi, ab cortm oculis non recedebat vis pro. digiorum illorum... 
procidebant, et sanabat omnes. Quot dimidiato corpore paralytici sanati sunt! Quot infirmi a suis morbis sanati sunt! Sine mora quippe curationes ille operabatur. Cum tamen omnium nomina non noverim. ideo supervacaneum duxi in hace ora5 tione ista perscribere et singillatim litteris mandare miracula, atque inenarrabilem vitam et macerationes huius (viri) divinitus electi.

14. Porro eparchus ad piissimum imperatorem Constanti[a]num litteras scripsit de prodigiis mirandisque operibus, quae per ro sanctum Iacobum Christi Spiritusque sancti virtute evenerant. st de suscitato fratris sui filio. Magnus Constanti[a]nus acceptam epistulam legit Deumque laudavit, et ad eparchum responsum scripsit hoc exemplo: " Tres sunt, qui hac nostra aetate, in terra fulgeant, servi electi Dei vivi, in quibus terra mea qua$15 \mathrm{si}$ in columna firmissima nitatur; qui veluti faces lucidae in mundo fulserunt, obcuratas generis humani mentes illustrarunt, lolium avulserunt quod sevit malus agricola, semenque bonum severunt doctrinae Christi. Isti sunt vagi, pauperes ac peregrini in terra, et dona multorum sibi compararunt 1: An. 20 tonius in terra Aegypti, Silvester Romae, in terra nostra, et Iacobus in urbe Nisibi, quae est in Mesopotamia. Memoria Eccli. eorum in benedictione erit et orationes eorum super omnes terras. Iam vero eos flagito et rogo ut pro nobis precentur, Deumque rogent ut sub umbra misericordiae suae regni nostri 25 potestatem custodiat, et in die illo supremo, quando apparebit misericordia Christi, digños faciat nos, qui cum illis laudibus prosequamur sanctissimam Trinitatem. „

15. Post haec omnia sanctus Iacobus, in (suam) dioecesin egressus, circuibat ut christianae religionis plantas inviseret;

14. Vit. Aug. : p. 424, 1. 14-425, 1. 18. - 1 trit. isti Aug. : surit pau. peres et peregrini, qui multos locupletarunt. - 2 Vit. Aug.: Antonius in terra Aegypti, Hilarion in litore maris, et dommus Augin, qui ex Aegypto mi. gravit. [Var. : Hilarion in litore maris Gazae et patris Ascalon : rescribe : stom of the: (maris) Gazae vel in Ascalon.]

15. Theodoreti Relig. Hisior. ; P. G., t. c., p. 1296 B.D 
quibus evangelium regni praedicabat èsque in vera fide confirmabat. Porro prope fon tem quemdam puellas conspexit, quae vestes lavabant. Quae cum beatum conspexissent, gloriam eius vultus non reveritae, nec suras nec: capita sua vela verunt, sed impudenter oculos in eius vultum defixerunt. Sanctus, hanc protervita- 5 tem esse ducens, eas corripere voluit : fonti maledixit, qui continuo exaruit, et comas earum in canitiem convertit. Illae, ut fontem exaruisse comasque suas incanuisse viderunt, post sanctum currentes, ad pedes eius prociderunt, eumque obsccraverunt ut ad fontem rediens aquas eliceret. Rediit ille, oravit, et ro unda scaturivit sicut antea. Verum puellarum comis nigredinem non restituit, ut (canitiem) illam conspicientes Dei non obliviscerentur.

16. Cum autem ad urbem quamdam venisset, a iudice vidit de partitione inter duos fratres iniquum iudicium ferri. Cuius I 5 iniquitatem arguere volens, rupem quae ante illum stabat, maledixit : quae ilico procidens coram illo comminuta est. Pavore correpti sunt omnes, qui illic astabant; iudex vero haec conspicàtus, iudicium correxit. In hoc Dominum suum imitatus est sanctus Iacobus: non (enim) crucifigentes (se) maledixit I)omi- 20 nus noster, sed ficum maledixit, ne fructus ferret, et sic discipulos suos docuit. Quod in Domino suo imitatus sanctus Iacobus non iniquum iudicem maledixit, sed rupem comminuendo, iudicem ad iustitiam reduxit.

17. Porro ex eo die quo ad episcopatum vocatus est, neque 25 victum suum mutavit neque vestitum; solum quidem mutavit, non mutavit mores suos. Deinde vero cum in urbem quamdam venisset, pauperes quidam, qui ibi erant, aliquem mortuum esse simularunt, et (sanctum) adeuntes eum rogaverunt, ut sibi daret unde funus illi facerent. Qui impositis illi manibus, ei veniam pec- $3^{\circ}$ catorum precatus est. Cum autem ab illis aliquantulum recessisset sanctus Iacobus, clamore compellarunt sodalem suum, qui stratus iacebat, eumque mortuum viderunt. (Itaque) post sanc-

16. THEODORETI Relig. Histor., P. G., t. c., p. I298, A-B.

17. Theodoreti Relig. Histor, P. G., t. c., p. I 298 B - I300 B. 
tum currentes eum obsecrarunt ut animam illius revocaret et dixerunt: «Egestate (pressi id) egimus; lac nobis ignoscas , Ille vero revertit, oravit et mortuum suscitavit. Quod simile est miraculis Petri apostoli. quae fecit in Anania et Sapphira; 5 qui, cum nummos furati et mendacio usi essent, mortis poena plexi sunt. Haud aliter et beatus pauperem istum qui se reapse vivere $<$ dissimulaverat $>$ ad mortem transtulit. Verum beatus Petrus a Spiritu sancto admonitus erat ut mortis sententiam ad exemplum in illos ederet; contra beatus hice ut erat roillorum consilii ignarus, huic veniam peccatorum a Deo precatus erat, neque mortuum eum cognovit; sed Deus preces eius ad effectum perduxit, morti tradens eum qui vivus erat, neque illius (beati), supplicationes frustravit. Quod autem beatus apostolus mortis sententiam in illos edidit, <idcirco $I_{5}$ fecit $>$ quia in praedicationis suae exordio (apostolos) timorem incutere expediebat; at beatus iste, Dominum sum imitatus hunc vitae restituit. Verum ad alia huius mirabilia facinora propero, (quae) brevi oratione referam.

18. Arius haereticorum caput, qui pater fuit blasphemias, 2o et Unigenito sanctoque Spiritui conviciatus est, linguam suam exacuit ut Deo iniuriam inferret, atque mala amaraque doctrina sua Aegyptum constupravit. Sed Constanti[a]nus rex fidelis, par prioris illius Zorobabel, (et) cuius memoria in benedictione sit - hac enim (nostra) aetate fidelium captivitatem $25 \mathrm{ab}$ exsilio reduxit, et templum aedificavit, quod ab alienigenis eversum erat; - ille (inquam) iussit episcopos et ecclesiarum praesules in urbem Nicaeam convenire, (numero) trecentos decem et octo pontifices, ad evertendum Arium: inter quos adfuit et beatus iste domnus Iacobus. In eorum autem nume30 ro, huic synodo interfuerunt nonnulli qui Arii sectae adhaerebant; quam ob causam isti ab Achilla et Alexandro flagitarunt ut Arius a vinculis solveretur. Sanctus vero Iacobus cum aliis constituit ut per septem dies ieiunium servarent, petentes ut signum in Ario (fieret). Quippe sanctus Iacobus concilio erat instar

18. Theodoreti Relig. Histor., t. c., p. 1300 B - I30I D; cf. supr., p. 294-9j. 
nauarchi. Die dominico sacrificium obtulerunt, et signum magnum a Deo editum est. Cum enim Arius locum petivisset ubi corporis sui necessitatibus fungeretur, una cum stercore viscera etiam illic effudit. IEt mortuus est homo foedus in foedo loco; quia beati patriarchae postulationes perceperat 5 $<$ Deus $>$. Omnes autem ad sua quisque reverterunt.

19. Sanctus Iacobus e concilio redux, ut vidit multiplicatam esse christianae religionis plantam, ecclesiam aedificare constituit. Cum igitur ad sanctum Marugam in solitudinem ascendisset ", salute in vicem data redditaque, dixit sanctus Iacobus : 10 - Consilium mihi est aedificandae ecclesiae, si Dominus voluerit. Surgite igitur; descendamus ad videndum situm (aedis) sacrae. > Dixit sanctus Maruge: $<<$ Non $>$ expedit < nos > quidem descendere, quia hebdomas prope est. Surge tu, descende, atque mittet tibi Dominus angelum suum'qui ostendat I 5 tibi locum ubi aedificare oporteat: quia idolorum plenus iste locus est, et impietatis cantica in eo $<$ decantantur $>$. Iam vero pro canticis illis divina cantica illic cantabuntur, et corpus ac sanguis Domini nostri Iesu Christi ibidem litabuntur. * Dixit sanctus Iacobus: * Preces vestrae sint super nos, uti 20 dixisti. . Et consurgens descendit in urbem, et convocatis optimatibus principibusque civitatis dixit: , Ubinam auctores estis ut aedificetur ecclesia ? Illi ostenderunt ei tria quattuorve loca. At sanctus Iacobus ad noctem usque tacuit. Ut autem adfuit hora tertia noctis, consurgens ampullam olei as- 25 sumpsit et e tuguriolo suo egressus est. Angelus autem Domini se ostendit ei; qui accedens eum salutavit. Interrogavit eum sanctus Iacobus et dixit: « Quis es tu? . Et dixit ei angelus: Missus sum ego a Domino ut ostenderem tibi locum ecclesiae huiusque mensuram. D Neque dubitavit sanctus Iaco- 30 bus viso angelo, ut qui Dei visione persaepe frui solitus esset.

19. Vit. Aug. p. 428 , 1. I6-43I, 1. I2. $-{ }^{1}$ Cf. Vit. Aug. : Ascendit autem ante hebdomadem aestatis, ut senem omtresque fratres inviseret: multi enim ex iis in animo habebant per hanc hebdomadem se domi concludere neque cellis suis exire. Apud Syros incipit aestas hebdomade octava post Pentecosten. - 2 Cf. Vit. Aug.: Descendere quidem vobiscum non possumus, quia haec est hobdomas; hebdomadem autem aut canonem solvere nefas est. Verum nuntius ad te veniet aliquis ex angelis. 
Et perrexit cum eo angelus ad locum, qui idolorum Antiochi regis completus erat, et dixit: "Is est ecclesiae locus. \& Et huius mensuram ostendit.

20. Hoc tempore Hierosolymis adveniens sanctus Meles 5 episcopus, cum sanctum Iacobum ecclesiae aedificandae manum admovisse videret, non modica laetitia perfusus est. Is a mercatoribus, qui in ea regione erant, tria milia denariorum mutuo accepta dedit ecclesiae subsidio : nihil enim omnino secum habebat praeter bacillum et evangelium. Deinde ascendit ad sancro tum Marugam ut éum salutaret, et ad sedem suam reverteretur. Ad sancti adventum convenerunt omnes fratres eumque consalutarunt. Salute ultro citroque data, dixit sanctus Maıuge : * $O$ vir Dei, qui ambitioni non servis; ecce in Orientem profecturus es, ubi Phipum ' coargues,' qui sedem patriarchalem I5 sibi ipse constituit ; et correptioni tuae oboedire nolentem dirissima exsecratione perstringes, atque dimidia pars eius (corporis) exarescet. Tunc respondit ei sanctus Meles episcopus et dixit ei : Salve, senex, miraculorum patrator, qui vidisti maledictum draconem huiusque prolem, atque exstinctionem eius$20 \mathrm{dem}$ et prolis eius interitum. "Tunc dixit ei Maruge : "Unde tibi hoc (innotuit) frater? Numquid fortasse illud conspexisti ? Dixit sanctus Meles : "Qui me tibi indicavit, idem indicavit et te mihi. Dixit sanctus Maruge: * Beatus es, frater mi Meles : appropinquat (enim) martyrii tul tempus. Instar Pauli, qui ab ${ }_{25}$ impio Nerone martyrium passus est, tu quoque impios argues et Domini tui causa martyrium passus coronam gloriae accipies. Qui (Meles), postquam apud nos duobus diebus ${ }^{2}$ commoratus est, fratribus universis iam valedixit, eumque extra coenobium deduximus. Et dixit nobis : * Precamini, fratres, ut dig30 ni efriciamur, qui coram Domino, nos mutuo conspiciamus. Nam in hace vita, non amplius futurum est ut nos mutuo vi-

20. Vit., Aug., p. 43I, 1. 13- 433, 1.17 (cf. Assemane, Acla martyrum orientalium, p. 72-73, et supra, p. 340\%. - 'Var. : Philippum; Vit. Aug.: Papam, lag. Is est Päpã Bar Haggaï, episcopus Seleuciae et Ctesiphontis, de quo LabourT, op. cil., p. 2 I-24; cf. supr., p. 342, annot. 1). - 2 Var. : diebus tribus. - Vit. Aug., itidem : postquam apud nos fuit duobus diebus. 
deamus. Cum igitur Meles ad urbem Aramaeorum descendisset, Phipum ${ }^{3}$ propter huius facinora reprehendit : haud enim recte primatu fungebatur. Phipus autem dixit ei : Qui tibi sumis ut ista omnia mihi dicas? Dixit ei sanctus Meles : "Lege sanctum evangelium, et id te docebit." Ille, assump- 5 to manibus evangelio, dixit arroganter : "Loquere, evangelium, loquere. "Tunc indignabundus dixit ei sanctus Meles : "Heus tu, homo ! Domino tuo conviciaris? Et maledixit ei : eiusque manus dextera cum dimidiato corpore exaruit, secundum Marugae dicta. Neque amplius sanitatem recuperavit.

21. Et ascendens sanctus Meles perrexit ad patriam suam. Multi eius discipuli facti sunt, multasque curationes per eum Dominus operatus est. Cum autem ad sedem suam pervenisset, eum apud principem (nonnulli) criminati sunt dicentes : - Ecce ille omnem terram nostram baptizat. " Tum rex eum $\mathrm{I}_{5}$ pedibus manisbusque ligatum ad se adduci, universamque contionem (ad se convenire) iussit. Ut igitur bearus ante iudicem adductus est, eum criminari coeperunt, et dicere: * En veneficus iste nostras sorores filiasque baptizat, atque omnes ad suam fidem converit. "Interrogavit eum iudex et dixit : * Cu- 20 ius iussu iudaeos magosque baptizas? " Dixit ei beatus : * Equidem nemini vim intuli; sed doctrinam Christi praedicamus: illi vero sponte sua baptizati sunt. "Princeps, ut haec audivit, ferre non potuit, sed furore percitus atque indignatione exardescens in pedibus se erexit, gladiurn eduxit, apprehensum-25 que sanctum resupinum deiecit et medium diffindens ac scindens dexteram eius (corporis) partem abscidit. Eodem tempore assurrexit et principis frater, qui beluae modo insiliens sinistram illius partem a tergo abscidit. Dixit sanctus Meles : "Alter alterius gladio ambo perituri estis, eadem hora qua me interfecistis. " 30 Quod evenit uti dixerat beatus. (Nempe) postridie ambo illi equos suos conscenderunt, ut venatum irent. Ecce autem ante (eos) se ostendit capreolus, in quem ambo e regione irruentes, alter a dex-

"Var. : Philippum, hic et infr. CE. Vit. Aug. : Cum autem descendisset domnus Meles ad urbem Aranaeorum, ut Papam catholicum inviseret...

21. Vit. Aug,., p, 433, 1. I8-435, 1. I5. 
tro latere capreoli a sinistro alter, sum quisque arcum intende runt emissaque sagitta, capreolum quidem nihil laeserunt, (sed) alter $a b$ altero feriti perierunt. Et ex equis delapsi miserrime mortui sunt. Atque in illis eventu comprobatum est oraculum 5 prophetae (sic) aientis : * Gladii eorum intrent in corda ipsorum Ps. ${ }^{6}$, et arcus eorum confringantur.» Sanctus autem Meles honorificentissime sepultus est, et prout olim Maruge vaticinans dixerat, accepit immarcessibilem gloriae coronam a Christo Iesu, I Petr. Domino nostro. Memoria eius sit in benedictione et preces eius to super omnes fideles.

22. Alia quoque facinora atque prodigia sancti Iacobi narrare nos decet neque laborem refugere. Hoc tempore sanctus Iacobus, cum consilium cepisset ad eum locum adeundi, ubi requievit arca in monte Airarat, preces sine intermissione I5 fundebat Dominumque orabat ut sibi arcam ostenderet, qua mundi renovatio ${ }^{2}$ facta est. Itaque sanctum Marugam conveniens eum impulit ut secum illuc iret; quod ille in animum non induxit, senium corporisque debilitatem excusans. Et dixit sancto Iacobo: "Tu a consilio tuo ne prohibeare, neque 20 pigreris. Fiet tibi sicut optas. Mittet tibi Dominus angelum suum, qui tibi ostendat quae sint Domini voluntates. Inseret angelus ille manum suam in terrae sinum, et educet tibi tabulae fragmentum propter laborem tuum. Itaque sanctus Iacobus nihil moratus est ad montem proficisci. Ut pervenit ad ra25 dices montis, angelus Domini viam illi praeire coepit. Cum autem sanctus, per dies aliquot (producta) oratione fatigatus obdormivisset ${ }^{3}$, angelus Domini tabulan unam accepit, alla-

22. Iam notavimus (supr., p. 32 I) Armenium nostrum in hac narratione pleraque non ex Fausto esse mutuatum sed ex hagiographo Syro; cf. Vit. Aug., p. 435, 1, I8-437, 1. x $_{5}$; quem locum germanice reddidit Eb. Nestue (Die Auffindung der Arche Nö̈ durch facob von Nisibis. in Zeitschrift fïr Kirchengeschichte, t. c., p. 242-43). Locum Fausti Byzantini, videsis supr. p. 313-15, ubi, p. $3^{14}$, annot. 2 , pro nomen est provinciae interioris Armeniae. minime autem nomen montis Masis. Vid. supr, p. 322-26. Vit. Aug. : ad montes Cordyenos (Qardu : o, :0). - I Vit.

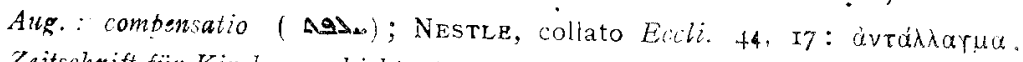
Zeitschrift für Kirchengeschiclute, t. c., p. 342. - Var. : dis quodan, orationi 
tamque ad sancti caput deposuit, cui in viso dixit: * Nefas est cuipiam arcam conspicere. Sume tibi hance tabulam quemadmodum exoptabas, et vade in domum tuam. Ille, excitatus a somno, summa cum laetitia tabulam accipiens ${ }^{4}$, Deo gratias egit, et iter ingressus domum suam abiit. Cum autem 5 ad sanctum Marugen pervenisset, in spelucam ubi habitabat, rettulit ei de monte in quo arca erat. Qui acceptam manibus tabulam osculatus est, et benedixit Deum eiusque patientiam ${ }^{5}$, et dixit : « Hoc fecisti nobis instar edicti, quod videntes (homines) a malis suis averterentur.» Sanctus vero Iacobus, Io accepta tabula, ad civitatem suam abiit et coenobium aedificavit in quo tabulam deposuit.

23. Hac porro aetate magnuș admirabilisque (vir) Constanti[a]nus e terra migravit, atque in eius regium solium successerunt eius filii. Sapor autem rex Persaru'n filios. regis contemp- I5 sit dicens : * Isti non possunt patri suo pares esse. * Et ascendens in terram Mesopotamiam ingressus est, adversus Nisiben civitatem, cum multis copiis et peditibus elephantisque compluribus ad gerendum bellum. Copias suas in quattuor partes divisit, circumsedit uribem et multiplici machinationum artificio conatus 20 est ut eam diripiendam caperet. Eius autem incolas gladio trucidare, pueros autem et mulieres captivos abducere volebat. Turrim aedilicavit, in qua sagittarios scutatosque (milites) collocavit, qui emissis in urbem sarittis plurimos homines vulnerabant. Neque (tamen) ullae artes ei successerunt. Quidquid enim 25

valans oblormivisset. - "Vita Aug. : ... praeire coepit usque ad locum in uno arca obnuta cyat. [Add. cod. ait.: quem ostendens dixit ei: hic est locus in quo recondita est arcal. Tunc sanctus Doninum nostrum precatus est, eum obsecrans wt unum "sieren ex arca sibi eulugite loco donaret. Atque Dets effecit ut coram sancto tabulc repiriretur, quam ille summa cum laetitia accepit...

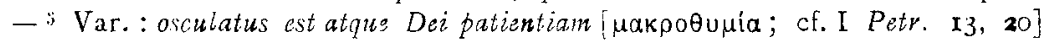
benedixit. - Vit. Aug. : ... senex asserem accepit et illud patientiae Dei [cf. supr.] mysterium ( $110 \mathrm{~N}$ ) salutavit, quod multis annis fabricatum est, ut eius aspectu fortasse tererentur et a malitia sua averterentur saccula praeterita. quibics diluvinm praedicatim est (ct. supr., p. 314, annot. 4 et 5). Porro ex illa

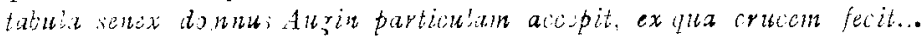

23. Cl. Theudoketr Relig. Histor., supr., p. 297-208. 
excogitahat rex Sapor, omnia eius consilia a sancto Iacobo dissolvebantur. Rursus commentatus est quibus artibus urbein oppugnare' posset. Itaque militibus suis edixit, ut fluvium occluderent eumque secundum muros oppidi deducerent. Fece5 runt isti quae iusserat, deductaque aqua circum murum oppidi labefactare coepit muri fundamentum, atque nonnullis locis murus partim collapsus est. Exercitus Persarum se victores conclamare coeperunt, (incolae) autem urbis in magno discrimine et angustia erant. Verum sanctus Iacobus, ut vidit Saporis ro eiusque exercitus ferociam, (eam) ferre non potuit. Preces ad Deum intendit, et commentatus eșt quibus artibus (illi) possent ex impiorum manibus liberari. Exaudivit Deus obsecrationes eius, et maledixit Iacobus Saporem eiusque copias. Continuo in istos eruperunt locustae, vespae, fuci et culices. Oravit ilr5le, Deus autem (eum) sicuti Moysen exaudivit. Neque istorum equi et elephariti consistere potuerunt prae vesparum fuco. rumque multitudine, ita ut equorum multi morerentur, alii vero frena excuterent; et huc illuc prosilientes diffugerunt. Angebantur itaque castra (hostium) gravi periculo propter plagas 20 quae divinitus eos perculerant. Tum vir divinus Iacobus in murum ascendens eum circuivit; et cum ante Saporem pervenisset, consedit (arcae) tabulam attollens super caput sum. Et Sapori visus est quasi rex purpura indutus angelorumque exercitus circum eum quasi exercitus humani videbantur. Rex ${ }_{25}$ Sapor hoc viso graviter animo pertur'atus est, et in magnum timorem tremoremque incidit. Et ira furoreque plenus evocari iussit eos qui expeditionis huius auctores ei fuerant, atque in eos mortis sententiam edixit. Ipse vero cum copiis suis festinanter profectus abiit in terram suam. Manadzirhus autem 30 Restunius, cum aliquot presbyteros ac diaconos ex agro urbi finitimo " captivos cepisset, eos adduxit in castrum finibus Restuniorum vicinum, quod Mantzikiert s appellatur. Haec igitur sunt

'Verbum e verbo : obsideve. - 2. e. Nisibis; quasi Manadzirhus in Saporis exercitu Nisibis obsidioni interfuisset. - Manazkert, hodie Melaz-

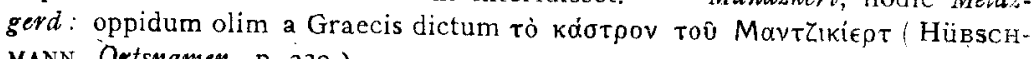
MANN, Ortsnamen, p. 330 ). 
miracula quae per alterum Ezechiam ‘ Deus edidit. Nempe, sicut illius oratu Hierosolyma e manibus Assyriorum liberavit, haud aliter sanctus Iacobus suis precibus istam urbem e manibus regis Persarum liberavit. Et dixerim equidem hunc illo multo etiam praestantiorem. Impius enim et iniquus (rex), superbia tu- 5 mens, artificiosissimis suis machinationibus victoriam adipisci non potuit, neque murum huius (urbis) funditus exscindere. Aliunde etiam mirabile fuit, quod eius exsecrationes protinus ad effectum deductae sunt. Neque, sicut Elias, rogavit ut ignis in istos demitteretur : quippe audierat id quod Iacobo et Iohanni ro a Domino dictum erat, cum in hunc modum ignem e caelo invocassent ; dixit illis Dominus : * Nescitis cuius spiritus estis. * Quapropter impiorum castra non evertit, sed pusillis culicibus eos compunxit (et) in fugam dedit.

24. Post haec omnia consurgens insecutus est Manadzırhum ${ }_{15}$ principem Restuniorum, a quo presbyteros, diaconos aliosque repetiit. Iste vero adduci non potuit ut eius postulata exsequeretur, sed pro moribus suis quam pessimis, (homo) foedus et iustitiae infensus militibus suis praecepit ut hos presbyteros diaconosque in aquarum vertices mergendos immitterent. Porro 20 sanctus Iacobus, ut infelicem hunc casum vidit, animo commotus est, et indignabundus iraque plenus a Manadzirhi terra secessit (et) abiit. Atque in itinere pergens, prope pagum Arzanenen ${ }^{4}$ pervenit, in vallem Fossorum ferri, ibique requievit. Cum autem sitiret - erat enim tempus aestivum et sol calore 25 suo torrebat omnia - (sanctus) ad sui et eorum qui cum illo erant refrigerationem, aquam elicuit. Atque ascendens in promunturium quoddam, conspexit terram Restuniorum. Et maledixit Manadzirhum eiusque terram et exercitum, propter homines quos ille aquis mergendos proiecerat. Ipse vero inde profectus 30 abiit in terram suam ibique habitavit.

25. Cum igitur, multis laboribus ac sudoribus exantlatis,

4. Var. : Ezschiel.

24. Faust i Bxzant., Histor. 1. III., c. to ; sup., p. 315. - ' Vid. supr., p. $33^{6}$, annot. 8 .

25. TheOdoratr Relig. Histor., P. G., t. c., P. 1305 B.; Fausti ByzanTii Histor. 1. III, c. ro; supr., p. 3r5-16. 
patratisque miraculis compluribus, domnus Iacobus, in his moribus perseverasset omnibus diebus aetatis suae, post paucos dies obdormivit et ex. ista terra in terram futuram ad tabernacula exoptabilia migravit. Post mortem sancti Iacobi 5 exercitus Romanorum ex illa urbe cesserunt, adveniensque rex Persarum urbem cepit, non bello sed benevolo foedere. At Restuniorum terra, quam maledixerat sanctus, gravibus plagis a Deo affecta fuit. Nempe hiante terra humus diffindebatur, adeo ut olera non crescerent hominum atque animantium usibus ro utilia, et vinearum stirpes pro uvis spinas ferrent. Postea vero homines (quidam) cilicio induti a Spiritu sancto admoniti sunt fieri non posse ut Restuniorum terra benediceretur, nisi (huc) adirent qui e sancti Iacobi reliquiis partem (eo) referrent. Isti igitur (huc) advenientes nobis narraverunt omnia quae. I5 cumque in eorum terra evenerant. Nos vero casus, quibus illi se perculsos narrabant, miserati desumptam e (sancti) reliquiis partem iis dedimus, qua isti accepta, cum ingenti gaudio profecti sunt in terram suam, ad locum qui Arzenanae terrae finitimus est. Ibi exstant illius reliquiae ad hodiernum usque 20 tempus, multae iis fiunt curationes ad gloriam Dei.

26. Haec de viro divino sancto Iacobo narravi, atque de sancto Maruge et de Mele episcopo adumbravi, ut eorum preces et benedictio nobis subveniant.

Absoluta sunt Vita et Miracula insignis gratia apostolica viri 25 Dei sancti Iacobi, Nisibis patriarchae, et cum eo sancti patris Marugae ascetae cilicio induti, et sancti Melis, Persarum episcopi. Ad gloriam Dei in saecula saeculorum. Amen.

\section{Appendix ${ }^{1}$.}

(Ex Vita sancti Iavobi Nisibis patriarchue. Bibliotheca Armenia, t. c.p. 60-63).

Per tres annos exsecratione obligata mansit Restuniorum 30 terra; homines iumentaque steriles erant; pomariae arbures aruerant et venustas illa tanta emarcuerat, de qua dixit quidam 
ex historicis, terram Restuniorum, antequam Iacobus ei malediceret, Paradisi Eden similem fuisse. Demum, capto consilio, quidam e genere Manadzirhi, quem alii eius sororem fuisse dicunt, alii fratrem patruelem, - ipse enim Manadzirhus interierat, - itineri se committens profectus est ut (sancti) reliquias anquireret (et) gentis ac provinciae salutem flagitaret. Qui multo cum labore in faciem (pronus) humi reptans, ita ut dilaceraretur, cum tandem ad (sancti), loculum pervenisser, perpetua precatione per dies quadraginta lamentatus est. Demum sanctus Iacobus cum illius obsecrationes exaudivisset, miseri- ro cordia motus particula eum muneravit. (Nempe) quasi vivus accedens amputatum (ex) integerrima sanctaque dextera digiti ossiculum ei de zit. Obstupuere ministri propier hoc visum, et illius labori gratulantes eum dimiserunt .

Qui cum in pagum Arzanenen ovans pervenisset, ad collem 15 Ferrifodinae, pago faustum nuntium attulit. Ut igitur secundus hice sparsus est rumor, una concurrens populi multitudo convenit ad collem qui dicitur Apostolorum. Et cum illuc etiam nuntii advenissent, catervae aliae aliis consertae ad pedes eius qui reliquias attulerat prociderunt.' Exstat hodieque 20 lapillorum acervus, qui numerum refert multitudinis quae convenerat. Assumptas itaque reliquias ad eundem illum montem perferre (voluerunt) in terram Restuniorum. Et statim hoc prohibiti sunt, quod neque ex iumentis neque ex hominibus quisquam loco moveri poterat. Obstupefactae remanserunt tur- 25 bae per tres dies. Porro angelus Dei in viso se (iis) ostendens e loco eos descendere iussit. Qui cum is in convalli locum quemdam editum designasset, ibi sanctae ecclesiae fundamenta posuerunt. Ut autem sanctae dexterae fama increbuit, illuc e propinquis remotisque partibus festinarunt dona ferentes, 3o et misericordia Dei curationes factae sunt omnis generis morborum et infirmitatum. Fines autem in quibus condita est ecclesia sancti Iacobi, in dicione erant Thraciorum ${ }^{5}$, quae

2 Text.: dimisit - 3 Fictum, ut videtur, nomen, quod Armeniae geographi non norunt (INDJIDJian, t. c., p. I67, annot.) 
nunc Mogi appellatur. Rex vero Armeniae. qui genere erat Ardsrunius, e nepotibus Abdelmalek "filii Sennacherib regis Syriae ${ }^{6}$, vim pecuniae dedit, fundum comparavit, splendidam ecclesiam aedificavit, (in qua) sacerdotes et monachos consti5 tui ad laudem sanctissimae Trinitatis, nunc et semper et in saecula.

4. I. e. Magos ; pervagatum quidem in Armenia nomen, sed ab is locis, de quibus nunc agitur, prorsus alienum (cf. INDJIDJIAN, ibid.) neque confundendum cum nomine Moxoenae, (armenice Mokq, in accusativo Moks; de quo Hübschmann, Ortsnamen, pp. 254-55, 331, al.). - ' Var. : Abdimeléq : (in quo nemo erit qui nomen arabicum stlll non agnoscat). - "De fabulosa Ardsruniorum prosapia, adeatur Moyses CHOREnENSIs, 1. II, c.' 7 . 